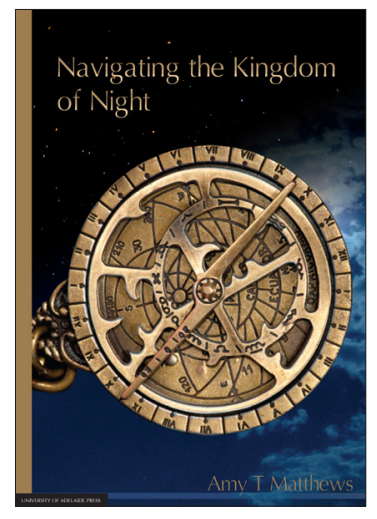

Welcome to the electronic edition of Navigating the Kingdom of Night.

The book opens with the bookmark panel and you will see the contents page. Click on this anytime to return to the contents. You can also add your own bookmarks.

Each chapter heading in the contents table is clickable and will take you direct to the chapter. Return using the contents link in the bookmarks.

The whole document is fully searchable.

Enjoy. 
Navigating the Kingdom of Night

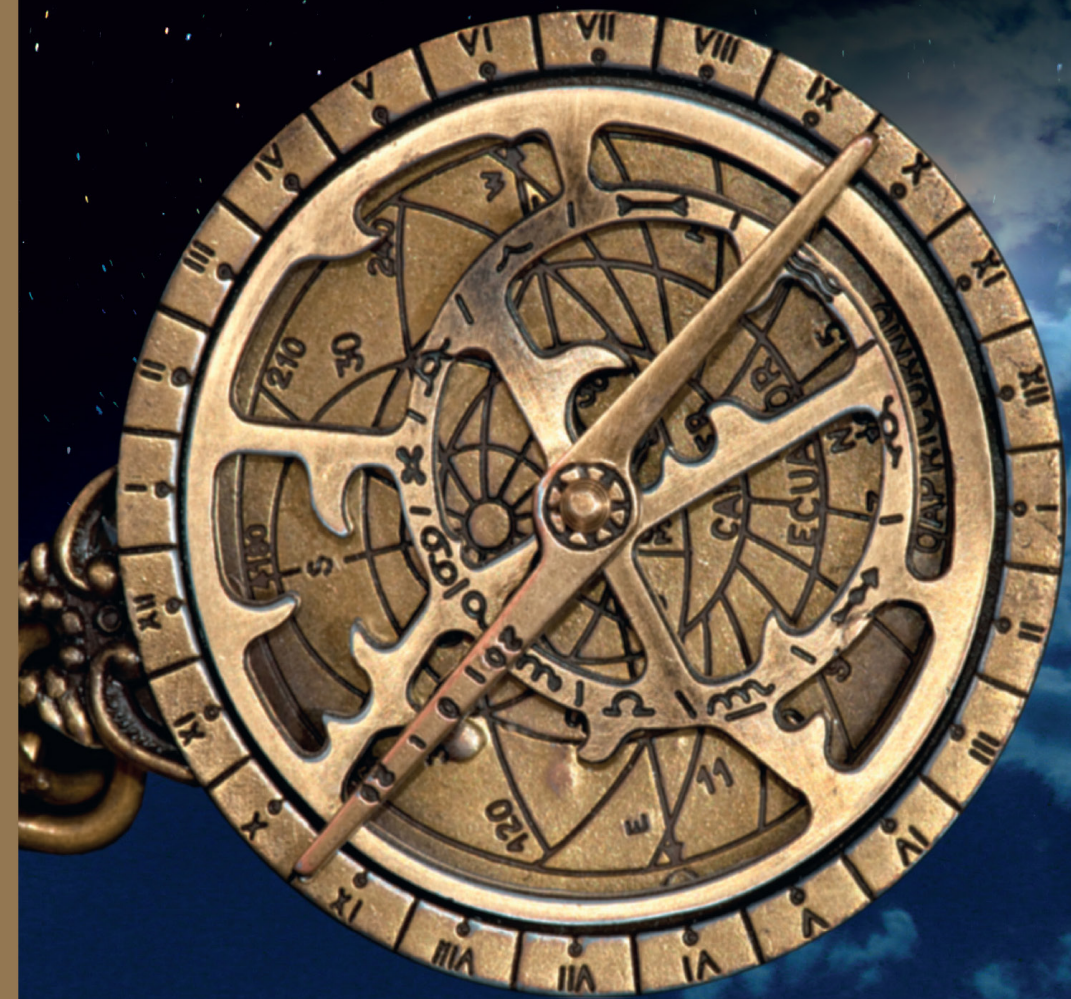

UNIVERSITY OF ADELAIDE PRESS

Amy T Matthews 


\section{Navigating the Kingdom of Night}

\section{by Amy T Matthews}

In 2011, Amy T Matthews published End of the Night Girl, a novel which engages creatively with questions of identity politics and the ethics of fictionalising the Holocaust. In Navigating the Kingdom of Night, Matthews contextualises End of the Night Girl in terms of the critical debate surrounding Holocaust fiction.

The critic Theodor Adorno once famously proclaimed that 'To write poetry after Auschwitz is barbaric'. He made this proclamation in 1949 , at a time when high-ranking Nazis faced the Nuremberg Trials: when the world was watching newsreels of bodies in pits and walking skeletons in striped pyjamas; when the Holocaust was a recent, raw and stunning event; and when the victims faced a disbelieving world and the perpetrators a divided, beaten and shamed homeland. Adorno's statement, made so soon after the horrors, still resonates today and can be applied critically to all imaginative literature about the Holocaust.

Critics, historians and Holocaust survivors have argued for decades over whether the Holocaust should be accessible to fiction and, if so, who has the right to write those fictions. Navigating the Kingdom of Night addresses such concerns and analyses various literary strategies adopted by authors of Holocaust fiction, including the non-realist narrative techniques used by authors such as Yaffa Eliach, Jonathan Safran Foer and John Boyne and the self-reflexivity of Art Spiegelman. Matthews frames the discussion by self-examining her experience as an author of a Holocaust fiction.

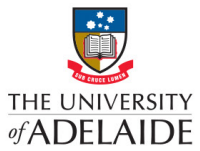

UNIVERSITY OF ADELAIDE PRESS 


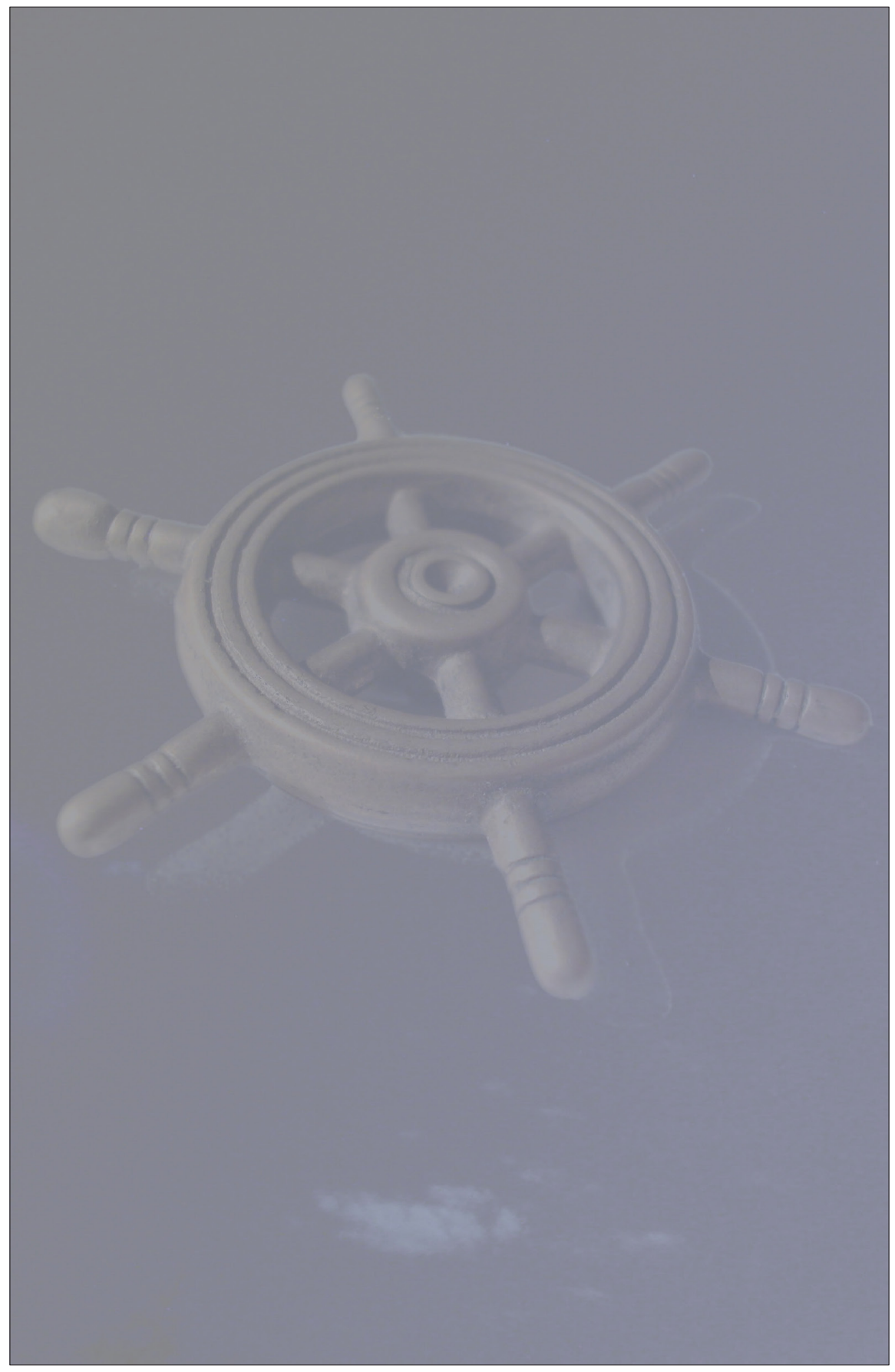




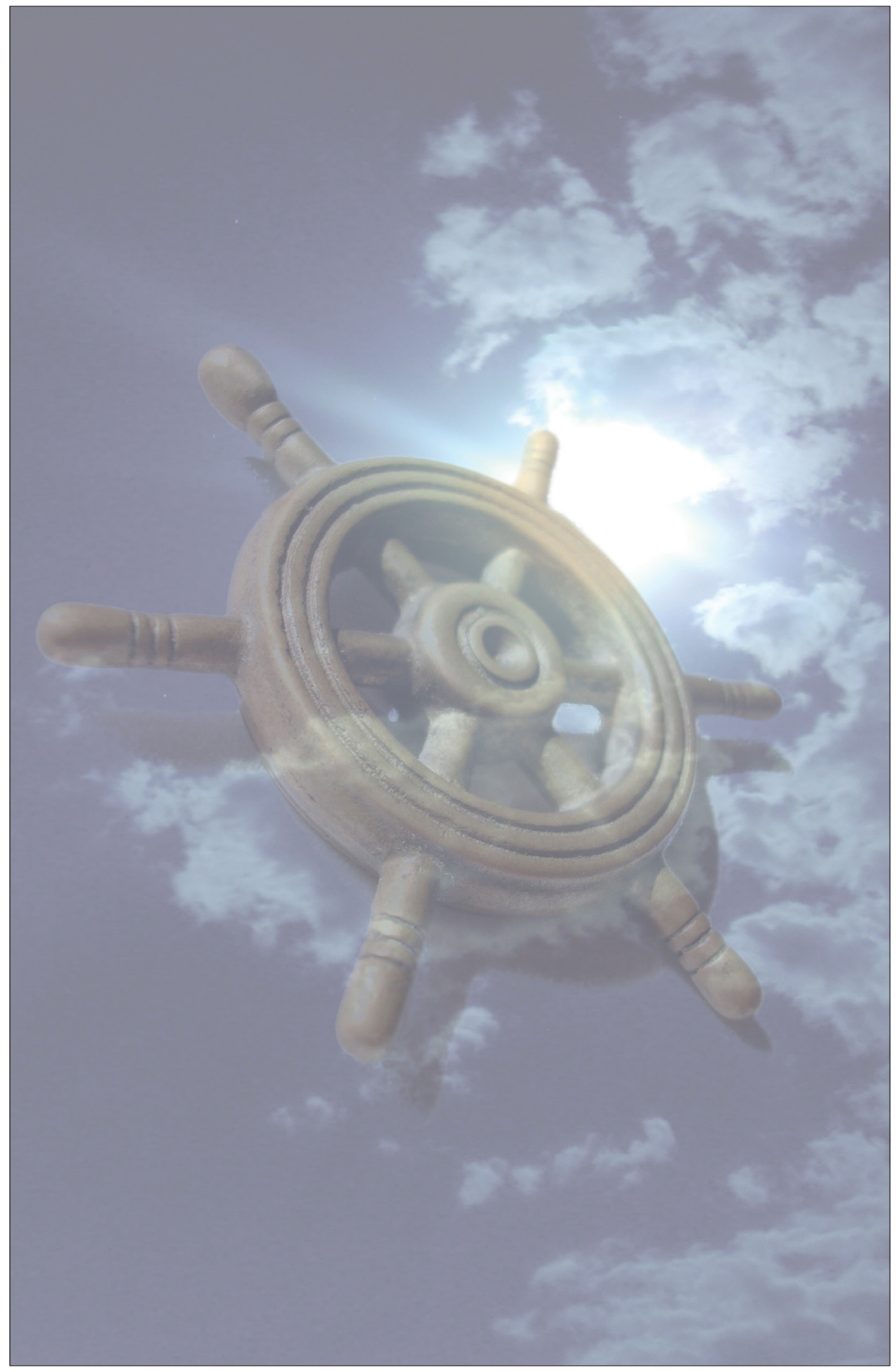




\section{Amy T Matthews}

Amy T Matthews is a novelist and an academic. She is Lecturer in Creative Writing at Flinders University and a Visiting Research Fellow in the Discipline of English and Creative Writing at the University of Adelaide. She was the winner of the 2010 Adelaide Festival Unpublished Manuscript Award for her novel End of the Night Girl, which was published by Wakefield Press in 2011. End of the Night Girl was shortlisted for the 2012 Dobbie Literary Award and the 2012 Colin Roderick Award. She has published short stories in collections including Best Australian Stories, and been longlisted for the Australian/Vogel literary award. She has co-edited two anthologies of short stories and poetry. 
This book is available as a free fully-searchable PDF from www.adelaide.edu.au/press 


\section{Navigating the Kingdom of Night}

Amy T Matthews

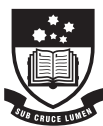

THE UNIVERSITY

of ADELAIDE

UNIVERSITY OF

ADELAIDE PRESS 



\section{For Chelsea Avard,}

\section{my sister-in-arms,}

and for 'casual' academics everywhere. 
Published in Adelaide by

University of Adelaide Press

The University of Adelaide

Level 1, 254 North Terrace

South Australia 5005

press@adelaide.edu.au

www.adelaide.edu.au/press

The University of Adelaide Press publishes externally refereed scholarly books by staff of the University of Adelaide. It aims to maximise access to the University's best research by publishing works through the internet as free downloads and for sale as high quality printed volumes.

\section{(C) 2013 Amy T Matthews}

This work is licenced under the Creative Commons AttributionNonCommercial-NoDerivs 3.0 Unported (CC BY-NC-ND 3.0) License. To view a copy of this licence, visit http://creativecommons.org/licenses/ by-nc-nd/3.0 or send a letter to Creative Commons, 444 Castro Street, Suite 900, Mountain View, California, 94041, USA. This licence allows for the copying, distribution, display and performance of this work for noncommercial purposes providing the work is clearly attributed to the copyright holder. Address all inquiries to the Director at the above address.

\section{(c) (1) $\Theta \Theta$}

For the full Cataloguing-in-Publication data please contact the National Library of Australia: cip@nla.gov.au

ISBN (paperback) 978-1-922064-57-8

ISBN (ebook) 978-1-922064-58-5

Project editor: Patrick Allington

Cover design: Emma Spoehr

Book design: Zoë Stokes

Paperback printed by Griffin Press, South Australia

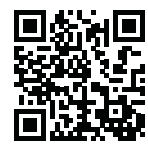




\section{Contents}

Introduction $\quad 1$

Why? 5

Literary Risk and Moral Peril 15

Taking a Breath $\quad 55$

Fantastic Narrative Strategies $\quad 61$

Amy, Meet Molly $\quad 85$

Contracts with the Reader $\quad 93$

The Great Redraft 123

Triangulation of Memory $\quad 129$

Beyond the Kingdom of Night 139

Acknowledgements 149

Works Cited 153 



\section{Introduction}

In late 2011 I was approached about turning the exegesis from my Creative Writing PhD into a book. I was flattered, but also apprehensive about returning to the Holocaust material after three years away from it. What excited me was the idea of embodying the experience of a creative $\mathrm{PhD}$. Over the course of my $\mathrm{PhD}$ I'd lived multiple lives, switching between the roles of researcher, academic, teacher, daughter, partner, wife and mother. This isn't unusual: we all lead multiple existences, slipping in and out of roles on a daily basis. But with my work, which consisted of a novel about a Holocaust-obsessed waitress named Molly (End of the Night Girl, published by Wakefield Press in 2011) and an essay called 'Navigating the Kingdom of Night', I knew that each and every one of those selves had contributed to the work. They were all part of the creative process. I wanted to try and capture how those different 'me's' had been part of my thinking and writing.

Easier said than done. In the first draft of this book I separated out the two main voices, 'Everyday Amy' and 'Academic Amy', because that was how my thinking had worked throughout my $\mathrm{PhD}$; there were always two modes of operating and two voices in my head. After two degrees and a year of Honours, the critical mode came naturally to me. When I wrote about Holocaust literature I thought in academic 
language; the concepts were easier to grasp that way, and could be unpacked more carefully and with greater complexity. But there was always another side of me that operated at a much cruder level — and this part was as much a writer as the critical part of me. This was the part of me that linked everything I read back to my novel-in-progress (the craftsperson) and the part of me that linked everything back to my real world life (the person). I felt they were very separate people. I didn't switch effortlessly between them. I would spend months thinking and writing in one mode when I was working on the historical research, then I would switch into the other mode when I began writing the novel, then switch back again when working on the exegetical essay. I was two different writers. And sandwiched between both of them were all the personal roles: the woman who was a daughter and wife and mother, who juggled all of the Life stuff that got in the way: insecure paid work, illness, marriage and babies and divorce, and the stress of unemployment.

The first draft of this book tried to combine two different ways of writing and thinking: the critical and the personal. It was clunky and not very successful. I have tried to address the clunkiness in subsequent drafts. The problem is that the two voices and two ways of thinking are strikingly different, even though they sit right alongside one another. I didn't approach the task of writing about the Holocaust entirely as an academic, or entirely as a fiction writer. I did both simultaneously, and the juxtaposition is unsettling. End of the Night Girl took me nine years and thirteen drafts to write and rewrite. Perhaps if I had as many years to work on Navigating the Kingdom of Night I could render its structure more elegantly, with greater fluidity and sophistication.

But I don't want to. I want you to see how the process worked, the awkward slippage between modes of thinking: the unsettling juxtaposition is precisely the point of this book and of its observations. I am a critic and an academic and the critical mode is comfortable to 
me, but I am also a writer of fiction and that mode is comfortable to me too. What might not be comfortable for you, the reader, is the schizophrenic shifting between the two. I am sorry. But to smooth over the clunks would erase the clunky process. Switching between the two ways of thinking is often stomach-turningly vertiginous for me; I feel a kind of breathless anxiety until I settle into the other thought pattern. If you feel that too as you read, that makes sense to me. 



\section{Why?}

Why? That was the first question anyone asked me when I said I was writing a novel about the Holocaust. It's a question I've struggled to answer. Who am I to write about the Shoah? I'm not Jewish, I'm not German; I don't have any familial connection; I have no direct sense of guilt or responsibility. I'm an Australian woman (of mongrel heritage, with no sense of belonging to any nation other than Australia), born in the late twentieth century, distanced from the Holocaust by time, nationality, geography, culture, language and experience. Like many of my generation my first exposure to the Holocaust was reading The Diary of Anne Frank, seeing fragments of documentaries on weekend $\mathrm{TV}$, and meeting the Nazis as cartoonish villains in the movies, as they dabbled in the supernatural and were frustrated by Indiana Jones.

I have one strong memory from childhood. It was the mid-1980s (I want to say 1986, but who can be sure?) and I was around ten years old. I was watching Sunday afternoon television with my grandmother. Grandma Matthews was a powerful presence in my life; calm, quiet, white-haired and sweet, she was a cliché of a grandmother. Everyone in the family loved her. I was the first grandchild and I've always been curious (okay, maybe nosy is a better word). I loved asking questions about the way things used to be, way back when. Grandma was born 
in 1912 and it staggered me to think that she had been alive during both world wars, that she had seen the introduction of radio and television, cars, refrigerators and compulsory schooling. Her greatest regret was being forced to leave school at the age of twelve in order to work. Twelve! I couldn't imagine leaving school so young. She was from a large family and her father had run off with the barmaid from his local pub, leaving her Irish mother to raise a pack of kids on her own. I only ever knew the girls of the family: Grandma (who was the second to youngest), my Great-Aunty Alma (the second eldest) and Great-Aunty Dord (the youngest). My aunts were fierce and funny, as volatile as my grandmother was calm, and their stories fascinated me. Alma and Grandma lived together after Alma's daughter died. I used to fake being sick so I could skip school, hang out at their place, and listen to the family history. All their brothers were dead and gone by the time I was born, as was my grandfather, so my childhood seemed to be filled with absences (mostly male), all these people who were my family but whom I would never meet. Their silvery faces stared out at me from Grandma's photos, which were loose in a cupboard, locked away out of sight. We wrote their names in pencil on the back of each photo, so after she was gone we would know who they were.

To me, my grandmother was the twentieth century. She'd seen it all. And when the documentary came on that quiet Sunday as we sat watching the television, she stayed silent. That was the first time I realised that there were things in the world — dark, terrifying things - that I, with my comfortable middle-class first world existence, had no idea about. I'd heard about polio epidemics from my grandma; I'd heard about the Great Depression; and I understood there was some disturbing reason why you should never get into the front seat next to the taxi driver, or go into a public toilet block without an adult, but I had no idea she knew about this thing called the Holocaust. It was staggering to me that this thing had happened and the adults around 
me knew about it and had kept silent. What if it happened again? How could I protect myself if I didn't know about it? (As a child, I immediately identified with the victims. Children know about being powerless.)

It was a documentary about a woman returning to what I now realise was Auschwitz: Birkenau. My memory of the program itself is both vague and hyper-detailed. The woman was short and compact, not quite stocky but thick about the middle; her hair was dyed stark black and she wore bright pink lipstick and a tan trench-coat (although it's possible none of this is true - it's possible that time has heightened the colours and added detail). I remember watching her walk through the neat ruins of the camp, pausing (catching really, as though snagged on the past) to describe what had happened to her. She gestured to things and experiences that no longer existed: the latrines where she had clung to the slimy boards, terrified of falling in, of drowning; the barracks, crawling with lice, where they had slept crowded together; dying of heat stroke in summer, freezing to death in winter. There was something unspeakable in her expression, something I don't have words to explain. Part of her wasn't there at all — part of her was back in the past, not re-living it but still living it. This wasn't over, I realised. And that must have reinforced something I knew instinctively: history isn't dead. It isn't consigned to the past. It's here with us now, shaping the world. From the moment I saw that woman, with her black hair and pink lips, the Holocaust was alive to me.

When I was in Year 7, I wrote a story in class about children escaping from a concentration camp (I didn't know then that children were rare to non-existent in Birkenau - as a rule they were gassed on arrival). The story was essentially a fairy tale: the children ran into the forest and were taken in by a good witch who took them on a flying carpet to sabotage the Nazis. Obviously I used narrative structures I was familiar with. I suppose the fairy tale style and content was comforting, 
a shield against the horror of the material, as well as a way I could fit my new knowledge into an existing way of understanding the world.

Does this answer the question why? Only a little. There's more.

Early October 2001. I was going to be 26 at the end of the month. This seems young to me now, but at the time I felt a rising sense of panic. I was failing at this life thing. I'd finished an Arts degree, majoring in English and History, in 1995. I was only 20 when I graduated and I had no idea what to do next. I liked studying. So I enrolled in a Communications degree, with a double major in Film and Electronic Media. I made short films and flirted with the idea of being a director. I graduated in 1998, still only 23 years old and now with two degrees. I applied for internships, planning to apply for the Australian Film \& Television School. I took a job waitressing to pay the bills. I got a brief internship with a local director, Rolf de Heer. I got to copy-edit a script and watch as he struggled to raise money for a project. He showed me how he wrote, pinning cards to a wall and shuffling them around. $\mathrm{He}$ asked if I wanted to stay on.

I didn't.

Dear Lord, I thought, I don't want to make films at all. I felt sick to my stomach. What had that last degree been for then? Why bother spending all those gruelling days and sleepless nights shooting and editing those short films? There was something wrong with me. I was missing that thing other people had: that thing that told you what you should do with your life, that told you what you were good at.

I kept waitressing and then I was promoted to Functions Manager, organising weddings and corporate events. I waitressed as well, but at least I had a business card with my name on it. That was something, right? I was good at my job. In my first nine months as 
Functions Manager I tripled the business. Leading up to Christmas we had between two and four functions a day; every Saturday was booked out for weddings nearly two years in advance. I worked sixteen-hour shifts during busy times. I made decent money for the first time in my life. And I was miserable.

Then in September 2001, the planes hit the World Trade Centre. I remember someone at work doodled the burning towers on the desk calendar by the computer, in the neat square of Tuesday September 11 . Spirals of smoke curled out of the confines of the square, all the way up to the red 2001 at the top of the calendar. Every time I answered the phones that month, or sat at the computer typing up menus for functions, I would see those blue biro towers and all of that curly smoke. A stick figure, way out of proportion to the towers, was falling into the white space below the towers. Its foot crossed into the day below. It made me feel sick to look at it, but I left it there, and I never asked who drew it. And at the beginning of October $2001 \mathrm{I}$ decided to quit my job. Why? Because of a salad. I got to work at 7am, as usual, getting my partner to drop me off on his way to work so I could do a few quiet hours before the chefs started turning up, before the Manager came in, before the phones started ringing (the phones never stopped and it was my job to answer them). It was a beautiful spring day and we were full for lunch, so I had to work the floor as well. Mid-service, a man called about organising a lunch for twenty people. I asked if I could call him back after lunch service. He didn't sound happy but agreed.

Ten minutes later he called back about the menu. The chef was banging the bell and shouting food was up: 'Move it, it's getting cold!' The guy called back half a dozen times through lunch. He thought the menu was too fussy. And expensive. I offered him a set menu at a cheaper price. Then he wanted free side dishes. I told him it wasn't possible. 
'Salad?' he snapped. By now he was pissed off. To understand how unfair this is, you probably had to be there. At 26 I was about the most polite person you could ever hope to meet: naturally shy, conciliatory, friendly. That was one reason I was a good Functions Manager: I could make the most uptight bride relax. Not so this guy, who was out to bully me into submission. I put him on hold and went to ask the chef if we could throw in some complimentary salads. Anyone who has ever worked with chefs, watched Hell's Kitchen, or read my book knows how that was going to go.

'Get fucked! Why would I give the cunt free salad? He's already getting a deal on the set menu. Would you go to get your tyres changed and ask for a free fucking tyre? Or ask your hairdresser for a free fucking dye job? Tell him to go fuck himself.'

'He won't like that.'

'Then tell the fuckhead to go somewhere else.'

In my experience, this is why chefs work in back of house and not with customers. When I broke the news the guy started yelling at me down the phone. Then he rang the Manager and complained. The Manager gave me a talking to.

I went to the bathroom, locked the door and sat on the tiles. Three men had just shouted at me in the space of half an hour (well, the Manager didn't really shout, he wasn't the shouting type, but it felt about the same). And why? Because of a salad.

I banged my head against the wall. This can't be my life, I thought. I'm four years away from 30, hiding away in a job I hate, being yelled at about a salad. And that was when it struck me how desperately unhappy I was. When was the last time I'd been happy? Studying. That had been it. I remembered the last day of my second degree, sitting at the Unibar with my friends Will and Kylie, feeling excited about graduation and life afterwards. I have a photo of the three of us that 
day, sitting at an outdoor table, raising our beer bottles, looking young and smiley. Will had gone on to be a successful journalist and Kylie was happy working for a company on Magill Road. I didn't really know what she did, but it seemed like a grown-up job and she was getting married and buying a house and settling into being an adult. I was sitting in a restaurant toilet, banging my head against the wall.

I went to see my parents the next day. My dad has always been enamoured of us studying - he was the first person in his family to go to university and for him studying was a noble thing. So when I told him the last time I was happy was at university, he didn't bat an eye. 'So, why don't you go back? You were invited to do Honours. At both places.' To me, it felt like hiding again, to go crawling backwards in time to university. But what else was there?

I didn't want to go back to study Film, so I was left with returning to my first degree, which was a double major in English and History. Which one should I do? I had loved History and my favourite teacher ever had been my third year History professor. But he'd come to a function at the restaurant earlier in the year and I'd waited on his table, feeling an acute and crippling sense of shame that I was nothing more than a waitress. He'd chatted to me, friendly enough, but I still felt ashamed when I thought of it. There's nothing wrong with being a waitress, by the way. It's a profession as respectable as any other, and good waiters are skilled and knowledgeable creatures. The shame came because I knew I was in hiding. That I was only waiting on tables because I was scared. What was I scared of? You'll see.

I made an appointment with the Head of English to discuss doing Honours. Her name was Sue Hosking and I'd been in several of her classes during my years as an undergraduate. Sue has a powerful but incredibly gentle presence. Somehow she always makes me think of peaceful waters: billabongs, lakes, creeks. I crept into her office, which had a rag rug on the floor and pot plants on the window-sill. Her blue 
eyes were sparkly and merry and kind. She remembered me from my undergraduate days, and let me blurt out my misery.

'Do you know,' she said quietly, when I'd finished, 'that we've also started up a PhD, Masters and Honours in Creative Writing?'

I felt like she'd thrown something at me. I may have even flinched. Because there's something I haven't been telling you. Something about this almost-26 year-old me. That girl, hiding in her apron, had always wanted to be a writer. She wrote picture books as a kid. As a teenager, she'd planned out an epic fantasy, filling several exercise books. She'd written three teenage novels and a lot of bad adolescent poetry. At 15 she'd written a short play which was performed at the Come Out youth festival; as an undergraduate she'd written longer plays, which had never seen the light of day. She'd written all the short films she and Will and Kylie had made at uni. And, while she was waitressing, she had written a 90,000 word historical novel.

There's something else I haven't told you. She had a secret obsession with the Holocaust. She'd spent years reading every work of history, testimony, memoir and fiction she could get her hands on; she'd seen every movie; she'd watched every documentary. And, secretly, she'd started to write some historical fiction about it.

So you see it was a lie, that stuff about not knowing what I wanted to do with my life. I knew what I wanted to do. When I copyedited Rolf de Heer's script I was thinking: I don't want to make films, I want to write stories. I was just too scared to do it. Because if I tried, really tried, and I failed ... what then? There really would be nothing else for me. Because writing was all I wanted.

But at 26, spurred on by my refusal to ever again be yelled at because of a salad, I quit my job and embarked on my Honours in Creative Writing. I was lucky enough to have wonderful teachers: the great poet and novelist Tom Shapcott, and the amazing Eva Sallis (now 
Eva Hornung). Eva particularly helped me change the course of my life.

During Honours I gradually brought my Holocaust stories into the light. I was terrified. Not because of the subject (not yet, anyway, that would come later), but because I wondered what I would do if I was no good. It felt like I was stripping naked in front of the class every week as I submitted work. But something remarkable happened. They took me seriously. I said I wanted to be a writer and no one laughed. For my final thesis I submitted a 15,000 word novella about a Jewish family's experiences of the Warsaw ghetto. The story ended with the door to the cattle car sliding closed. I didn't want to enter the camps yet.

I felt sick as I waited for the examination report. And this time it wasn't just because I was worried about what they were going to say about my writing. I felt as if I'd just dug up a bunch of graves. What were they going to say about my choice of material?

Well, they didn't disparage me. But they did say my novella didn't say anything new about the Holocaust. And how could it? I was callow. I was writing the experiences secondhand. I didn't know what I thought about ... anything.

By the end of Honours I'd taken some mighty big steps. I'd had my first short story published. I was gathering some confidence in my writing. But there was a question ringing in my ears and I needed to answer it.

Why? Why the Holocaust?

I am a trespasser. I am a voyeur. What I am doing is wrong. These are all thoughts I had as I finished Honours, embarked on a PhD, and kept writing about the Holocaust. I decided the best thing to do during my $\mathrm{PhD}$ would be to examine this unease. Why was I compelled to write about the Holocaust? Did there have to be a reason? There must 
be one. I couldn't articulate it, but somewhere in my subconscious it must be there.

I'll write two novels in one, I decided. One story about a contemporary Australian woman like myself and one story about a Polish Jewish woman during the Holocaust; maybe that way I could navigate this barbed-wire fenced territory. I had no idea how this was going to work. I figured I'd just dive in and see how it went.

I began my $\mathrm{PhD}$ with Tom Shapcott as my principal supervisor and Sue Hosking as my co-supervisor. 'Read,' Tom counselled me. 'Read as widely as you can. That's how you should begin.'

So I read. With the question 'Why?' ringing in my ears. 


\section{Literary Risk and Moral Peril}

\section{A brief outline of the debate about fictionalising the Holocaust}

Here's the thing about reading: it shows you what you don't know. It took me less than half a day in the Barr Smith Library at the University of Adelaide to realise the enormity of my hubris. By the end of the day not only had I doubled my doubts about the project, I'd also gained a nemesis called Adorno. For most of the next decade I half-imagined he followed me around, grunting disapprovingly at my reading material, and glaring over my shoulder as I tried to write.

The critic Theodor Adorno famously proclaimed 'To write poetry after Auschwitz is barbaric' ('Cultural Criticism' 34). Out of context it seems blunt and accusatory; absolute. There's no room for discussion. But it's also bewildering. What exactly does he mean? How is it barbaric? The first few times I encountered Adorno's dictate, it was out of context, embedded in someone else's critical argument. What was confusing was how it was wielded in different ways. It seemed there was some difference of opinion about his exact meaning. Critics have interpreted his words in a multitude of ways: Susan Gubar believes his statement was 'sometimes taken to be an admonition (beware of 
writing poetry), sometimes a directive (poetry ought not be written), sometimes simply a diagnosis (poetry cannot be written)' (4). Which was it? I felt more desperate the more I read, because each of these interpretations has a different implication for writers. 'Beware' does not mean 'do not write' but it is a warning, an admonition to be sensitive, to not ride roughshod over difficult and painful terrain; 'ought not be written' is a moral judgment, implying the writing is in bad taste or disrespectful or harmful; and 'cannot' refers to a literal impossibility: this material is so unspeakable and/or unknowable that it cannot be written about. Critics have adopted all three of these interpretations. Irving Howe thinks Adorno 'probably meant to focus upon the sheer difficulty — the literary risk, the moral peril — of dealing with the Holocaust in literature' (Schwarz 22); his interpretation fuses all three of the above into one.

The debate over Adorno's meaning led me to believe that the original essay, 'Cultural Criticism and Society', must be cryptic. In all honesty I was a little daunted by reading Adorno and I am guilty of using the quote out of context in conference papers and early drafts of this book, as I focused on the way critics interpreted him rather than on the original essay itself. Adorno's claim that 'poetry after Auschwitz is barbaric' (34) appears right at the end of 'Cultural Criticism and Society' and feels startlingly direct after an essay which is written in careful, painstakingly argued prose (which is full of jargon). To be honest, it's written for other critics, readers who enjoy spending time on every sentence, exploring the complexity of meaning and engaging in a 'game' of interpretation.

Reading Adorno requires an education and an ability to read closely and think critically: it's academic writing. He has a reason for this. Critics are the people he wants to critique. The bluntness of 'poetry after Auschwitz is barbaric' is shocking and on first reading can seem as though it belongs to another essay entirely (although it's 
actually the climax of his argument, underscoring all the main points of the essay). I confess that when I first read the essay I was baffled. Typically, I blamed myself. My first response to bafflement is always to think that I'm stupid. Clearly, the essay was written for people much smarter than I was. I could barely make heads or tails of it. He seemed to be saying something about the problem of 'cultural critics' (what the problem was I wasn't quite sure, as I was having to get my dictionary out in order to understand half of every sentence). While I struggled to read and re-read the original essay, I also read criticism seeking to interpret him, which only made the essay seem more enigmatic.

The word 'barbaric' always made me break out in a cold sweat. I couldn't work out what Adorno meant, and all of the possible interpretations seemed horrifying. Barbaric. That's what my project was. An ill-conceived obscenity. I had simply been too naïve to realise how impossible it was; how hopeless; how offensive. What are you doing writing about it, you barbaric idiot?

So many of my problems as a writer are caused by insecurity. I think I'm slower, dumber, less able than everyone else, and liable to embarrass myself or commit an obscenity simply though naïveté or stupidity. It's not true. I'm not actually stupid. And most writers and academics have similar feelings of inadequacy; it's called Imposter Syndrome. Fortunately for me, the overwhelming panicky insecurity is coupled with a stubbornness that makes me keep butting my head against the wall, even when I'm struggling to understand things. So I kept persevering with Adorno.

'Cultural Criticism and Society' was first published in 1949, at a time when high-ranking Nazis were facing the Nuremberg Trials, when the world was watching newsreels of bodies in pits and walking skeletons in striped pyjamas, when the Holocaust was a recent, raw and stunning event, and when the victims faced a disbelieving world and the perpetrators a divided, beaten and shamed homeland. Adorno's 
essay does not initially seem to be an essay about the Holocaust. It is an essay about cultural critics and criticism: he interrogates the notion that critics can stand back from their culture in order to criticise it. His two main concerns are the conceit that critics are 'elevated' above the culture, and that intellectual life is being absorbed by abstraction. He suggests that all criticism is embedded with ideology and is often a product of the culture it seeks to critique. In the context of Europe in 1949, his essay is particularly chilling: the continent had experienced fascism, communism, dictatorships and war — and in the wake of war, there was an emerging Cold War, which was a war of ideology: capitalist democracy versus Stalinist communism. The twentieth century was a turbulent time of emerging and conflicting ideologies, ideologies which brought down governments and nations, caused global warfare, and led to genocide.

Adorno's fight is with reification, that is, treating an abstraction as though it is a concrete, material thing. He argues that 'where there is despair and measureless misery, [the critic] sees only spiritual phenomena, the state of man's consciousness, the decline of norms' (19). The essay argues elegantly and bitingly against reification until it reaches that blunt final paragraph for which Adorno has become famous. The first time he mentions the Holocaust specifically is at the end of his argument, when he declares 'To write poetry after Auschwitz is barbaric' (34); the naming of the genocide increases the stakes of his essay. It becomes clear that he was speaking of the Holocaust when he wrote that by 'elevating' themselves above the culture 'criticism is tempted to forget the unutterable, instead of striving, however impotently, so that man may be spared' (19). Abstraction is what critics do. They take ideas and unpack them, but Adorno seems to be arguing that the Holocaust needs to stay a material event, that there is a danger in 'lifting' the idea of the Holocaust, in removing it from the camps, the starving bodies, the gas chambers, the corpses. To abstract it is another 
form of death (worse, erasure) for the victims. To complicate it further, it is impossible to 'lift' the idea from the cultural web the critics sit within. All critics write from a place within a society, culture, religion/ non-religion, gender, race, political perspective. No critic can divorce themselves from their ideologies completely (and some are writing to further their ideology). Therefore, criticism of and about the Holocaust can never be purely about the Holocaust; to some extent it will always carry the critic's ideology.

Thus the Holocaust runs the risk of being erased by historical, philosophical, political and artistic writing, because those writings cannot help but to abstract and to colour in their representations. Adorno is arguing for anti-abstraction: 'Absolute reification, which presupposed intellectual progress as one of its elements, is now preparing to absorb the mind entirely' (34). His dialectic of culture and barbarism finds poetry (and all criticism/writing about the Holocaust) in the barbaric camp, because the brutal material reality risks being absorbed by abstraction. To treat the quest for understanding an event like the Holocaust as an intellectual exercise abstracts it, which is the antithesis of the experience of the Holocaust itself. Worse, the intellectual exercise is polluted by ideologies which then co-opt the Holocaust for their own purposes.

It seems to me that Adorno singled out poetry because of its status as art object. Poetry is culture and beauty at its most 'elevated'. And fiction is in some ways an even worse offender because of its role as entertainment. If poetry is barbaric, treating the Holocaust as fodder for entertainment must be doubly so...

The Australian historian and literary critic Inga Clendinnen, who turned her attention to Holocaust literature in the wake of the Helen Darville/Demidenko scandal (which I discuss at length later), defines fiction as 'kind of a game, a circumscribed place of play. Once inside I have no responsibility, beyond my responsibility to respond to 
the text'. But when it comes to the case of 'true' stories, such as stories of the Holocaust, 'I engage with them differently because I stand in a moral relationship with these people, because they are my fellowhumans, whose blood is real and whose deaths are final and cannot be cancelled by turning back a page' (191).

Aha. This is what's been giving you palpitations. I read Clendinnen's words so many times I broke the spine of the book and turned the pages grubby with my fingerprints. Here was the heart of it: the weight of history; the suffocating horror of fact. The deaths of so many human beings couldn't be reversed, redeemed, or really ever understood. Characters live eternally in fiction. When I think of Scarlett O'Hara I picture her at Tara, surrounded by beaus. She is not defined by her ending; as a character she exists in all her incarnations, at all points of her journey. But this isn't necessarily true when it comes to the Holocaust. When I think of Anne Frank (who was a real person but also exists as a character in film and television) I think of her end: her death. Auschwitz is in many ways metonymic for gas chambers and ovens: for genocide. For me, death overshadows every character in Holocaust narratives: they are defined by their endings. Closing the book does not return the character to a status quo, the way closing Gone With the Wind returns Scarlett O'Hara to her beginning. Any character I wrote who was headed for Auschwitz would be defined by their death, which terrified me. What if the fictional deaths I wrote became metonymic for all Holocaust deaths? What if my flimsy fiction only served to paper over history? What if my made-up characters stood in front of the dead, obscuring them, killing their memory and substituting it with a story told by a woman who gleaned all her knowledge from books? What truth was there in that? What art? What possible value could there be in it?

Although characters and plot may be invented in a Holocaust narrative, although it may be fictionalised, the fact remains that these 
events happened to real people who suffered and died in the millions, and it is inevitable that in the reader's mind the invented characters come to stand for real people. As such there is a moral implication because the fictional character is then representative of an actual human being. In the words of Lawrence Langer, an historian whose career has been devoted to the Holocaust and the literature of the Holocaust: 'in the literature of atrocity, no fiction can ever be completely that - a fiction' (Literary Imagination 91).

Fiction is a land of play, of imagination and invention. History is a land of timelines and dates and events. Usually fiction is cut free from the kind of rigorous analysis accorded to historical writing. As a novelist, I feel free to cut loose: I would be comfortable using Napoleon as a character in a novel set during the Napoleonic wars; I would be comfortable imagining how pre-historic humans lived; I would be comfortable writing about a poor prostitute hunted by Jack the Ripper. It's not history per se that I was having trouble writing about. I didn't mind appropriating other historical figures or events. Fiction writers have always fudged dates and events, compressing characters and time for the sake of the narrative. But in the case of my 'Holocaust book' I could never bring myself to sacrifice historical veracity in order to service my plot, and as I read more criticism I began to understand why I was feeling this way. Because, as Langer suggested, fiction could never be purely fiction in this case. Certainly not in my case. I felt like I was committing murder every time I tried to write; not actual murder but the murder of memory, as if I was replacing history with fiction. Is this ridiculous? Should fiction be expected to bear such a burden? I don't know, but I do know that my personal response was to agree with Langer.

This conferred moral responsibilities on me as an author. Reinhard Baumgart said that Holocaust fiction particularly 'imposes artificial meaning on mass suffering' (Rosenfeld Double Dying 2) and the choice 
of fictions, the choice of meanings, is a moral choice. I remembered my Honours report: doesn't add anything new. My Honours novella didn't say anything about the Holocaust. Because I was terrified of making meaning: of ascribing my own thoughts and feelings and beliefs onto someone else's horror and death. My characters were made up. My writing was fiction. But I couldn't escape the gnawing fear that every time I wrote a word I wrote over a piece of history or, worse, erased it.

What on earth did the Holocaust mean? And to whom: to me; to my society; to the survivors; to Europe; to Western systems of thought ...? Every question led to a bigger, harder, more terrifying question. Still convinced that books could help me, I turned to the survivors. I emptied the library shelves of every memoir, autobiography, biography and testimony.

Survivors such as Elie Wiesel and Primo Levi expressed their struggles with the meaninglessness of their experiences in their work. Night documents Wiesel's experiences in the camp, his relationship with his father and his relationship with God and his religion. If This Is a Man is a more darkly ironic account of Levi's time in the Lager. Neither of these authors attempt to ascribe meaning to their experiences in the traditional sense. The texts are tense with pain, literary but not artificial. There is not a sense of a plot constructed with an eye towards an inevitable denouement or contrived thematic material. This is because they are memoir, autobiography and testament. Nicholas Patruno believes Levi dignifies himself and the reader by allowing the facts to speak for themselves, so that 'each person may therefore experience and interpret them within one's own emotional framework' (93).

But I couldn't do what those writers did. I was just a girl from Adelaide who'd read about their experiences in a book. They were relating events whereas I was choosing events and then fictionalising them. Every choice I made was loaded with possible meanings, and 
the way I chose to write them would add or subtract meaning. Wiesel and Levi's accounts opened up difficult, uncomfortable and horrific terrain and left the reader struggling to make meaning. There's a huge difference between the two acts. Their testimony lays things bare. Look, it says. Look at what happened to me. But it doesn't necessarily tell you how to interpret what you're looking at.

Fiction, on the other hand, especially written by non-survivors, is perceived to be a more manipulative construct. Everything must be imagined, rather than relived; all meanings are ascribed rather than described. This, Elana Gomel claims, 'courts the inevitable falsification of memory' (xvi). The feeling of being held to ransom by history is not unique to me. There is a widely held belief that writers have a responsibility to history, to represent the events of the Holocaust factually. Partially this arises from the sheer horror of the events, which strain the limits of understanding. The Holocaust is an event so extreme, so premeditated and mechanised, and a failure of humanism so astonishing that it beggars belief. The more I read, the more I discovered that from the very earliest Holocaust literature, when the survivors and historians began to write, veracity was considered paramount, (mostly by the critics I was reading, although I noticed that readers I spoke to assumed historical veracity, which suggested it didn't even occur to them that someone would 'play' with the historical facts). The literary scandals that have occurred, involving writers like Benjamin Wilkormirski and Helen Demidenko, happen when readers feel deceived by authors: 'lied to'. In contrast, novelists such as John Boyne find themselves on bestseller lists and high school curricula, even though they play fast and loose with history. Critics, though, have held novelists to a higher standard than the general readership might. The assumption among critics has been that 'only "facts" tell the whole truth and that fiction somehow lies' (Ezrahi Words Alone 25). Berel Lang expresses a strong belief that 'all literary representations of the 
Holocaust are violations of the facts of history, and that the violation of the facts of history is immoral in the same way that the violation of persons is' (Hungerford 102), a statement which reveals the heightened emotional discourse of the debate. I soaked in this heightened emotional tone and it made me increasingly anxious.

Ultimately art 'shapes, edits, invents, lifts, abstracts, colours, remixes, twists or embroiders fact to create something that is no longer fact but a product of imagination' ('Unoriginal Sins'). Perhaps this is why even those survivors who have ventured into fiction (Wiesel, Levi and Imre Kertész among them) 'have written memoirs or histories as well as fiction, as if to establish the historicity of the subject before admitting it to the imagination' (Ezrahi Words Alone 22). The 'legitimate fears that fictional discourse might then usurp the "history of the Holocaust" altogether' (Young 7) becomes even more relevant the further we move in time from the events themselves. We are now the generations who learn about the Holocaust through second- and third-hand accounts, for whom it is history (and history that belongs to other people, not our own family history), even though it is still (just) within living memory. Does this reduce our responsibility with regard to historical veracity, or increase it? Blake Eskin paraphrases one of Lawrence Langer's arguments quite neatly: 'When Auschwitz recedes from the collective memory as the battlefields of the Napoleonic wars and World War I did, a future Tolstoy or Hemingway can render the camp with his full imaginative powers ... but not before' (71). This statement seems to suggest that the need to refrain from fictionalising the Holocaust is primarily out of respect for those still living, rather than a general belief that history should not be muddied by fiction. When no survivors, perpetrators or witnesses remain, perhaps fiction then becomes a way to recover memory when lived memory is no more. 


\section{Sitting among the tombstones}

Did you mean it? I asked Adorno's ghost, as he read over my shoulder. Is it impossible? If that's what you meant, just tell me now, because otherwise this is all a waste of time...

He didn't answer me. Dead authors. All they leave you with is their words on the page. Not even clear words. Poetry after Auschwitz is barbaric. I wanted to glare at him, but of course he wasn't actually there to be glared at. My desk was littered with books; the floor around my bed was littered with books; my kitchen table, my couch. I left a trail of books the way Hansel and Gretel left breadcrumbs. They sat like miniature toppled tombstones - red and blue cloth, leather, plastic, the odd paperback - each and every one of them full of the dead. The silent, watchful dead.

I don't want to do you harm. They didn't answer me either. The dead don't speak.

I was claustrophobic with the silence and sick to death of my own thoughts. The result was lethargy. I sat about staring at the closed books and feeling overwhelmed. When I couldn't handle it anymore I turned on the TV and watched Oprah. I spent weeks sitting on the couch amid the cloth and plastic tombstones, staring at bad daytime television.

But then the bossy side of me reasserted itself. Bossy Amy can't stand inertia; she knows I'm lazy at heart and refuses to let me sit about for too long. You won't find the answer on Oprah, she sniffed at me. So you can't read any more criticism right now; that doesn't mean you can't read anything. Try some fiction. See what other people have done.

I didn't want to go back into the Kingdom of Night (as Elie Wiesel calls it), not even a fictional one. It was a dark, scary place. But I had a novel to write, so I reluctantly turned off the TV, crawled off the 
couch, and headed back to the library.

Confront your fears, Bossy Amy ordered. Find authors who made every mistake you're worried about making. Find books that transgress, appropriate, offend.

I ploughed through book after book. I found many which offended me. But the one which stopped me cold was DM Thomas's The White Hotel. I didn't know what to make of it on the first reading. I re-read it. I read reviews and criticism. I returned to it over and over again as I wrote and re-wrote End of the Night Girl, and struggled with my personal ethics.

DM Thomas went into the Kingdom of Night, even though he had no right to. He went right in there and stomped about. Curious, I followed him in, feeling a little ill as I took in the wreckage of his footsteps.

\section{A case study: DM Thomas's The White Hotel}

As well as raising concerns about misrepresenting history, a fiction writer's creation of meaning around imagined plots and characters can lead to charges of appropriation. Such was the case when DM Thomas wrote The White Hotel, a novel which seeks to explode Freudian theory. When it was published in 1981, The White Hotel won numerous international awards, including the Los Angeles Times Fiction Prize, the Cheltenham Prize and the PEN Prize; it was shortlisted for the Booker Prize; it was a Number One bestseller in the UK and Number Two bestseller in the US; and it has been translated into 30 languages. The book has also, however, had its share of controversy. Thomas has been accused of being a pornographer, a plagiarist, and of appropriating the Holocaust for the purposes of his own intellectual games.

The White Hotel is a novel in fragments, consisting of two 
paratexts (a Yeats epigraph and an Author's Note); a Prologue; a first person erotic poem; a third person omniscient narration covering the same events as the erotic poem but this time in prose; Freud's case study of the 'protagonist' (and I use this word loosely because the postmodernism of the novel denies such a fixed way of viewing a character); a realist depiction of the 'real' Frau Anna G — Lisa Erdman — in her life as an opera singer a decade after quitting her analysis with Freud; the chapter called 'The Sleeping Carriage' in which, through shifting third person points of view, readers see Lisa and her stepson go to their deaths at Babi Yar; and the final section, 'The Camp', in which Lisa enters the afterlife.

The postmodernity of Thomas's novel is central to the debate about his alleged 'transgression'. In the novel Thomas is interrogating the theories of one of the fathers of Modernism: Sigmund Freud. Modernist literature problematised representations of selfhood and perception, but there was still a basic underlying assumption that there was such a thing as the 'self'; it is a core assumption of Freudian analysis that there is a 'self' to analyse. Freud was interested in how this self was formed, how it could be uncovered, how it could be mapped and how it could be healed. Postmodernity, on the other hand, challenges the idea that there is even such a thing as a 'self'. In postmodern literature the concept of identity is exploded; it is refused stability. The self becomes a shifting, unstable construct - unable to be mapped because it has no materiality and because it doesn't retain cohesion for long enough to be pinned down. Talking about The White Hotel, Lisa Hutcheon says, 'The multiple points of view prevent any totalizing concept of the protagonist's subjectivity, and simultaneously prevent the reader from finding or taking any subject position from which to make the novel coherent' (Vine 15).

In The White Hotel, Thomas offers us multiple representations of the protagonist, from multiple points of view. She has no name at 
all until a third of the way into the novel, and after that she has many. There is no fixed character. In the graphically sexual and violent poem Don Giovanni she is our unnamed narrator. In a Freudian reading the reader is conditioned to read the poem as an expression of her unconscious, so I was hunting for ways to interpret the symbols in order to build a conception of her psyche. In the following chapter there is an external view of what is assumed to be the same character. Although 'The Gastein Journal' is in prose, it has the same dream logic as Don Giovanni. Once again, it is a struggle to construct a character from the symbolic material at hand, adding to the impression formed in Don Giovanni and trying, outside of the page, to make them cohere with one another.

The 'Frau Anna G' section is Freud's case study: here we have his professional opinion of a patient, whom he has given a pseudonym, in order to protect her identity. This is a subjective construct, in the very specific context of psychoanalysis. This section coerces the reader into a psychoanalytic reading of the character: looking for hidden depths, for the past to be causing ripples in her present. Her character is defined as a complex, psychological being, one that can peeled and examined and interpreted. Next we meet Frau Elisabeth 'Lisa' Erdman, the opera singer, in 'The Health Resort' chapter. Again this is an external view of Lisa: we watch her behaviour without direct access to her consciousness, at least until we reach the letters exchanged between her and Freud. There we meet Lisa's construction of herself, a performed 'self' for her psychoanalyst (with who she is in the process of disagreeing). And, finally, the section ends with Lisa's letter to her Aunt Magda, where another version of herself is enacted.

Lisa Erdman-Berenstein is the character who is killed by the Nazis near the end of the book, in the section called 'The Sleeping Carriage'. In this chapter we are introduced to her through Kolya's perception, and she is presented as his mother. When we shift to her 
consciousness, she is called the 'old woman'. Although she is not so old, Kolya perceives her as old and his perception lingers, ghost-like, over hers, even though we have left his point of view. This complicates the concept of selfhood and identity even further (to say nothing of narrative point of view). In this chapter Lisa enacts self-sacrificing maternity. She is defined by her role as Kolya's mother.

Lisa Morozova is the version of Lisa we encounter in the final section of the novel, 'The Camp'. She has rejected the Jewish name Erdman, and the German name Berenstein, in favour of her mother's Polish name - a name which was never hers in life. Here she prepares to hand Kolya over to his biological mother, Vera, and to surrender her role as 'Mother'. At the very end of the chapter, the pains in her reproductive organs (which were phantom pains in the early chapters of the novel, until they became real in the ravine of Babi Yar) vanish.

The White Hotel is an attack on Freudian theory, and these multiple Lisas undermine Freudian theories of the self. What hope can Freudian analysis have of uncovering and healing the psyche if there isn't a fixed and solid self at all? All of the fictional Freud's interpretations are seen to be misinterpretations. He interprets Lisa's dreams and anxieties according to his sexual paradigm of analysis. Steve Vine observes that this fictional Freud 'interprets the meaning of Frau Anna's (Lisa Erdman's) history in terms of sexual hysteria when her destiny in the narrative reveals her suffering to be a premonition of her death in the Shoah' (2).

On first reading, I only saw the attack on Freudian theory. I judged Thomas, as many critics did, for appropriating the Holocaust for the purpose of his own intellectual calisthenics. He was playing a game, I thought as I read, using the Holocaust in order to win points against Freud. But over the years, I've changed my mind. The more I re-read the book the more naïve I believe my initial reading was. Yes, the novel seeks to explode Freudian theory, but I was overlooking 
something: the Holocaust is the event which explodes it. The Holocaust cannot be swapped for another event. Thomas is not simply attacking Freudian theory; he is saying that the Holocaust is the fundamental flaw in the theory.

Freud himself was a Jew who fled Nazi Germany. In 1926 he said: 'My language is German. My culture, my attainments are German. I considered myself German intellectually, until I noticed the growth of anti-Semitic prejudice in Germany and German Austria. Since that time, I prefer to call myself a Jew' (Vine 16). Freud died in exile in Britain in 1939. The date of his death is significant: he didn't live to learn about the worst of the Nazi atrocities; he never saw the footage of the death camps; the killing squads had yet to enter Eastern Europe; and genocide was still something unthinkable to the postEnlightenment Western world. Freud's theories are a touchstone for Modernism, but they also belong to a pre-Holocaust world. In The White Hotel, Thomas is engaging with these theories as an artist who practices after Holocaust. He interrogates Freudian theory in terms of the catastrophic effect the Holocaust had on our systems of thought.

Freud is a Modernist figure, not a Postmodern one. Modernism was a movement which arose at a moment of change. It came from the trauma of modernisation, which included mechanised wars such as World War I. While World War I was culturally traumatic and destabilised the artistic traditions of the nineteenth century, it didn't destroy the Utopian urge or the bedrock faith that Science and Reason could improve the world. This belief might have been shaken by the war but it was not entirely destroyed. The Holocaust, on the other hand, can be seen as the point at which Western culture found that Humanism (and the belief that education was morally uplifting and could improve us) had failed. The Holocaust showed us that an educated first world nation was able to commit genocide (a word which itself didn't exist until 1944, coined by Raphael Lemkin to describe this specific mass 
extermination of a religious/cultural/ethnic group). And not just any first world nation: Germany was the seat of Western art and culture and thought; it was the culture that produced Martin Luther, Goethe, Nietzsche, Kant, Engels, Hegel, Heidegger, Schopenhauer, Marx, Bach, Beethoven, Mozart, Händel, Strauss, Adorno, Benjamin and Einstein. Germany had given the world some of the greatest philosophers, mathematicians, physicists, botanists, chemists, engineers, composers, artists and writers. And it was Germany that took Modernity to its extreme, to its breaking point.

In the 1940s Germany took its wealth of learning and knowledge and built death factories. Auschwitz has become metonymic for the Holocaust, but there were other camps (camps like Treblinka and Sobibor), constructed on the Henry Ford model: well-oiled production lines whose only product was death. The Holocaust was not a crime of passion; it was an industrial operation. At the height of the transports to Treblinka it took only two hours to 'process' a transport.

'Processing a transport': in this phrase the signs fail to signify the horror. Behind these words thousands of people were delivered to Treblinka, having spent days crammed into cattle cars, without food or water, urinating and defecating where they stood. Many people died on the way and often the corpses remained standing, held up by the crush of bodies. When they arrived at Treblinka where guards herded them into a receiving area, ordered them to strip, sheared their hair, and funnelled them into 'The Tube', which led to the gas chambers. At Treblinka they were killed with carbon monoxide, not Zyklon B (which was used at Auschwitz). Potentially up to 3,800 people could be murdered every half an hour. 'Process a transport in two hours' translates to the murder of thousands of human beings, potentially up to 12,000 people a day. These 'factories' were so successful that there were few survivors left at war's end to bear witness to them.

Dominant conceptions of Western culture often suggest a 
teleological arc, with Utopia at its end point, and history advancing us forward: the Dark Ages lead to the Renaissance; the Renaissance leads to the age of rationalism; democracy is born; slavery is abolished. We invent medicines to beat back sickness and death; technology allows more widespread wealth and comfort. But the Nazi death factories disrupt this idea that the West keeps advancing towards Utopia. Education, art, technology, science and philosophy: they didn't lead us to Utopia but to the Holocaust. We can see the trauma of this realisation in postmodern literature: in the fragmentation, the discontinuity, the instability of identity, and the distrust of language to represent reality.

And yet. Freud is still arguably one of the most influential figures of the twentieth century. His work is so embedded in our paradigms of thinking - the ideas of the Unconscious, psychosexual development, the Ego and the Id, the Life and Death drives - that many of us are familiar with the concepts even if we've never actually read any of Freud's work. Thomas engages with all of these concepts in The White Hotel, and he does so from a post-Holocaust perspective.

Richard Cross argues that the novel pivots 'on the alternate ways in which one could interpret the protagonist's hysterical symptoms' (25). Are they a result of her repressed sexuality? Are they the result of a repressed primal scene? Do they suggest a death impulse? And do the answers to these questions reside in her unconscious, as represented by the Don Giovanni erotic poem and 'The Gastein Journal', with its prose rendering of the same dream-like experiences of sex and death?

Freud has been criticised both before and since his death, particularly for being blinkered by his focus on repressed sexuality. Thomas seeks to test Freud's theories against the historical moment of the Holocaust. Vine notes that 'Thomas's Freud indeed gets it wrong. He interprets the meaning of Frau Anna's (Lisa Erdman's) history in terms of sexual hysteria when her destiny in the narrative reveals her suffering to be a premonition of her death in the Shoah' (Vine 2). 
Freudian theory focuses on the interiority of the individual - on the unconscious, on sexual development and drives, on Ego and Id - and denies race, history, culture and major systemic external forces.

We enter the novel culturally trained to 'buy into' a Freudian reading, engaging in the symbolic game play of deciphering Lisa's unconscious, only to have the symbols destroyed later in the novel by the brutality of Babi Yar and the Holocaust. We are implicated in the system of thought - Freudian psychoanalysis - through our reading processes, which heightens the impact of 'The Sleeping Carriage' chapter, where we find we have misinterpreted all of the symbols. The symbolic system we employed to read the novel is utterly destabilised.

There are clues early on that Freudian readings will fail us. This fictional Freud is seen to be a product of his time, prudish towards the erotic poem, which he describes as 'gross' (14), 'pornographic' (104) and 'disgusting' (105). He has a narrow definition of 'normalcy', bypassing, Michael observes, 'the possibility of lesbianism as a healthy sexual option [and also] the possibility that close relationships between women need not be sexual in nature' (68). He is woefully unobservant, only shallowly acknowledging the title of the opera score (Don Giovanni) that his patient has written her poem on, even though, Simonds points out, 'Don Juan is surely Europe's most famous personification of the unrepressed libido, the pleasure principle, the devil, and the death wish, all concentrated within one character who comes to an exceedingly bad end' (52). Don Giovanni is a moral tale, about punishment of libidinous excess - Freud concentrates on the libido, completely ignoring the concept of morality and punishment.

The authority of Thomas's fictional Freud is consistently undermined. For example, he hunts for the primal scene, believing it holds the power to unlock the secrets of the psyche, but when he finds Lisa's primal scene (as a child she discovered her mother involved in an incestuous ménage à trois with her aunt and uncle) it doesn't cure Lisa. 
It's just another piece among many others of a still unassembled puzzle.

We also see his patient — Lisa — struggling against his interpretations of her. He admits that 'an innocent inquiry, as for example on the subject of childhood masturbation (an almost universal phenomenon), was met with blank denial' (92). In 'The Health Resort' (the most realist chapter, giving the impression that here we are meeting the 'real' Lisa - although can that impression be trusted?) Lisa takes issue with Freud's reading of her. 'It has been like reading the life story of a younger sister who is dead,' she writes to Freud after reading his 'Frau Anna G' case study, 'I can see a family resemblance yet also great differences: characteristics and actions that could never have applied to me' (Thomas 163). We learn that Lisa lied to Freud during her analysis: 'you saw what I allowed you to see' (Thomas 166). She hid from him the fact that she was targeted for sexual assault at the age of 15 because of her Jewishness: 'They forced me to commit acts of oral sex with them, saying all I was good for, as a dirty Jewess, was to - But you'll guess the expression they used' (168). She also never told him about her husband's anti-Semitism and how she was 'passing' as a Gentile. She refuses to agree with his theory of her homosexuality and argues that she doesn't feel disturbed about her sexuality: 'it is possible that there might be a slight bisexual component in my makeup; but nothing specifically sexual, or at least nothing I haven't been able to cope with very easily' (171). Despite all of Lisa's objections and corrections, Freud decides to go ahead and publish his case study without change. As well as being chauvinistic, his decision, Michael claims, 'sets up Lisa's interpretation as competing with his and thus inherently challenging it' (72).

Thomas's Freud fails because he is blinkered, because he cannot recognise the looming shadow of the Holocaust. Simonds argues that Thomas has Freud make three basic errors: first, Thomas's Freud insists that repressed memories are the cause of all neurotic symptoms; 
second, he sees everything in terms of his own ego and not in terms of cultural context; and third, he refuses 'to consider religious experiences or religious symbols as authentic in their own right and not merely as sublimations of the sexual urge or as reflections of the hypothetical death instinct' (55). In The White Hotel, Lisa's hysteria is not a result of her repressed past - it is a sign of her future pain. She will be stabbed in the reproductive organs, raped by a bayonet, and buried beneath the dead bodies in the Babi Yar ravine.

Lisa's pains are at odds with Freudian theory. They refuse to be contained to her psyche or her past. According to Vine, the novel 'reverses the temporal pattern of Freud's analytic case histories: where Freud works backward toward a founding scene or disturbance in the patient's history [the primal scene] in order to recover it for analysis, The White Hotel projects the ur-scene into futurity - Lisa's death in the Shoah' (3). In The White Hotel the primal scene is not located in the past; it is yet-to-happen. Thomas has said that 'Mythologically ... hysteria was associated with powers of premonition - the Delphic Oracle and Cassandra. Might not some of the hysterics treated by Freud have been caused by apprehensions of the future rather than suppressions of the past?' (Cross 25).

Freud focuses inward: the sickness belongs to the individual, not the society. But Lisa is a Jew living in Europe during the rise of Nazism. She is surrounded by anti-Semitism: 'There was even a disgusting organization,' she tells Freud, 'advocating the extermination of the Jews as a race. My father gave me one of their pamphlets to read, as part of my "education" in being a member of a persecuted clan' (168). Isn't it possible her hysteria - and by extension the hysteria outlined in the actual Freud's case studies — is caused by external forces, rather than internal, repressed sexual forces?

When writing his case study, Thomas's fictional Freud literally only includes his patient's Jewishness as a footnote. And yet, as a Jew, 
she is about to face marginalisation, deprivation and ultimately death. Freud's theories do not make allowances for those in society who are marginalised, deprived, hated or hunted. Freudian theory doesn't take into account cultural context - for example, being a woman in a misogynistic culture, being gay in a homophobic culture, or being a Jew in anti-Semitic Europe. If your society is against you, isn't it possible that your psychological state isn't dependent on repressed sexual forces so much as socio-political ones? In Thomas's novel, Lisa's hysteria is linked to very present real world forces. The psychiatrist Robert Jay Lifton, who has worked with survivors of the concentration camps, as well as survivors of Hiroshima and Vietnam veterans, thinks 'it is essential to amend the Freudian model of the psyche from one of repression of sexual urges to anesthesia from historical trauma' (Robertson 457). The White Hotel consistently suggests that history is the cause of pain and that persecution has a profound psychological effect.

I didn't discover this way of reading the novel for years. Initially I resisted Thomas's use of the Holocaust. It wasn't until I had to write a series of lectures on The White Hotel for an undergraduate course on postmodernism that this approach opened itself to me. Because the focus of the lectures was on postmodernity, and not the Holocaust, I saw it afresh. A colleague of mine suggested that he preferred to read the book in reverse, from end to beginning; curious, I gave it a try. And as I read it occurred to me that I'd been hypersensitive to the issue of appropriation. As a result, this was all I was looking for when I read the novel. On this new, backwards reading, I tried to look for everything except appropriation. Instead of asking myself 'what is the novel failing to do?' I tried to ask 'what is the novel doing?'

Until 'The Sleeping Carriage' chapter, the novel operates on a symbolic level, using the symbolic structures of dream analysis. But once the narrative reaches the Holocaust these symbolic structures are 
exploded. Robertson contends that 'Modernist art and psychoanalysis in its classical form share the prejudice that significant reality is to be found not in empirical fact but in a complex inference drawn from mediating and disguising signs' (452). Laura Tanner suggests that in The White Hotel, 'Lisa's pain serves as the variable that generates a hermeneutical contest; the narrative documents opposing interpretations of Lisa's symptoms that vie for authority within the text ... The novel goes on to expose the degree to which Freud's critical forms misrepresent Lisa's experience by recasting it in purely symbolic terms' (132). Essentially what is happening is that Thomas is testing metaphor; he is looking at symbolic terms and the ways in which they 'contain and transform violence' (Tanner 132). Tanner argues that because Freud approaches everything as symbolic — including Lisa's physical pain — 'the immediacy of [her] suffering is denied as her pain is relegated to purely symbolic status' (133). In Thomas's novel, Freud's focus on the symbolic, and the resulting narrow choice of questions he asks his patients, dictates their discourse.

Cross argues that the 'The Sleeping Carriage' and 'The Camp' chapters of The White Hotel 'represent grave structural breaches ... What we discover in the last part of the book are strata of selfhood not dreamt of in Freud's psychology' (22). In 'The Sleeping Carriage' the reader slides from a space of intellectual play into a nightmarish land called History. Tanner believes that Thomas's detailing of the slaughter serves 'as the ultimate critique of all systems of interpretation that obscure those facts beneath fantastical or symbolic forms; the inability of Freud's forms to account for the immediate horror of that violence points to the need to reevaluate the conventional frameworks within which violence is understood and communicated' (148).

Since its release, The White Hotel has faced sustained and sometimes savage critical attacks, not because of its position on Freudian analysis but because of the role the Holocaust plays in his 
work. Some critics accused Thomas of exploiting the victims, 'making [their suffering] into an art object to be held at a distance and enjoyed' (Cross 38). Many (including me on my early readings) felt the novel appropriated suffering to make an intellectual point, thereby ascribing artificial meaning to real historical events. The historian Alvin Rosenfeld argues that 'to invoke a hundred thousand dead at Babi Yar as the means to delegitimise Freudian theory is to burden this novel with an historical weight far in excess of what it can easily carry' ('Perspectives').

Here, it is necessary to outline the historical facts of Babi Yar. In 1941 Nazi Germany launched Operation Barbarossa: the invasion of the Soviet Union. As the Wehrmacht invaded Soviet-occupied Poland, Latvia, Lithuania, Estonia, Ukraine and Russia, the Einsatzgruppen (killing squads) went with them. The Einsatzgruppen organised local collaborators into gangs and they rounded up the Jewish populations of the towns and villages. The 'production line' was much cruder, but it was still a form of production line - it was systematic, not random. They herded the Jews into their synagogues and burned them to the ground with the people inside. Or they made the Jewish people dig mass graves, and then they lined them up on the side of the pits and shot them.

The Jews of Kiev were brought by the Einsatzgruppen and local killing squads to the Babi Yar ravine on September 27 and 29 1941. A post-war account of an eyewitness says the killers:

drove the panic-stricken people towards the huge glade, where sticks, swearings, and dogs, who were tearing people's bodies, forced the people to undress, to form columns in hundreds, and then go in the columns in twos towards the mouth of the ravine ... they found themselves on the narrow ground above the precipice, twenty to twenty-five metres in height, and on the opposite side there were the Germans' machine guns. The killed, wounded and half-alive people fell down and were 
smashed there. Then the next hundred were brought, and everything repeated again. The policemen took the children by the legs and threw them down the Yar. (Gilbert 203)

Over 33,000 Ukrainian Jews were murdered at the Babi Yar ravine over two days.

Rosenfeld argues that Lisa's end at Babi Yar, where her phantom reproductive pain becomes an actuality as she is bayoneted through the reproductive organs, is gratuitous ('Perspectives'). Is the use of the Holocaust as the reason for Lisa's reproductive pain necessary? Or could another kind of attack in another context make the point just as well? I argue that the use of Babi Yar is necessary to the core concerns of the novel. The book is interested in hermeneutical clashes, in representations, in metaphors and symbols and their limitations. The Holocaust is the event that destabilises the systems of thought that Thomas is seeking to interrogate, and therefore is necessary to his novel.

The critical reactions to The White Hotel bring back into focus Adorno's statement and how to interpret it. In Thomas's case, the critics seem to be taking it to mean that literature ought not enter this territory in this way. That it is an act of bad taste. This might have more than a little bit to do with the disturbing mix of sex and violence in the book. The use of Babi Yar in the novel led to some accusations of voyeurism, and concerns that Thomas was 'narrating the Holocaust to give readers a sadomasochistic thrill' (Vice 39), an accusation no doubt also arising from the pornographic content of the early sections of the novel. Nazi imagery has figured in sadomasochistic pulp novels and magazines, and in pornographic films and images, since the war, effectively becoming a subgenre of sadomasochistic pornography. By linking sex so closely to violence in a novel which climaxes with the killings at Babi Yar, Thomas inevitably opens himself to charges of voyeurism. The critic Sylvia Kantaris stated that the 'element of titillation is ... strong - and wrapped up in an art package so that you can get it in the guise of 
culture and feel virtuous in the process' (Vice 54).

The question of when sexual representation becomes pornography is a thorny one. For me, the sex in The White Hotel is disturbing, and the effect of that disturbance carries through the rest of the novel. It is disturbing because it constantly flirts with taboos, such as maternity and sexuality, with the reoccurring link between breast milk, breastfeeding and sexual pleasure. The body is described in crude terms, which carries, if not violence, at least the threat of it: 'his tongue / churned every sunset in my barking cunt' (25). Here it is the body itself that is violent, beastly and yet also beautiful, as seen with the balance between 'sunset' and 'barking cunt'. Love and death, Eros and Thanatos, exist together in the eroticism of The White Hotel. To my mind, pornography exists simply to cause and gratify sexual arousal. In contrast, The White Hotel has explicit sexual imagery and acts, but they are employed in jarring ways, eliciting intellectual engagement, rather than simply a physical response. The arguments that Thomas is appropriating the Holocaust in order to titillate seem to me unfair, although there is a very fine line between artistic experimentation and bad taste when blending sex and death in the context of Holocaust literature.

I felt punch-drunk as I waded through the reviews and criticism of The White Hotel. Was this what I'd be facing if I ever got around to publishing my book? I was also more than a little awe-struck by Thomas's nerve: combining pornography and violence in the context Holocaust; writing about Babi Yar; getting the boot into Freud; giving the victims an afterlife. It was like he'd taken in the terrain - Beware! You ought not! You cannot! - and then put on his combat gear and run head first at the obstacle course. Just to see what would happen. And what happened? Well, he made it to the end, but not without crawling through the mud, getting scratched up on the barbed wire, and struggling to scale the wall of representation. Then, once he'd 
hauled himself over the top, the critics called foul, accusing him of plagiarism.

The accusations came from Thomas's reliance on A Anatolii Kuznetsov's Babi Yar for his historical information (Vice 40). Dina Pronicheva was one of the only survivors of the Babi Yar massacres; Kuznetsov wrote her account of the slaughter. Most of Thomas's account of the massacre at Babi Yar in The White Hotel is drawn directly from Kuznetsov's work, and he uses strikingly similar language. He wasn't trying to pass Kuznetsov's work off as his own; his choice to rely on Babi Yar was deliberate and he frames it as an ethical choice. Thomas has said in interviews that he felt it would have been immoral if he, 'a comfortable Briton', completely fictionalised the events (Vice 39). As such, Sue Vice argues in Holocaust Fiction, Thomas's reliance on Kuznetsov's Babi Yar can be seen as 'a recourse to documentary sources' (40). The issue, she feels, is not so much with the fact that Thomas used Kuznetsov's work as his source, but more that he used his words 'verbatim' and, worse, changed them 'to fit the rest of a novelistic scheme' (40).

In her argument, Vice privileges Kuznetsov's work as 'purer' and more historical than Thomas's, yet seems to side-step the fact that Kuznetsov's work is fictionalised (using devices of fiction such as characterisation and dialogue) and therefore not 'pure' history at all. Kuznetsov's link to Dina Pronicheva, and the conceit that it is 'her' story and he is merely a vessel for it, seems to save him from the piercing attention novelists receive. Thomas privileged Kuznetsov's work over his own fiction too: 'I felt the only way I could do it would be not to play around with the Holocaust, but to accept the physical descriptions of the eye-witness, Dina Pronicheva, as reported to Kuznetsov ... I dealt with the Holocaust in fiction by, at the last moment, letting history take over' (Vine 17). No one argued that he didn't represent the massacre at Babi Yar accurately or powerfully; they just felt it wasn't 
'his'. In 'The DM Thomas Phenomenon', Martin Amis wrote: 'The testimony is unbearably powerful ... it is the climax of the novel; it is, in plain terms, the best bit — and Thomas didn't write it' (ebook).

Not all critics agree with this position. Mary Robertson, for example, contends that 'one cannot read the grave and terrible penultimate chapter ... without thinking it intends to bear historical witness to the Holocaust' (457). In 'The Sleeping Carriage' chapter of The White Hotel there is a sudden shift in tone and the narrative becomes didactic — in an attempt to shoulder the weight of the material, perhaps. This is the core of Thomas's literary experiment, and here I argue we find the power of the novel. In this chapter the novel is no longer purely about demythologising Freudian theory. Rather, Freudian psychoanalysis and its attention to the rich complexity of the individual's inner life becomes a way of illustrating the vast and devastating scale of the Nazi destruction. Thomas writes:

The soul of man is a far country, which cannot be approached or explored. Most of the dead were poor or illiterate. But every single one of them had dreamed dreams, seen visions and had amazing experiences, even the babes in arms (perhaps especially the babes in arms). Though most of them had never lived outside the Podol slum, their lives and histories were as rich and complex as Lisa Erdman-Berenstein's. If a Sugmund Freud had been listening and taking notes from the time of Adam, he would still not fully have explored even a single group, even a single person.

And this was only the first day. (220)

Thomas is not writing lightly; he is not being frivolous with the material. He is merely approaching it as a novelist rather than as an historian. For me, the most problematic aspect of the novel is not its representation of the Holocaust, or even the disturbing mix of sex and violence. For me the problem lies with the final chapter, 'The Camp', and the Christianisation of the ending. I may have reframed 
my position on the novel over the years, but I have never managed to come to terms with the final chapter.

Initially Thomas intended 'The Sleeping Carriage' to be the final chapter of the book, but he felt 'it couldn't end there, with thirty thousand corpses in a ravine'. He felt he needed 'a spiritual fantasy ... to succeed Lisa's sexual fantasy and Freud's intellectual fantasy' (Vine 12). In 'the Camp', Lisa arrives in a place beyond death. It's a mix of post-war Palestine with its Jewish immigrants — 'a utopia of sand dunes, palms, sweet air, and sparkling water' (Cross 41) — and a Christian purgatory. It echoes the Jewish exile in the Wilderness in the Book of Exodus and also alludes to Dante's Purgatorio. At times it feels like a Christianised version of an Israeli kibbutz. It's not a terminus, so much as another stop on the line. Here Lisa finds her mother and her son. Freud is there too, his jaw destroyed by cancer, looking 'dreadfully ill and unhappy' (Thomas 228), an atheist who has found himself, damaged, in an afterlife.

Every chapter of The White Hotel features a train journey. Trains are often interpreted as a sexual image but they are also an iconic image of the Holocaust, as millions of people were shipped to their deaths by train. And, Cross points out, 'It is one of the conventions of psychoanalytic dream interpretation that train journeys are death motifs' (33). In his case study, 'Frau Anna G', the fictional Freud even comments on his patient's dream about a train journey (he interprets it as a sign of suicidal tendencies): 'Train journeys are themselves dreams of death' (95). Trains arrive at The Camp every day, echoing the trains arriving at the death camps. Even the name 'The Camp' gestures towards concentration camps, death camps, and the displaced persons camps of the post-war period. Here, Cross says, unlike real-world Palestine after the war, 'these immigrants face no enemies, and although they still suffer from wounds to flesh and spirit incurred in their previous lives, no fresh afflictions are visited upon them here' (41). Here, he says, 
'they have arrived in a realm beyond history' (41).

There is no possibility for a happy ending for the millions who were murdered and this is something Thomas can't cope with. Ultimately, it's not simply their fate he is resisting, but the sheer despair the facts of the Holocaust cause us. Robert Newman thinks that The White Hotel 'contains or represses the terrors of history through a set of formal defenses', including a redemptive ending (Vine 5). Thomas attempts to cope with despair by turning to his own spiritual beliefs, and here he has done something that appals many critics. He Christianises Jewish suffering.

Lisa is the daughter of a Polish Catholic mother and a Russian Jewish father. Brought up Catholic by her devout Polish nurse, she is equally devout when her aunt takes over her care. Ultimately, she may not even be Jewish, readers find, when it is revealed that her mother had an affair with her uncle and so her Jewish father may not be her biological father at all. She is part of a Catholic minority during her years in Odessa and Petrograd, and she even makes a pilgrimage to Turin to see the shroud of Christ. At Babi Yar an SS man yanks a crucifix from her neck. This is the same crucifix she touched every time she withheld information from Freud. 'Even the bayonet rape,' Cross argues, 'can be seen as a perverse caricature of Jesus being pierced with a spear' (40). There is certainly the problematic question of sacrifice and its link to Christian imagery; Lisa's death is effectively a sacrificial one - she goes to her death as an act of sacrifice for Kolya. It is not only her love for Kolya that gives her the strength to make this sacrifice, it's also her faith. This, again, is problematic, as the Holocaust is an event which eradicated the faith of many Jewish victims (Eli Wiesel among them). Does this suggest that Christian faith is stronger than Jewish faith?

In Night, Eli Wiesel says: 'The student of the Talmud, the child that I was, had been consumed in the flames. There remained only 
a shape that looked like me. A dark flame had entered my soul and devoured it' (34). Much later, after he had been in the camp for some time, he is made to watch as the SS hang a 13-year-old boy. Behind him someone asks '"Where is God now?" ... And I heard a voice within me answer him: "Where is he? Here He is - He is hanging here on this gallows ..."' (62). For many Jews, as with Wiesel, the Holocaust has been the ultimate challenge to their faith. It brings into question their covenant with God. Wiesel spent his youth training to be a Rabbi, but his faith did not survive Auschwitz. 'I was the accuser,' he wrote, 'God the accused. My eyes were open and I was alone - terribly alone in a world without God and without man. Without love or mercy' (65). In light of this experience, by no means limited to Wiesel alone, Lisa's sacrificial death and her unwavering Christian faith seem more than a little insensitive on Thomas's part.

The fact that Lisa chooses her death is also problematic, given the fate of the Holocaust's several million victims. The Jews did not choose their deaths (no more than they chose to be persecuted and vilified). No death instinct led them to the ravine at Babi Yar; the SS and their helpers drove them there. The fact that Lisa chooses her death sidesteps the true horror of the event. Her choice renders her death an act of love, rather than the result of prejudice and violence. It empowers her, rather than disempowers her. If Lisa's death can be read as a Christian one then, by implication, Cross suggests, all of the deaths are Christian. Cross supports this reading with the example of Lisa noting the likeness between the victims of Babi Yar and the shroud of Turin; when Kolya covers his nakedness she thinks 'It was the way Jesus had been buried' (214). Does this linking of the victims of Babi Yar with Christ suggest that this is the reason readers encounter them in the purgatorial after-life of The Camp? Because their deaths have somehow made them sacred? Thomas has not been shy about admitting to his own spiritual beliefs; he believes in the immortal soul and he has stated that 'the Palestine of 
"The Camp" serve[s] as a metaphor for the soul's life in eternity' (Cross 43). The sticking point is that he has sent Jewish victims to an eternity with overtly Christian overtones.

Steve Vine calls 'The Camp' 'a symbolic rewriting of history founded on nothing more than the desire or call for a different story' (12). The chapter carries enormous weight, because of its position as the last chapter in the book, which gives it an added authority. Cross argues that the chapter denies 'the ultimacy of the Holocaust' and in doing so it 'subtracts something from the victims' dignity' (42). Robertson agrees: 'History defeated these Nazi victims,' she says, 'and it is an insult to them to pretend otherwise. They did not die nobly or for a good cause. One must not make them sublime in their deaths, even if the deaths numbered in the millions' (471).

\section{Thomas joins Adorno at my back}

Another ghost flickered to life behind me: DM Thomas. The man wasn't even dead. But he turned up to haunt me all the same, standing over one shoulder while Adorno stood over the other. Adorno represented the critics; Thomas represented intellectual and artistic bravery. I didn't always like his novel but I admired his courage and I was endlessly fascinated by the complexity of his work. The more I read it the more complex it became. Don't chicken out, he'd hiss at me when I paused, afraid to write for fear I'd offend someone. Follow your idea through. See where it takes you.

I followed my ideas. They took me to places I found frightening over the next few years. I sent my characters into the death camps; I broke their hearts and their spirits and their faith.

Adorno grunted disapprovingly. Now and then he'd give a moan of despair and I'd break out in gooseflesh. 
Ignore him; keep going, Thomas would hiss. And I did.

At least until I reached the place where it should end. There, I paused, on a precipice.

Endings are important, ghost-Adorno said.

But they don't have to end. Ghost-Thomas sounded smug and I knew he was thinking of the afterlife he'd given Lisa.

I felt sick. I couldn't give my characters an afterlife. Their endings were inevitable. Weren't they?

\section{Holocaust endings and the right to write}

In Holocaust narratives, Clendinnen observes, 'the closure is at once predictable, and utterly bereft of meaning and comfort' (188). The camps, Einsatzgruppen killing squads, the dehumanisation of the Nazi system, and, for the majority of the victims, their ultimate deaths at the hands of that system, are the endings for most victims of the Holocaust. These fixed and grim endings leave little creative room for the writer of fiction - and choices such as Thomas's (to end his novel in the after-life) receive wide criticism. The fact is, Vice points out, writing fiction about the Holocaust 'entails the loss of such novelistic staples as suspense, choosing one's ending, constructing characters with the power to alter their fate, allowing good to triumph over evil, or even the clear identification of such moral categories' (3). Fiction writers can write from the point of view of the survivors, as their endings contain more possibilities for hope, suspense and positive closure, but they are the minority of victims. Most Holocaust victims were murdered, and, according to Clendinnen, 'Only the dead know the full bitterness of their victimhood, and they are silent' (56). Which brings us to the issue of authority: who has the right to speak for the dead, and to write about the Holocaust? 
Whether or not Adorno meant it would always remain impossible to write about the Holocaust, the fact is that people have done so and many seem compelled to do so. These works fall into three categories: the literature by survivors, the literature by the children and grandchildren of survivors, and the literature written by non-survivors (by which I mean people like me, with no direct experience or familial connections). I'm not concerning myself in this chapter with literature by or about the perpetrators; I will address that issue in the 'Contracts with the Reader' chapter.

The right to write is often referred to as 'moral authority'. Critics, Vice observes, 'have invariably considered the biography of the author highly relevant' (3), with the survivors having the highest moral authority. The stories belong to them. Commenting on Night, Rosenfeld says that Elie Wiesel has 'a moral authority so pronounced and so rarely found in our day that, to grasp it, one has to bypass almost all of modern literature and seek for interpretive parallels in the Bible and its major commentators' (Double Dying 59). This kind of discourse reveals the way in which Holocaust survivors and their stories have become, in many ways, sacred. The language used in the debates about writing Holocaust stories is often religious in tone, as with the Rosenfeld quote above.

Clendinnen notes that 'Already precious by virtue of their rarity, the witness testimonies can seem imbued with an air of unchallengeable authority' (25). In contrast, in his writing on second-generation survivors, Andrew Furman declares that 'Artists who attempt to represent the Holocaust when their knowledge of the event is secondor third-hand, or transmitted by other cultural artifacts, can expect their work to elicit a special kind of scrutiny' (84). Presumably this is not only because of concerns about muddying the historical record but also because we are concerned about intent when it comes to writers who are not writing from experience: Why are they writing about the 
Holocaust? What are they trying to say and do they have a right to say it? This returns us to Adorno's assertions that the author's ideology cannot help but colour their representations.

Children and grandchildren of survivors (writers such as Yaffa Eliach, Jonathan Safran Foer and Art Spiegelman) are conferred a measure of authority by right of birth. Their families have suffered and, often, are still suffering; their childhoods have been imprinted with the events of the Holocaust and this therefore becomes an element of their story too. Often they write from the fringes of the victims' experiences, relating stories of family members, and their impressions of the impact the Holocaust has had on their own lives. Those who venture into the heart of the horrors, into the ghettos and concentration camps, qualify their accounts by giving their sources: Eliach names interviewees, and Spiegelman foregrounds his interviews with his father and attempts to make his creative processes transparent. They create a sense of trust between themselves and the reader by drawing attention to their source material and their personal connection to that source material.

The fact is, Vice says, 'readers are suspicious of the motives of outsiders' (4), suspecting them of voyeurism, appropriation, falsification and mystification (as Thomas was accused of). George Steiner, whose Language and Silence remains a pivotal text in Holocaust literary criticism, asks: 'Does any writer, does any human being other than an actual survivor have the right to put on this death-rig?' (Young 130). His choice of terminology, 'death-rig', reveals a deep discomfort, a suspicion of voyeurism, and a sense of fear and disgust. The question he poses, whether non-survivors have a right to 'don the death-rig', is not an easy question to answer.

Writers have always adopted voices different from their own, speaking across gender, race, culture, nationality and sexuality. They often tell stories that lie outside the bounds of their actual lived experience, stories based on research and imagination. To assign the 
Holocaust a sacred position, to put it beyond the grasp of writers and other artists, creates a barrier, separates Jews from non-Jews, victims from non-victims, those who lived through the events from those who came after. This barrier is constructed with the best of intentions: those who suffered through the Holocaust were stripped of their belongings, their citizenship, their dignity and their right to life. It is understandable that they are wary of their stories being appropriated too. Yet there is a danger in allowing the Holocaust to be cordoned off, with only certain writers allowed access to it (whether they are survivors or descendants of survivors): it denies our shared humanity and the power fiction has to break down barriers and see from different perspectives. Fiction has the ability to confront (and sometimes confirm) our prejudices, to make us identify with the 'other', and perhaps even to imagine we can feel as the 'other' feels. It is a unique way of addressing complex issues; it can frame the Holocaust in a way history and fact cannot, and can address an audience who may not be interested in pure historical record.

To fictionalise the Holocaust, then, is to address complex moral issues and raise questions that cannot be easily answered, if they can be answered at all. But that can also be where the power of fiction lies. The Holocaust makes us face what it means to be human in the twenty-first century, and to exclude fiction from entering the conversation denies our shared humanity. If writers can no longer write from the position of Holocaust victim or perpetrator, what other points of view can we no longer write from? Should straight writers refrain from writing queer characters? Should men be denied the opportunity to write from the female point of view? Should we be limited to writing about our own experiences and selves?

Since the rise of identity politics there is increased sensitivity to the adoption of other viewpoints. In Australia, for example, we have become sensitised to the appropriation of Aboriginal stories and of trespassing against Indigenous people's cultures and beliefs. This sensitivity is a 
necessary development, given the appropriation of Aboriginal stories, land and culture by European colonisers. I don't believe we should thoughtlessly trample over others' beliefs and cultures, but we need to recognise that sensitivity is not censorship - just as censure is not censorship. We can disapprove of the appropriation of stories, but are we willing to endorse and impose complete denial of access (which can happen informally, when publishers decide a book might be too 'risky' to publish)? Moral questions are foregrounded when we're discussing fictionalising the Holocaust, but does that mean it cannot be written, or that it ought not be written, or merely that we should beware writing it? Is it the sensitivity, responsibility and intelligence of the approach that matters? Do we merely wish the artist to be wary? We can feel discomfort when reading Holocaust fiction, but such discomfort makes us aware of the moral complexity of the issues involved and can be powerful in the hands of a responsible writer.

Ultimately, I believe my humanity gives me the right to don the death-rig and yet I believe there are limits to artistic freedom my artistic freedom anyway. We must be aware of 'hate speech' and racial vilification, and creative freedom should perhaps be qualified as freedom with responsibility. It may not be a question of who has the right to write, but how they write. There are occasions where artists enter sensitive territory and the responsible artist can display an awareness of that sensitivity by being more transparent and opening up questions. It may be that the way in which we wear the death-rig is more important than whether or not we have ownership of it.

When critics discuss the works of Sylvia Plath and her appropriation of Holocaust imagery as a metaphor for psychic pain, many argue that the Holocaust has filtered into the very fabric of Western culture and, as such, belongs to all of us. 'We might look to her poetry,' James Young suggests in his discussion of Holocaust narrative, 'for the ways the Holocaust has entered public consciousness as a trope' 
(132). The Holocaust has become a cultural reference for ultimate pain and suffering, and for ultimate evil. Plath's experience of the Holocaust was as a 'universal point of reference for all kinds of evil, oppression, and suffering' (Young 131). That said, it is important to note that Plath was not writing Holocaust literature per se, she was using the Holocaust as a metaphor. Plath's poetry, in particular her adoption of the Holocaust as metaphor, introduces readers to the idea that the Holocaust has become central to Western culture's understanding of itself. Along with other poets of her generation (Anne Sexton among them), Plath learned about the Holocaust second-hand. They are the first generation of artists to approach the Holocaust from a distance and they reveal a metamorphosis in what the Holocaust meant: it became a cultural reference point, part of a linguistic landscape, an historical horror rather than a contemporary one. These writers offer a new way of writing about the Holocaust, a new perspective arising from their distance from the material.

In his discussion of Modernity and the Holocaust, Zygmunt Bauman stresses that it is a way of belittling the Jews to see the Holocaust 'as something that happened to the Jews; as an event in Jewish history' (1). Rather Bauman intimates it was an event in human history, a pivotal moment in European and Western history and culture, and it has ramifications for everyone belonging to that culture. Schwarz believes that 'when Holocaust history is personalised and dramatised, when abstractions and numbers give way to human drama ... the distance between us and the victims closes' (33). Other critics agree; Berenbaum feels that in fiction 'death is restored to its human place as an event in the life of real people' (Vision 76). In other words, fiction allows us to remove the generalised label of 'Victim' and to see these people as human again, as people just like us (even though, as characters in fiction, they are representative rather than actual). 'History,' Langer declares, 'provides the details — then abruptly stops' 
(Literary Imagination 9), while I feel that literature allows us to explore beyond factual information to psychological impact, philosophical ramifications, and the human response to atrocity. It can potentially give us a window into the human condition that goes deeper than facts and figures. Even George Steiner, who in 1958 famously wrote that 'the best now, after so much has been set forth, is perhaps to be silent' (188), also said when remarking on Plath's poetry: 'perhaps it is only those who had no part in the events who can focus on them rationally and imaginatively' (330).

Those who argue for the necessity of a literature of the Holocaust believe that all writing is better than silence. Writing, Rosenfeld claims, is 'an effective counterforce to nihilism' and is an act of 'preserving the human' ('Problematics' 3). He feels that while writing fiction is fraught with dangers, 'how much greater the injustice and more terrible the blasphemy to remain silent' ('Problematics' 4) because to 'submit to the finality of silence is to confirm, however unwillingly, the triumphant nihilism of Nazism' ('Problematics' 185). Even Adorno himself said that 'not even silence gets us out of the circle' (367) because silence is a further death for the victims. Silence buries the events forever, which goes against the drive survivors have felt to testify, to ensure the world knows their stories and witnesses the crime. 'Better abused memory in this case,' Young decided, 'which might be critically qualified, than no memory at all' (133).

The literary critic Al Alvarez takes these arguments a step further, believing that 'from the fragile, tentative, individual discriminations of art emerge precisely those moral values which, if understood and accepted, would make totalitarian atrocities impossible' (23). Alvarez wants to return art to the humanistic. Although the value of artistry was questioned in the wake of Nazism and the Holocaust, Alvarez sees refusing to let the shadow of Nazism destroy the ideals of art as a continuing resistance. The contemporary critic Daniel Schwarz agrees, 
feeling that 'in truth it is barbaric not to write poetry, in part because if we do not write imaginary literature, how can there be a post-Holocaust era?' (22).

In the end, Langer claims, the 'literature of the Holocaust is neither awesome nor holy, only painful' (Divided Voice 45). If writers choose to write, we should be aware and respectful of this pain. Writing about the Holocaust involves a moral dimension; in the case of imaginative literature 'moral' writing can simply mean opening up questions about the construction and content of Holocaust narratives, not providing a 'neat' and/or melodramatic plot, and allowing there to be complexity without resolution.

In other words: Beware. 


\section{Taking a Breath}

When I came up for air after my first reading binge - which lasted about a year - I found myself dazed and confused. Oh, and married. The first year of my PhD was a mixed blur of dark and troubling reading and happy and frothy wedding plans. We'd finally decided to get married (after nine years of couplehood), partly because of my mother. During my Honours year she got sick. It all began with the flu; we all had it and it was a bad one, bad enough to trigger other disorders. My partner Ben ended up allergic to foods he'd never been allergic to before. Mum was the last to have it and when the flu went away she was a bit weak. We did yoga together twice a week and over the course of the year she grew weaker, until she could barely climb the stairs to the yoga studio, let alone do downward dog. Before the flu she'd been more flexible than I was; now she was unsteady on her feet. She had a couple of falls and she found she couldn't get up without assistance. By December she could barely walk.

Mum hates doctors and, typically, we couldn't drag her to one until her situation was acute. We knew by the GP's expression that things were bad, and when she ordered an immediate MRI we knew it was worse than bad. The worst thing was seeing Mum's fear. She's stoic, and tends to keep her worst feelings to herself, but we knew they 
were there and it was hell to watch. The Christmas and New Year's public holidays slowed the tests down and we spent a couple of weeks waiting. We all thought cancer but no one could bring themselves to say it aloud. I remember one awful afternoon, walking around the block with my dad while Mum was back for yet another MRI; we went around and around, passing the hospital several times, and we were both frozen with terror, holding hands, as though if we let go the other one would disappear. 'I always thought I'd go first,' Dad said helplessly.

But it wasn't a spinal tumour. I don't know how long it took to get the diagnosis but it felt interminable. It turned out a post-flu infection had triggered Guillan-Barré syndrome (otherwise known as Landry's paralysis), a very rare syndrome that affects the nervous system. She was lucky. The paralysis stopped at her legs and hands - some people can't breathe when the weakness hits their trunk; the worst cases can end up on life support. We were lucky. She could recover from it. My mother is the bedrock of my life; she's one of my closest friends and she's always given me good advice. And one of the best pieces of advice she ever gave me was: celebrate the good times, because you can't pick the bad times, they just happen to you, but you can pick the good times. On her birthday in early January, Ben and I met my parents for lunch and showed them the engagement ring. We were choosing the good times. And they were now.

I led a parallel existence that year. Half of me was designing bridesmaids' gowns and choosing wedding cakes and drinking copious amounts of champagne, while the other half was trudging grimly into the Kingdom of Night. The first year of my PhD was an oddly lonely time. The other candidates who started the $\mathrm{PhD}$ with me were introverts and soon disappeared into their own lives, rarely to be seen again, and both of my supervisors were quiet, retiring types. My fiancé, who was a high school English teacher, was teaching Year 11 and 12 classes for the first time and was distracted and busy. I spent an entire year alone with 
my research, and it was by turns overwhelming, distressing, daunting and traumatic. At my major review I showed Tom and Sue my bulging files and clumsily stumbled through some thoughts. I felt like I'd been dropped into the middle of some giant critical chess game: as a pawn, I was liable to be taken out of the game with my first move. The sheer volume of literature about the Holocaust was mind-boggling and, worse, the more I read the more I was convinced that my project was insensitive and ill-conceived.

'Just write,' Tom said soothingly, in an echo of his suggestion the year before to 'just read'.

'Keep going. You write like a dream,' Sue said, just as soothingly.

They had perfect confidence in me. Were they mad? I was a year into this insane endeavour and I'd barely written a word. I had character outlines and timelines and a great mess of historical detail, coupled with all the fears and anxieties a writer can have after reading theories of trauma narrative.

Just write. Easier said than done.

So, I wrote. And had the good luck to be chosen to be on the editorial team for an anthology. But for that anthology I might have remained isolated for the rest of my candidature. It got me out of my own head, gave me a concrete project that had nothing to do with the Holocaust, and gave me a chance to make some friends. The best thing about writing friends is that you can talk to them about your writing problems. Suddenly I had people to bounce ideas off. I got excited again. This was what university life was supposed to be, wasn't it? An exchange of ideas. I could show them my writing and get some feedback.

And I wrote the book, finished my exegesis, submitted my $\mathrm{PhD}$ and lived happily ever after. 
I'm sure it would have happened that way. If I hadn't screwed up the book. Oh, and had a baby. That's the thing about life, it just keeps getting in the way. Although, to be perfectly honest, I screwed up the book long before I had the baby. I must have written 60,000 words of historical fiction about the Holocaust: I wrote about Gienia in the shtetl, Gienia and her husband Elja in Warsaw, Gienia in the ghetto, Gienia in Birkenau, and then I started on a 40,000 word folly of Elja and his brother in Treblinka. None of it was continuous; nothing linked up; they were just chunky fragments of horror.

It was a disaster. And then I got pregnant. The pregnancy wasn't an accident. Maybe it wasn't the best time to have a baby, but I was 29, and when is a good time? Somehow my life had been segmented. There was 'PhD Amy' and 'Real World Amy'. Real World Amy was having a baby. This was not good news for PhD Amy, who had enough problems of her own without a baby to contend with. PhD Amy went into denial and just kept coughing up gobs of horror. Sometimes she would have a slight panic attack about the lack of structure, of cohesion, of logic ...

Take a deep breath. You need to finish this before the baby is born, Real World Amy told PhD Amy. 'I need to finish this before the baby is born,' $\mathrm{PhD}$ Amy told her supervisors.

'We're going on leave,' they said. Both of them. At the same time. In my last semester before the baby was born. Breathe. Fine. They would be on leave. I'd have a draft for them when they got back. I surveyed the mountainous terrain of my novel. It looked like Mordor. What I needed was structure. And the structure hinged on the contemporary story about the waitress.

Breathe. Breathe? You must be kidding, Pollyanna. Less than six months to pull this mess into shape and you want me to waste time breathing? I was doomed. I'd had a crack at my framing device, the wretched waitress, dozens of times. Nothing worked. I couldn't find her voice. She didn't have a voice. She was a cardboard cut-out. 
She didn't do anything. What was the point of her? 'You need to give her a connection to the Holocaust,' one of my writing buddies said. 'Make her grandfather a Nazi or something.' It was too neat. But I was desperate. So I made her grandfather a Nazi. It was worse than awful. And she was still wooden and boring and voiceless. What was wrong with me? I spat out tens of thousands of words about a Holocaust victim but I couldn't write about a young Australian waitress? I was a young Australian waitress.

$\mathrm{PhD}$ Amy threw up her hands in defeat. By the time my son was born (a month early — thanks for that, Life) I still didn't have a draft. Worse, Tom was retiring, so I was losing my primary supervisor. When I returned from maternity leave, I returned to a complete stranger.

Nick Jose must have taken one look at me and thought: what is this human wreckage that just washed up in my office? Three months into motherhood, I was sleepless and not entirely sane. I may have had baby vomit on my shirt. 'I'm just wondering if I should ditch the idea of the dual narratives,' I rambled witlessly. Part of me had given up on the idea that I could write a book I could be proud of. At this point I just wanted to finish something, anything. It didn't have to be good.

Nick is a very diplomatic person (some would say inscrutable, even) but I swear he wrinkled his nose at me. 'No,' he said.

'No?'

He swivelled in his chair and pulled my original $\mathrm{PhD}$ proposal off his desk. My heart sank. Oh no, he'd read it. He'd seen my ambition and hubris, and now he'd know how badly I'd screwed up. 'This is interesting,' he said, flipping through the pages.

'It is?'

'It's original.'

'Yes, but — '

Nick doesn't listen to 'buts', I discovered. 'Have you read Anne 
Michaels?' he asked. Then he reeled off a list of books. I scribbled madly to get them all down. 'And can you get me something on the waitress in two weeks, for our next meeting?'

Something on the waitress. I didn't even know who she was. 'How much do you want?' I asked weakly.

'Twenty pages?'

I'm nothing if not a people-pleaser. 'Sure.' Then I dragged off to the library, to gather as many books as I could from his list before I had to go home to my son. I left, staggering under the weight of books. More books. I could hardly believe there was a book left on the Holocaust that I hadn't read.

Still, I thought hopefully, maybe I'll find the answer in one of them. PhD Amy: ever the optimist. 


\section{Fantastic Narrative Strategies}

\section{Amy the optimist meets magical possibilities}

I can be a bit thick at times. As I sorted through books, deciding what to write on for my exegesis, I realised exactly how thick I was being. I was making lists of what I'd read, sorting titles into groups, when it struck me that my problem was Realism. Somehow I'd bogged myself down in Realism. It was because of my slavish need for historical veracity, I suppose, but somehow I'd forgotten that fiction isn't reality. As I stared at the list I saw stories that employed the forms of fable, folk tale and fairytale; I saw flickers of magic realism; I saw hauntings; I saw Death embodied as a character. A vista of possibilities opened up to me.

What happened when you ventured away from Realism, I wondered? How did it affect the historical veracity? Was it an ethical strategy, a way to represent the Holocaust without eclipsing history? Or was it problematic? If so, what were the problems?

I felt a little fizz of excitement as I hunted through my bookshelf. Over the next couple of years I read and considered many books that employed fantastic narrative strategies, but I chose to write on three: Yaffa Eliach's Hasidic Tales of the Holocaust, Jonathan 
Safran Foer's Everything is Illuminated, and John Boyne's The Boy in the Striped Pyjamas. Eliach's collection threw up a whole new batch of questions for me - about the appropriation of form and voice, and the continuation of tradition and culture through storytelling. I found Foer inspiring because he was facing many of the same issues I faced as a writer. And Boyne confronted me with my worst fears made manifest. Their texts grew steadily more broken-spined, soft-paged and grubby as I thumbed through them, looking for answers and (as usual) finding more questions.

\section{Yaffa Eliach's Hasidic Tales of the Holocaust}

When I wrote about Gienia at home in the shtetl I fell into a style of writing that felt like a folk tale. Or like Isaac Bashevis Singer's storytelling voice in short stories such as 'Yentl the Yeshiva Boy'. I worried about this. (Let's face it, by now I was completely neurotic about every aspect of writing, fretting over the implications of every choice. I worried about everything.) I liked the folk tale style and wanted to use it, but I also wanted to very clear about how I was using it. The reason I focused on Hasidic Tales of the Holocaust was because I knew I would never be comfortable writing a Hasidic tale. So in my head there was clearly a line between folk tale and Hasidic tale. What was the line, and what did it mean to be on one side of it, versus the other?

Hasidism is a branch of Judaism that emerged in Eastern Europe in the eighteenth century and Eliach claims that 'one of the movement's' most important contributions was its literature, particularly the tales and anecdotes' (Tales xvi). Hasidism secularised religion: storytelling and prayer about daily life was considered as important as the study of the Torah, the Talmud and the Midrash (Tales xv). 'The main themes of Hasidic Tales,' Eliach says in her Foreword, 'are love of humanity, optimism, and a boundless belief in God and the goodness of 
humankind' (Tales xvi). These themes are not ones we usually associate with Holocaust literature.

Yaffa Eliach is a Hasidic Jew. At the time of writing Hasidic Tales of the Holocaust in the late 1970s and early 1980s she was teaching courses on Hasidism and the Holocaust at Brooklyn College in New York. She and her students conducted oral interviews with friends and family who were survivors and also took note of stories that had circulated in the Hasidic communities they interviewed (the survivors interviewed were from New York, Israel, Europe and Australia). Eliach then turned these oral histories into 89 Hasidic tales, divided into four sections: 'Ancestors and Faith', 'Friendship', 'The Spirit Alone' and 'At The Gates of Freedom'. The reader's journey through these four sections follows the victims' progression through the experience of the Holocaust.

Perhaps the most famous tale in Eliach's book, quoted often, is the first one, 'Hovering above the Pit', in which Rabbi Israel Spira and a friend are ordered to jump across a pit at Janowska Road camp: 'Each of you dogs who values his miserable lives and wants to cling to it must jump over one of the pits and land on the other side. Those who miss will get what they rightfully deserve — ra-ta-ta-ta-ta' (Tales 3 ). The rabbi's friend despairs but the rabbi counsels him that it is God's will: 'If it was decreed from heaven that we be commanded to jump, pits will be dug and jump we must' (Tales 4). Their turn comes to jump: 'the rabbi closed his eyes and commanded in a powerful whisper, "We are jumping!"' (4). They jump and make it to other side, where the friend weeps and asks the rabbi how he got them across. The rabbi answers:

'I was holding onto my ancestral merit. I was holding on to the coattails of my father, and my grandfather and my great-grandfather, of blessed memory,' said the rabbi and his eyes searched the black sky above. 'Tell me, my friend, how did you reach the other side of the pit?' 
'I was holding on to you,' replied the rabbi's friend. (4)

This story can be seen to be problematic: it ascribes meaning to the jumping of the pit that is specifically religious; it claims that God was able to control, indeed decreed, the actions of the Nazis and Ukrainians; it takes the text from an historical account to a more fantastic level of storytelling; and it is obviously dramatised, as can be seen from the dialogue. Yet the major defence of Eliach's work rests on it status as a Hasidic tale (on its moral authority). How does the fact of it being a Hasidic tale sidestep the criticisms another style of Holocaust fiction might face? The writing of Hasidic tales is an act of memorial, an act of resistance, and an act of preservation.

The Holocaust almost succeeded in wiping out entire cultures in Eastern Europe - the Jewish shtetl and Jewish shtetl life no longer exists in countries such as Poland and the Ukraine. What remained of Jewish communities after the war were scattered to the corners of the globe and there was, and still is, the threat that the beliefs and cultures of those small rural communities would disappear forever. 'If the tale fails,' Eliach has stated, 'the only imprint of their existence will be a blackened sky and a handful of scattered ashes' (Tales xxv). When her book was published in 1982 it was the first work of original Hasidic tales in more than 100 years and the first to feature women as main protagonists and tellers of the Hasidic tale (Tales xxi). The act of not only preserving but advancing a religious and cultural form of storytelling (including writing tales with a post-feminist twentieth century filter) does more for the tale than simply 'commemorat[ing] the cultural universe that was destroyed along with the people' (Ezrahi Words Alone 97). Elie Wiesel once wrote that 'words have been our weapon, our shield, the tale our lifeboat' (Ezrahi Words Alone 98); the Hasidic tale is the lifeboat of a religious movement and cultural artifact, but in Eliach's work it is more than that. It is a living, breathing form, capable of flexibility and change, relevant to the late twentieth-century. 
The form may be flexible, but not indefinitely so. The core of the Hasidic tale is the framing of the world through optimistic belief; this cannot change or the Hasidic tale ceases to be a Hasidic tale and becomes something else entirely. The form is located in the wider landscape of Hebraic literature and storytelling and has common ground with many other forms of Hebraic tales. In traditional Hebraic literature, Ezrahi claims, 'historical events are absorbed into an inherited valuational framework' (Words Alone 97). For example, the exodus of the Jews from Egypt is structured into an existing system of religious beliefs and becomes part of a wider Jewish (and now Judeo-Christian) story. In her work on Jewish literature of the Holocaust, Sidra Ezrahi holds that 'the Hebraic writer cannot regard the Nazi epoch as unrelated to, or isolated from, the issue of both social and metaphysical continuity' ('Holocaust Writer' 135). The Jewish 'story' is a long one, stretching through history, coloured by many cultures and variations of religious practices, and the Nazi era is merely one chapter of that long story. The use of existing narrative forms, such as the Hasidic tale, reduces the Nazi atrocities to a containable historical moment (like the slavery of the Jews in ancient times and the exodus from Egypt), and is, Gomel believes, a strategy of resistance that '[uses] a rigid narrative formula to combat the disintegrating pull of the cataclysm' (182). The use of the Hasidic tale reaffirms and extends centuries of belief, and Eliach's narrative formula is an integral part of preserving her religious culture and defying Nazism. Eliach herself admits to feeling the weight of responsibility in her role as a story teller who is part of a long established tradition: 'Whenever I wrote the tales, I felt the need to cleanse my hands, as does the scribe who is writing a sacred book' (Tales xxv).

The nature of the Hasidic tale can be seen as problematic if we consider it in light of the fiery debates around Holocaust representation. Eliach has to fit the events into an existing structure, which implies manipulation, rearrangement and authorial interference. 'Eliach can 
finally transmit them,' Young argues, 'only as they are legendarily reformulated to fit Hasidic principles of righteousness and justice' (41). Michael Berenbaum discusses the tension between Eliach's attempts 'to view the Holocaust as the domain of the miraculous and as a world in which the Torah still reigned' and the cold fact that 'Auschwitz was not a place of miracles; the victims far outnumbered the survivors, and many people with an ancestral lineage of magnificent distinction perished along with those of more common background' ('Yaffa Eliach'). What do Eliach's tales mean for those who were not saved by miracles? Does 'Hovering above the Pit' suggest that the people who failed to jump the pit at Janowska Road believed in God less than Rabbi Spira? Were their ancestors less meritorious? Does the Hasidic tale inherently pass judgment on those who were not saved?

The form of the Hasidic tale raises many complex and troubling questions. But letting the form perish, or denying the Hasidic tale access to the Holocaust (which would single the Holocaust out as a sublime event, beyond 'normal' means of understanding, and existing frameworks), would deny a particular sect of Jews the right to weave the Holocaust into their longer cultural and religious history, in a form which has been part of their culture for centuries. Kremer declares that 'Throughout time, tale-tellers have made recourse to myth and fable to circumvent the strictures of fact while seeking a truth with even more resonance than realism' (41). The tale of Rabbi Spira resonates with the desperation of the moment, the horror of the violence, and the hope inherent not only in faith, but also in the act of striving to stay alive against near-impossible odds.

Eliach has been criticised for the conflict between her choice of narrative form and the fact that she attempts to claim historical veracity. Her work uncomfortably straddles a line between constructed tale and survivor testimony. The tales are based on interviews conducted by Eliach and her students with survivors (although there are a couple 
of apocryphal tales that were included because they were widely accepted in the survivor community). At the end of each tale Eliach has included a short italicised paragraph identifying the historical root of the story, for example at the end of 'Hovering above the Pit': 'Based on a conversation of the Grand Rabbi of Bluzhov, Rabbi Israel Spira, with Baruch Singer, January 3, 1975' (Tales 4). This identifies the characters as real, living people, and the event as an event in historical reality, which was related in an interview on a specific date with a specific interviewer. The historical root seems to indicate the tale's veracity, its 'truth'. The fact that the interview details are italicised can be seen a visual clue to the difference between the interview and the tale; they are in contrasting writing styles and hint at contrasting aims. The tale is a 'lifeboat', a form of cultural preservation, with the form as the key element, while the interview details seem to suggest what the written tale should be understood as an historical document or testament. Are the two mutually exclusive?

Eliach's tales are centred around a belief in God and a belief in the possibility of miracles - neither of which, I suggest, have a place in late twentieth century or early twenty-first century historical practice. Young believes Eliach's inclusion of the interview details reflects the 'impulse in Holocaust writers to insist on a documentary link between their texts and the events inspiring them' (51), which is understandable given the ferocity of the debate over who has the right to write Holocaust literature. There seems to be a feeling that if stories are rooted in 'truth', in actual happenings to actual people, then the author automatically assumes greater moral authority over the right to tell the tale.

Young questions Eliach's work with regard to her need to verify the historical sources of the tales. He claims that 'they are not documents of fact amenable to historical verification and analysis' (42). There are few specifics in the tales; they are broad brush-strokes of atrocity and 
camp life told in the tone of religious parable, with the intent of showing that 'there is a way out of the inferno, not just a way into it' (Eliach Tales xxi). In this sense, Young argues, 'they are necessarily allegorical and parabolic in both mode and intent, [and an] affirmation of spirit over fact, the triumph of vision over events' (42). Therefore there is an inherent conflict between the form of the tale and Eliach's attempted verification of the stories (I say 'attempted' because not all of them could be verified) and the way in which she presents them as historical fact. Young also notes that in the first printing of the book Eliach was credited as the 'editor' but in subsequent editions the 'edited by' has been removed, 'leaving the relationship between Eliach and these tales ambiguously unstated' (Young 40). There is a considerable difference between collecting tales and writing them. 'Collection' implies a collation of written record, and of many voices, while 'writing' is an explicit admission of an act of creation, of manipulation and craft. The foreword to the 1988 Vintage edition seems to indicate that Eliach collected the interviews and wrote them up as Hasidic tales, thereby becoming the author of the stories.

Ezrahi claims that the tradition of the tale is a defence against arguments such as Young's: 'unlike myth, the midrashic manner commands a certain authenticity, and communal experience must be transmitted with a measure of realism as well as miracle' (Words Alone 120). The Hasidic tale is a story rooted in secular life, in actual events. 'The role of the witness or transmitter of collective Jewish experience,' Ezrahi holds, 'is to establish at least a degree of verisimilitude and then to interpret and explore the event and to assign it a place in Jewish history' ('Holocaust Writer' 143). The tension here is between the history of a religion and religious group and the secular history of Europe, World War II and the Holocaust.

The Hasidic tale is culture specific; it is not a widespread form common to all Jewish communities but belongs to a specific sect from 
a specific region of Eastern Europe. The question of moral authority seems pertinent to the consideration of the form. Could a non-Hasid write a Hasidic tale of the Holocaust without being vilified? Critics often focus on intent. Why would a non-Hasid adopt the form? What would you be hoping to achieve? Is saying that the Hasidic tale should only be the province of Hasidic Jews exclusionary, or merely respectful? Intent is everything in this fraught land.

'The optimistic power vested in the Hasidic tale,' Eliach writes in the Foreword, 'defies the burning furnaces and glowing chimneys of the concentration camp universe' (Tales $\mathrm{xx}$ ). There is a wonderful sense of reclamation in Eliach's tales, a sense of faith conquering history, and while it may not be palatable to all survivors or critics, it is an important and unique voice in Holocaust literature.

I felt I could never write a Hasidic tale because I was not Hasidic. If writing from the perspective of a victim makes me uncomfortable, writing in a specific Judaic form feels untenable. Why is the form of religious parable the final straw for me? It might be because I am an atheist and religion surprises and confounds me. I would feel false and somehow that would be too much of a transgression. The Hasidic tale is too much a part of a unique, and endangered, culture. Eliach's act of writing/collecting was an act of resistance; if I wrote in this mode it would be an act of appropriation. But the folk tale is another matter. It is not exclusively Jewish. It is broader, more universal; I feel I have some ownership of it. (This question of 'ownership' is problematic, I know, and I will circle back to it in later chapters.) I was instinctively using a folk tale voice in the shtetl sections of my novel and I was curious about why this was and what effects it had. I knew Jonathan Safran Foer used folk tales, so I concentrated on his work to see how they operated. 


\section{Jonathan Safran Foer's Everything is Illuminated}

Jonathan Safran Foer's Everything is Illuminated adopts a non-realist style but doesn't rely on a strictly defined, culturally determined narrative structure that way Eliach's work does. Foer is of my generation, the generation whose grandparents, not parents, lived through the war years, a generation distanced from the Holocaust by time, culture and experience. His writing adds to an existing literature of the Holocaust, a literature that includes work by those who lived through the events and work from subsequent generations, who wrote at varying degrees of distance from the material. In other words, by the time Foer began writing his Holocaust narrative, he was writing in an evolved and evolving literary landscape and entering a discourse that had a tradition.

Foer engages with his family's past (defining a moral authority based on familial connection) and he has adopted postmodern and magic realist strategies for dealing with his difficulties in fictionalising the Holocaust. The novel consists of three prose styles: first, fictional letters written by Alexander Perchov, a tour guide, to a fictional Foer; second, Alexander's account of his trip around the Ukraine with Jonathan (the fictional author), which he is ostensibly posting to Foer with the letters; and third, magic realist folk tales of Foer's ancestors' Jewish shtetl life in the late eighteenth and early nineteenth centuries, as well as during the 1940s. The novel explores the inherent manipulation involved in writing, as Alexander admits to changing events and descriptions of people and places, and through the construction of a fictional Foer. The reader is left not knowing what is real and what is imagined.

Apparently the author Jonathan Safran Foer, just like the character Jonathan in the novel, went to the Ukraine in search of the woman who rescued his grandfather from the Nazis. The actual 
Foer found very little information and left the country without the documentary material for the novel he planned to write. The novel he wrote in the absence of this documentary material is an exploration of the 'unknowability' of the past: Jonathan is unable to represent his ancestors except through the distancing and fairy tale-like shtetl folk tales, which are set for the most part centuries before the Holocaust itself. His ancestors inhabit a world that is a construction, a place he is unable to physically visit because it no longer exists. Alexander's narrative is another marker of unknowability, as his accounts are written in broken and often hilariously inaccurate English, suggesting the impossibility of transmitting (wholly comprehensible) meaning through storytelling. The Holocaust is merely glimpsed by the reader, through secondhand accounts given by Alexander's grandfather and Augustine, which are further filtered through Alexander's broken English and Jonathan's authorial manipulation.

The presence of Foer in the novel could be seen to give it documentary weight, were it not undercut by the reflexive and nonrealist techniques he adopts. Authors are usually consigned to nonfiction and creative non-fiction, as their presence in a text breaks the 'spell' of fiction, the illusion that the story has autonomy. The presence of the author gives a sense of authenticity: a sense that the events actually happened and were witnessed, rather than invented. Foer's editor at Houghton Mifflin, Eric Chinsky, claimed that having Foer as a character in the book 'adds an immediacy and a power to the book that would otherwise be lacking' because the core of the book is about 'the play [between] fact and fiction, which leaves the reader wondering what really happened' (Dahlin). From the opening of the novel readers are aware that we are at the mercy of untrustworthy narrators. The character of Jonathan is not a first person narrator, he only appears as a character seen through Alexander's eyes: 
When we found each other, I was very flabbergasted by his appearance. This is an American? I thought. And also, This is a Jew? He was severely short ...He was wearing nor blue jeans nor the uniform. In truth, he did not look like anything special at all. I was underwhelmed to the maximum. (Foer 32)

Alexander punctures the character Jonathan/Foer's authority from the first, even as he refers to him as 'the hero' (which again gestures to the fact that we're reading a constructed narrative, a story with a 'hero'). Jonathan is not Jonathan Safran Foer. Rather, he too is a fictional construct, held up to mockery from the first, an 'underwhelming' figure, suggesting perhaps that beside their texts all authors are 'short' and 'underwhelming'.

We are alerted to the fact that Jonathan is the author of the folk tale chapters by Alexander's letters, which make it clear that Jonathan is sending him chapters of the book and asking for Alexander to write his own version of their journey. In an early letter Alexander comments on the first folk tale chapter: "The Beginning of the World Often Comes" was a very exalted beginning. There were parts I did not understand, but I conjecture this is because they were very Jewish, and only a Jewish person could understand something so Jewish' (Foer 25). Foer's novel reveals a nuanced awareness of the literary risks and moral perils of fictionalising the Holocaust. In this one comment from Alexander, we see a couple of strategies at work. First, by drawing attention to the authorship of the folk tale, Foer is highlighting the fact that we are reading a representation. This is not history; it is a construction, and a fraught one at that. Second, Alexander alerts us to the idea of 'Jewish' knowledge and the idea that being non-Jewish might exclude readers from complete comprehension or 'ownership' of the story.

Foer plays with this idea of story-construction throughout the novel, drawing the reader's attention to the fact that the stories have been crafted, reworked and manipulated. Jonathan, the fictional 
author, remains a largely unknowable figure, revealed only through Alexander's portrayal, which draws attention to the fact that in most cases we only have the text, with no clear idea how it has been crafted and manipulated by its absent author. The character of Jonathan doesn't even make an appearance until Chapter Five, after all of the narrative forms (recount, folk tale, letter) have been introduced. When he does appear he is entirely eclipsed by Alexander, who is a far more dynamic and interesting character.

Everything is Illuminated is essentially about the distortion inherent in writing. Alexander's English is a prime example: he uses words in unusual ways, opening new meanings (or defying interpretation completely); language becomes slippery and untrustworthy. The reader must be a translator of meaning, as Alexander's incorrect or inappropriate word choices produce bizarre and occasionally opaque images. For example: 'I know many people who dig rapid cars and famous discotheques. There are so many who perform the Sputnik Bosom Dalliance - which is always terminated with a slimy underface - that I cannot tally them on my hands' (2).

The way authors have the ability to manipulate representations is constantly laid bare. In his first written account Alexander describes himself as 'unequivocally tall. I do not know any women who are taller than me. The woman I know who are taller than me are lesbians' (3). Later, in a 'private' letter (the privacy undermined by the fact that it appears in a published book), he writes: 'And thank you, I feel indebted to utter, for not mentioning the not-truth about how I am tall. I thought it might appear superior if I was tall (24). Alexander is, by his own admission, an untrustworthy narrator. Through his letters readers are also made aware of Jonathan's influence over Alexander's writing:

I did fashion all of the other corrections you commanded. I inserted what you ordered me to in the part where I first encountered you. (Do you in truth think that we are comparable?) As you 
commanded, I removed the sentence 'He was severely short,' and inserted in its place, 'Like me, he was not tall.' (53)

The accounts are not only manipulated by Alexander but by the character of Jonathan (and, readers may make the leap, by the unseen and unknown actual author, Foer). Foer uses this technique to explore the dangers of fictionalising such a serious subject matter, for example when Alexander asks:

We are being nomadic with the truth, yes? The both of us? Do you think this is acceptable when we are writing about things that occurred? If your answer is no, then why do you write about Trachimbrod and your grandfather in the manner that you do, and why do you command me to be untruthful? If your answer is yes, then this creates another question, which is if we are to be such nomads with the truth, why do we not make the story more premium than life? (179)

Using Alexander's voice, with its warped language, Foer directly addresses his own ethical concerns, and, Behlman believes, he 'foregrounds, through a set of untrustworthy narrators, the impossibility of any unmediated, wholly accurate access to the past' (59).

The Holocaust is a shadow and an absence in the novel. Until Alexander's grandfather tells the story of Herschel, the only Jews we meet are Jonathan and the characters who live in Jonathan's magic realist construction. Readers are introduced to the magical world of the shtetl as Jonathan's great-great-great-grandmother is born from the river Brod after a carriage has crashed:

In the middle of the string and feathers, surrounded by candles and soaked matches, prawns, pawns, and silk tassels that curtsied like jelly-fish, was a baby girl, still mucus-glazed, still pink as the inside of a plum. (13)

The town is renamed after the crashed driver (Trachim) and the river (Brod), and the baby is named Brod (after the river that birthed her); 
Jonathan's ancestors are intrinsically linked to the town, even to the point of sharing the same name. Jonathan's folk tales follow the lives of his ancestors until 1941. We have fragments of Brod's life: her adoption, which is decided by means of a lottery; her marriage, which arises out of an act of rape; and fragments of his grandfather Safran's life. Safran is a man with a dead arm who pleasures old ladies and drives a Gypsy girl to suicide; he experiences his only orgasm during a German bombing. The tales are as much about the surreal world of prewar Eastern Europe (as seen through a fantastic filter) as they are about Jonathan's imagined ancestors. This magical world is peopled with the likes of The Wisps of Ardisht:

The Wisps of Ardisht — that clan of artisan smokers in Rovno who smoked so much they smoked even when they were not smoking, and were condemned by shtetl proclamation to a life of rooftops as shingle layers and chimney sweeps. (16)

The religious life of the Jews in Trachimbrod is divided into two distinct groups: those of the Upright Synagogue (a synagogue on wheels that is moved whenever the line between the 'Human' section of town and the Jewish section of town moves, which it does, often) and the Slouchers. The Jews of the Upright Synagogue shout every word they utter: 'since the Venerable Rabbi enlightened that we are always drowning, and our prayers are nothing less than pleas for rescue from deep under the spiritual waters' (17). They also hang from high ropes, so that they are closer to God, and walk with an affected limp (or refuse to walk at all), because of the time a fly bothered them during prayer and the Rabbi shouted: 'SHOULD WE NOT RISE TO ITS CHALLENGE? AND I URGE YOU: CRASH TO THE GROUND BEFORE YOU DROP THE GREAT BOOK!' (17). Those who became the Upright Synagogue fell to the floor and held the book, while those who became the Slouchers dropped the book and held onto the rope - forever dividing the Jews of Trachimbrod. 
What Foer is doing is admitting the Holocaust to the realm of the imagination; he's allowing it into the magic circles of existing narrative structures. But that's not all these chapters are doing; they also deploy humour, another human strategy for coping with adversity and horror. Foer claims that when he initially approached the project he thought: 'I can't be whimsical, and certainly can't be funny about this' (Dahlin). It's true that very little Holocaust literature is humorous. The events are so grave that humour seems in poor taste - and it must be noted that when Foer eventually confronts the Holocaust head on, the humour evaporates. Yet his use of humour in the folk tale chapters and through Alexander's mangled narration, doesn't feel inappropriate or disrespectful (at least not to me). With regards to the character of Alexander, the humour is a gentle and non-didactic technique for addressing ideas of authorial manipulation and the inadequacies of language. Alexander also gives Foer a means to address the concerns raised by a 'humorous' Holocaust novel, which admits the spectre of the debate about appropriate ways of 'speaking' (of the critical caveats on artistic engagement with the material). Alexander asks Jonathan: 'Are you being a humorous writer here, or an uninformed one?' (25).

In the folk tales, the humour is affectionate and is perhaps only successful because Jonathan and Foer, while not members of the community mocked, have a sense of 'belonging' to the community by right of birth. It is an insider's joke, rather than a cruel parody. Foer cannot access the now lost shtetls; they can exist only in history and the memories of others, and so his creation is a way of accessing the inaccessible while simultaneously signalling that inaccessibility. Again, Foer foregrounds his narrative choices, alerting the reader to the use of humour as a strategy for navigating the treacherous terrain. In a letter to Jonathan, Alexander says 'I wanted to be truthful and humorous, as you counseled (101). The humour adds poignancy and humanity and counterpoints the harsh and horrible history to come. 
In portraying Trachimbrod as a fairy tale world (and by fairy tale I mean the troubling kind like in the Brothers Grimm, not the Disney kind), Foer heightens the impact when Augustine (the sole survivor of Trachimbrod; the memory keeper who guards the towers of boxes filled with the possessions of the dead) tells Jonathan and his guides about the arrival of the Nazis and the shooting of the townspeople.

Foer maps his choices, so by the time readers reaches the climax, finding out about the destruction of Trachimbrod and Alexander's grandfather's role in the events, they are likely aware of the complexity involved in fictionalising the subject. At this point the narrative tone shifts and Augustine uses the spare language of survivor testimony: 'And the General shot my sister. I could not look at her, but I remember the sound when things hit the ground still' (186). The Trachimbrod that Alexander brings Jonathan to (a deserted field; a woman who is not really the woman they are looking for but who accepts the name Augustine when they call her by the absent woman's name) is a world away from the whimsical, humorous and charming place Jonathan creates in his shtetl tales. Foer's prose style shifts and the contrast has enormous impact. This is what lies at the end of the fairy tale: the Holocaust. An entire world, a history, a culture, and even the constructed illusion, reduced to a monument in an empty field, and a woman who 'had a very unusual walk, which went from here to there with heaviness' (146).

In his analysis of the novel, Lee Behlman observes that 'the reader's sense of shock or surprise ... derives from the apparent clash between the familiar characters, conventions, and storylines of Jewish folklore and the dreadful events that would destroy the culture that produced them' (58). Foer's novel is a sophisticated narrative that addresses the very complex issues surrounding fictionalising the Holocaust. Like Art Spiegelman in Maus, he has used self-reflexivity as a way to reconcile fictionalising the Holocaust with his discomfort 
and his inability to access the Holocaust itself. The use of texts within texts, the encouragement of the reader's awareness of storytelling techniques and authorial manipulation, the use of humour, and the acknowledgment of the unbridgeable distance were a liberating revelation to me as an author. I wanted more texts that challenged the boundaries and acknowledged the inherent difficulties in representing atrocity. I needed role models; I needed models of any sort.

\section{John Boyne's The Boy in the Striped Pyjamas}

John Boyne's The Boy in the Striped Pyjamas was also a revelation to me. It startled me and appalled me and challenged me. His fable about the son of the commandant at Auschwitz befriending a Jewish boy through the wire is a work that sacrifices historical veracity for the sake of a dramatic denouement. The self-consciously childlike voice and the historical inaccuracies are chosen to serve the plot and they raise many concerns about the ethics of dealing with the Holocaust in fiction. Boyne is an Irish writer who is from the same generation as Foer but who is even more distanced from the material, as he has no familial connection.

The Boy in the Striped Pyjamas is told from the point of view of Bruno, an extraordinarily naive boy of nine, who relates the story of his father's promotion and the family's move to the camp in a way that reveals a complete lack of understanding and thus a complete absence of guilt or ownership of the situation. Throughout the novel the camp is referred to as 'Out-With', Hitler as 'The Fury', and Bruno imitates his father's salute supposedly without understanding it: "Heil Hitler," he said, which, he presumed, was another way of saying, "Well, goodbye for now, have a pleasant afternoon"' (54). Boyne establishes that Bruno has no concept of what a Jew is, for example when Lieutenant Kotler chastises one of the servants working in the house: 
'And afterwards, when you return to the kitchen, make sure you wash your hands before touching any of the food, you filthy - '

Liuetenant Kotler repeated the word he had used twice already and he spat a little as he spoke. (76)

Near the end of the novel Bruno's sister attempts to explain to him about the Jews:

'Jews,' Bruno said, testing the word out. He quite liked the way it sounded. 'Jews,' he repeated. 'All the people over that side of the fence are Jews.'

'Yes, that's right,' said Gretel.

'Are we Jews?'

Gretel opened her mouth wide, as if she had been slapped in the face. (182)

Bruno's naïveté stretches the bounds of belief. The fact that any German child living under the Nazi regime would not know the word 'Führer' (a simple German word meaning 'leader') or would not know what a Jew was lacks credibility. The fact that the son of a high-ranking Nazi would not have been indoctrinated (and aware of the climate of racial hatred) is ridiculous. Bruno has the tone and naïveté of a five-year-old, not a nine-year-old. In his review, Ed Wright describes it as a 'tonal clunkiness where you can almost hear the author thinking "how do I write a child?"' ('The Boy'). Boyne needs Bruno to be naïve, to not comprehend the horror of the world around him, in order for the denouement to have its impact (even though the naïveté and incomprehension is highly improbable).

Bored at 'Out-With' and secluded in the house with only his sister, who dislikes him, Bruno is lonely and restless. Eventually he starts 'exploring' and in the chapter 'The Dot That Became a Blob That Became a Figure That Became a Boy' he meets Shmuel. Shmuel sits on the other side of the wire fence: 
The boy was smaller than Bruno and was sitting on the ground with a forlorn expression. He wore the same striped pyjamas that all the other people on that side of the fence wore, and a striped cloth cap on his head. He wasn't wearing any shoes or socks and his feet were rather dirty. On his arm he wore an armband with a star on it. (106)

The boys find that they share a birthday and are the same age. Bruno begins visiting Shmuel. When he remembers he brings food for the boy, but he often gets hungry and eats it himself on the walk to the fence. Their discussions do little to enlighten Bruno; for example, when Shmuel reveals that he is Polish (Bruno has no idea that Out-With is in Poland), Bruno responds:

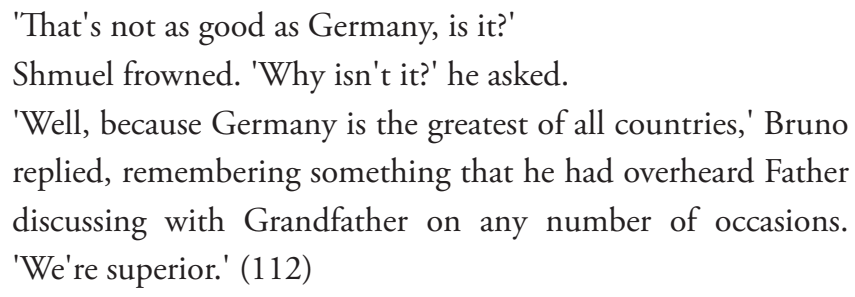

When Bruno gets lice, his head is shaved. 'I look just like you now,' Bruno tells Shmuel, to which his friend replies: 'Only fatter' (185). When Shmuel's father goes missing, he steals a pair of striped pyjamas for Bruno to wear and Bruno slips through the fence to help him search. Bruno doesn't find the café and the village life he imagined was behind the wire and responds to his first glimpse of the camp by telling Shmuel, 'I don't like it here' (208). Inevitably, the boys find themselves being rounded up with a group of others and herded into a long room.

And then the room went very dark and somehow, despite the chaos that followed, Bruno found that he was still holding Shmuel's hand in his own and nothing in the world would have persuaded him to let it go. (213) 
The only clue Bruno's father has to his disappearance is the pile of clothes beside the fence. The book ends with a dry summary:

And that's the story about Bruno and his family. Of course all this happened a long time ago and nothing like that could ever happen again.

Not in this day and age. (215)

Boyne's plot can only work because of the deliberate historical inaccuracies. For example, the fences at Auschwitz were electrified and there were manned watchtowers at regular intervals. Prisoners who came too close to the fences were shot. Shmuel would have been warned away from the wire and shot if he'd ignored the warning; historically, there would have been no chance for him to speak to anyone through the wire. There is also no chance an outsider could have crawled through the wire. Without these inaccuracies Boyne would have no story. Similarly, without Bruno's excessive naïveté there would be no story. If Bruno was aware of what a Jew was, and aware of his father's role in their persecution, there is no way he would have befriended Shmuel. The denouement, where the son of the commandant is gassed along with his father's victims, is powerful and heartbreaking because of these inaccuracies.

But it's a fable: isn't that its defence? The word appears on the cover of some editions, and on the frontispiece of others: The Boy in the Striped Pyjamas: a fable. Can you sidestep historical fact by calling a work a 'fable'? The words appear on the inside cover, so the reader is adequately warned that this isn't history. Does the form of the fable bear less of a historical and/or ethical burden than other fictional forms? Fables are tales with a moral. Boyne is certainly taking a position, albeit a very simplistic one. His portrayal of Hitler is an unsubtle portrayal of an uncharismatic, unlikeable 'Fury', who is accompanied by a blonde woman. In actual fact, Hitler was usually very charming toward women and children and the children of higher-ranked party officials often 
referred to him as 'Uncle'. Also, Eva Braun was not seen publicly; she was usually confined to a chalet on the Obersalzberg. Her existence was not widely known about until after their deaths. Boyne has chosen to ignore these ways of seeing Hitler in favour of a more one-dimensional version. Hitler — the 'Fury' - is not a nice man. This is important in terms of the fable because the lesson is aimed at Bruno's father: the Nazi, the commandant of Auschwitz, a man directly responsible for millions of deaths. In the novel, Bruno's father's boss is portrayed as an 'evil' man, evil as it is understood in a children's story: he is unattractive and unappealing. Here, 'evil' has no charm. Bruno's father is clearly on the 'wrong' side. The moral of the fable seems to be that we are all human and when you kill another human, you kill your kin. Boyne also includes a warning ('beware this does not happen again') in the final lines of the novel.

The choice of fable as narrative form means the story is inherently reductive. To simplify the Holocaust in such an extreme way is problematic. It is easy to adopt an 'us and them' mentality. Bruno himself is neither perpetrator nor victim: he is The Innocent. That said, in her review of the book Kathryn Hughes argues that it is possible to read Bruno's innocence as representative of 'the willful refusal of all adult Germans to see what was going on under their noses' ('Educating Bruno'). Gomel notes that in most fairy tale narratives 'the child is often the central figure: a personification of tough and stubborn innocence' (182). Bruno is humanity before hatred has taken root and he stands in for the reader, a reader who views the Holocaust with incomprehension and at a distance.

The fact that the boys die together, holding hands for comfort, reinforces their shared humanity. But Bruno is not a Nazi. Does this keep the Nazis as 'other'? Even though he repeats the words of his father and grandfather, Bruno doesn't comprehend the meaning of those words. In the fable his death functions as a punishment and a 
lesson for his father. Again, it is possible to argue (as with DM Thomas and The White Hotel) that Boyne's appropriation of the material to teach a moral lesson is problematic. Boyne has reconfigured Auschwitz, created a Hitler who fits a contemporary (mis) understanding of the man, and positioned us with the innocent in order to tell a tale with a simplistic moral. However, the fable only works if the reader has the knowledge to fill certain gaps. It requires prior knowledge of the Holocaust. This is a strategy 'which relies on the informed position of the reader while leaving ambiguous just how much or how little the speaker herself suspects' (Fridman 40).

The lacunae are many in The Boy in the Striped Pyjamas. For example, as previously noted, 'Out-With' is never referred to as Auschwitz, although Bruno's sister constantly tells him he's saying it wrong; it's never explicitly stated that the 'Fury' is Hitler; it's readers' pre-existing knowledge of Hitler and Eva Braun that makes them recognisable. Even the gassing of the boys is not explicit. There is mention of a long room and darkness, but the fable only works if the reader has prior knowledge of the gas chambers. Perhaps the lacunae are not such a problem if the book is taken as a work for adults, but it is currently being marketed for the Young Adult market. Nearly seventy years after the Holocaust, do children and young adults have the knowledge to fill the gaps? Many would argue that The Boy in the Striped Pyjamas is a way for the next generations to learn about the Holocaust. In fact, it is taught at high school level in some South Australian schools and is an opportunity for the students to learn the history of the Holocaust as a context for reading the book. But what about the historical inaccuracies in the novel? The fact that this book may be the first introduction to the Holocaust for many of its readers places a heavy burden on it. Is it better for people to learn about the Holocaust in any form, accepting the inaccuracies, or is such simplification dangerous? 
Stories are not history. Fables are especially not history. And yet, unlike Foer, Boyne has set his fable in a concretely historical world, peopled with actual historical figures. Young believes that by 'mixing actual events with completely fictional characters, a writer simultaneously relieves himself of an obligation to historical inaccuracy (invoking poetic license), even as he imbues his fiction with the historical authority of real events' (52).

The question then becomes: is history sacred? Do all stories - whether they are realist, magic realist, fairy tale or fable — bear the burden of historical veracity? This is an important and vigorously debated question for creative writers. I will explore this issue in greater detail in the chapter 'Contracts with the Reader'. My reservations about The Boy in the Striped Pyjamas sent me off into the stacks of the library again, hunting out the literary journals where these debates raged. During this time the Australian so-called 'history wars' were in full force and there was plenty of material to read on the subject of fiction's responsibility to history. 


\section{Amy, Meet Molly}

It's better than sex. Ok, I said it. I admit I said it. My writing friends have made fun of me for years over that comment. I have a tendency to exaggerate, but I wasn't far off the mark. Being in flow is a kind of heightened arousal, not unlike falling in love (or lust). All of your senses are sharper and there's kind of a manic edge to your thought processes. Everything connects to your work, everything feeds into your writing: every gesture other people make, every comment, every book you read, every TV show you see. Your synapses snap and your blood sings and it's just a wonderful thing.

But it's rare. With some projects you have to swim a long way out before you can catch that current (and sometimes you never do). Most writing is hard graft. But then there are those sublime times when you're in flow. And while maybe it's not better than sex, it's as least as good as sex. And not standard missionary position sex; I'm talking lifechanging, fireworks exploding, blow-your-mind sex.

When Molly finally showed up, she dragged me into flow. I sat down to write those 20 pages for Nick Jose, and there she was. She came spilling out and just took over. Why hadn't she come earlier? Truthfully, I think I was blocking her. Real World Amy's life was too 
close to Molly's and when I tried to write all I got was my own life. I think it only worked now because I had changed. I wasn't a waitress anymore; I was a writer, a student, and a mum. Amy the Waitress had grown insubstantial and, when I sat down to write after my maternity leave, she swirled away like smoke. And in her place stood a prickly, foul-mouthed, funny, frustrated waitress named Molly.

'This is good,' Nick said when he read it. 'Keep going.'

No problems there. I was having fun. The bulk of Molly's story came rushing out in the space of six weeks, and the first twenty pages are still virtually unchanged thirteen drafts and many years later.

Ok, that makes it sound way too easy. It was fun and I loved it; it felt great and it wasn't difficult to write, but finding the time to write was a whole new problem. My son was a month premature, and that comes with its own problems. We never quite got breastfeeding down. Or sleeping. In fact, he didn't sleep a night through for the next four years. When he was twelve weeks old I went back to tutoring at the university, partly because of financial necessity and partly to keep my resume current. So, twelve weeks into motherhood, sleepless and slightly freaked out about having to keep another human being alive, I started a new job. My husband had started a new job too, just weeks before our son was born, so he was busy and stressed, disappearing from the house between six in the morning and seven at night. Fun times. Luckily, I had my mother, who came over at breakfast time and helped me in every possible way she could. My mother-in-law babysat one afternoon a week while I went to work; my dad popped in every lunchtime to visit the baby. Somehow, with their help, we managed to work and parent. Don't ask me how I fit the writing in. In retrospect I have no idea. Except that I've always had a mantra when it comes to writing: just shut up and do it (I'm doing it right now, sitting at the kitchen table in my pyjamas in a spare 45 minutes before the kids return from their dad's. It's school holidays - this will be my last 
spare minute of the day). There's always an excuse not to write. Usually several in my case. At some point you need to decide that no excuse is good enough. If you want to finish a book, there's only one way to do it: sit down, shut up, and write.

It helped that I was in flow. I could snatch half an hour here and there without having to 'warm up'; I sat down and Molly was there at my fingertips, speaking for me. When I look back at that time, I see someone who was skating a little close to the edge. I went five weeks without sleeping at one point (not by choice: baby, remember). My memory of writing is a great blurred flood of colour and sensation. I went with instinct and inserted bits of Gienia's story into Molly's outpouring as I went along. I went with the emotional tone, and left vast wedges of Gienia's story unused. There was very little conscious thought and planning; I was all id.

Then one day I found I had a draft. Everything became impossibly still and I suddenly realised I'd been living in a whirlwind. The stillness didn't last for more than a minute or two, I'm sure; the baby probably started crying and a pile of marking probably arrived in my pigeonhole. But I didn't have to write the book anymore and that was something, right? I sent it off to Nick.

'It's got a poetic structure,' he said thoughtfully. I nodded like I knew what he meant. I didn't know what he meant. I would have, I'm sure, if I hadn't been so tired, but as he spoke I was probably fantasising about sleeping. I used to do that a lot. Nick had these comfortably spongy retro armchairs in his office; I'd sink into them and immediately feel a bit sleepy. I made sure to write down everything he said in my notebook, because my sleepy-brain couldn't quite make sense of everything at the time. 'This is going to be a question of balance,' he said. 'Because Molly's quite immediate, isn't she? We feel for her, even next to Gienia.' He was disturbed by it. This was not a problem I'd anticipated. I'd never thought caring for Molly might be 
uncomfortable for readers.

I was lucky to have supportive and intelligent readers like Nick during the writing of End of the Night Girl, all of whom gave me useful criticism and advice. In retrospect there were a lot of them: three university supervisors; a mentor (who was a professional editor with a publisher); The Australian/Vogel judges; two other $\mathrm{PhD}$ candidates who swapped work with me; two examiners; the judges of the Adelaide Festival Unpublished Manuscript Award; and finally my editor and publisher. Thinking back on it now, I wonder how different the work would have been if I'd hidden away and written it on my own, without any reader feedback through the early drafts.

Doing a Creative Writing PhD gives you access to experienced writers and critics, who are with you through every step of your process. You discuss your initial ideas with them and share your first tentative efforts. They see the unwieldy chaos of your first draft and discuss all the possibilities and pitfalls of your redrafting choices. This may not always be a good thing. I once worked with a colleague who insisted he wanted to see work in progress from all of his students at regular intervals, to catch them immediately if they went 'off track'. It gave me a chill when he said it. Because what is 'off track'? End of the Night Girl was always off track; it wouldn't exist if I hadn't been able to stumble around, beating my own track through uncharted country. Some of the most wonderful creative moments happen, I believe, when we have no idea where we are, or where we're going, or where the hell we're going to end up. It strikes me as dangerous to hand over the decision of what is considered 'on track' or 'off track' to someone other than the writer (although, realistically, I know it happens in publishing all the time). I count myself as very fortunate that after that first 20 pages Nick left me alone until I had a draft. His influence came in the redrafting process and even then he was sensitive to give no directives or judgments. His style was to ask me questions (usually questions I couldn't easily 
answer) and to challenge me so I would justify my choices (or reconsider them). To be honest, at that age (my late 20s) and with that level of experience (meaning, I had precious little), I was very impressionable. If he'd asked me to change something, I probably would have changed it, because he was a professor, he'd written half a dozen novels, he was a critic and a very intelligent man. He intimidated me, not deliberately just because he was accomplished and I was young and a nobody. I assumed he knew what he was doing and I knew I had no idea what $I$ was doing. The relationship between supervisor and student has an unquestionable power dynamic and in these circumstances it's clear to see that a beginning writer might be overly influenced by an established one.

I sit on the other side of the desk these days, supervising Honours, Masters and PhD students and I'm well aware of the power dynamic. I feel like I walk a very careful line between critiquing their work and allowing them to develop their unique voice and style. I'm pressured to get them to complete on time, so the temptation is to keep them 'on track', but as I writer I know that 'off track' is where the good stuff happens. I know they'll get lost, make a mess, despair and want to give up. But I don't want to rob them of that experience, because it's there in the mess and despair that they'll be pushed to find their originality. I don't want them to write the book I would write; I want them to write the book only they can write. Maybe it will succeed and maybe it won't, but what's the point in writing to please your supervisor? I'm one person, with specific tastes and ideas about writing, and I can't see into their heads or read the future - who knows what marvellous solutions they'll find to their messes?

This was something Nick knew. To get of my way and let me solve my own problems. He'd point the problems out. It was up to me to decide if I agreed that they were problems, and also up to me to decide what to do about them. When he read my first draft he illustrated an 
issue in that first draft that I was to struggle with for four more years and twelve more drafts: the disparity of suffering between Molly and Gienia. The contrast between Molly's suffering (which in the first draft was limited to her love life) and Gienia's (enduring the Holocaust) are obviously out of proportion to one another. It's discomfiting to respond to Molly's suffering as well as Gienia's (and, oddly, Molly's section stood up beside Gienia's; it wasn't overshadowed). What right did Molly have to suffer about the Holocaust? How on earth could waitressing seem miserable after Auschwitz? How did Molly earn her right to suffer? Was the novel lessened by the immediacy of Molly's 'suffering'? Should Gienia's suffering cancel out Molly's? Was it morally questionable, even dangerous, that Molly's voice/story was as strong (or stronger) than Gienia's?

If the writing of the book had been a struggle, now I was about to learn that the writing was nothing compared to the rewriting. If being in flow is like great sex, redrafting is like marriage counselling: you will strip yourself bare, confront your failures, cry a lot, and hope against hope that some elbow grease can make it all work.

Nick gave me notes on the first draft. Lots of notes. Big picture stuff, because line edits don't belong to this stage of redrafting. Shame. Commas are easier to move about than ideas. He pointed out my clunky transitions and a few confusing passages; I could handle that. What I couldn't handle were the questions. Questions like why? Why is Molly writing about the Holocaust? What are you trying to say by contrasting Molly and Gienia? And the one he didn't actually ask but which I felt hanging above me like the sword of Damocles: what's the point of it all? What are you doing? And why are you doing it?

I left his office feeling like I wanted to vomit. Here I was again, at the heart of the matter. Why? I felt the same crippling panic I'd felt when I couldn't find Molly's voice. But worse. The book would succeed or fail based on my answer to that question (or so I felt at the 
time). Why was I writing about the Holocaust? What was I trying to say? If I didn't know what I was trying to say, then all the book could ever be was a collection of pretty (or not so pretty) words. Worse, they had the potential to be harmful words. 



\section{Contracts with the Reader}

When we pick up a book, I suggest, we have expectations. We may not even be aware of them, and we don't spend much time analysing how those expectations are formed and how they're influencing our experience of the book, but they do exist, as we discover every time there's a great literary scandal surrounding 'fraudulent' writers who have 'misrepresented' themselves and their work. Think of James Frey, Norma Khouri, Mudrooroo, and, in the case of Holocaust literature, Benjamin Wilkomirski, Jerzy Kosinski and Helen Demidenko.

The relationship between reader/author/text is a complex one. There is an invisible, unspoken contract: the reader expects the author and text to hold true to this contract, even though the terms can be shifting, misunderstood, manipulated and even unacknowledged. The questions of author intent and 'what the book is' (what it claims to be, what it is marketed as, what the cover and blurb say it is trying to be, what the author says about it in interviews) are of heightened importance when it comes to Holocaust literature, because of the 'moral perils'. The success of Eliach's, Foer's and Boyne's narratives rely on clear contracts with the reader. Young's concerns about whether Eliach is credited as 'editor' or 'author' are concerns about the clarity of 
the reader/author contract. Editing is one thing, authoring another in Young's opinion it is important that the reader know and understand which is which in the case of the text. Because they assume different modes of reading.

If Eliach's contract with her reader specifies that she is collecting and editing the tales, then we approach them from a more historical angle: as testimonies and oral histories. If, however, she has authored them, the reader approaches the text differently: we read it as fictionalised, as having deeper symbolic or metaphorical meaning, as speaking to us in terms of form, and not just in terms of content. Art and documentary are fundamentally different beasts, even though both are constructs. In Foer's case he works to undermine his contract with his reader, foregrounding the constructedness of his narrative, as if proclaiming 'Do not trust me. This is invented,' and introducing the idea of the author as unreliable and 'tricky'.

As I sat with my first messy draft of End of the Night Girl, I knew I had ghosts to wrestle with. Not just Adorno and DM Thomas, but also the ghosts of the 'fraudulent' writers. And the dead. They were always present. I was one haunted author. During this time, when I couldn't make head or tails of my own intentions, or how to restructure my novel, the easiest ghosts to acknowledge were the frauds. I felt like one of them. I didn't know what kind of contract to establish with my reader because I didn't yet consciously understand what I was trying to achieve. The two authors I focused on were Jerzy Kosinski and Helen Darville, mostly because the critical reaction to their frauds was so virulent.

The literary scandals surrounding Jerzy Kosinski and Helen Darville's Holocaust narratives highlight the importance of the invisible contract between reader and author, and show how poisonous the response from the literary community can be when they feel they have been 'duped' with a false contract. The books themselves don't 
change when readers find out that the authors are not who we thought they were. The words on the page are the same and yet, I argue, the way many of us read them is fundamentally different. This suggests that there are multiple layers of meaning drifting between the lines, many brought to the text from beyond its pages.

\section{Jerzy Kosinski's The Painted Bird}

Jerzy Kosinski was a Jew who survived the war in hiding; in the Afterword of the second edition of his novel The Painted Bird he writes: 'that I survived was due solely to chance, and I had always been acutely aware that hundred of thousands of other children had been condemned' (xi). Kosinski is deliberately vague in the Afterword about his nationality ('Eastern Europe' is as specific as he will get) and he is at great pains to establish the book as fiction: 'Facts about my life,' he writes, 'and my origins should not be used to test the book's authenticity' (xiii). This is a problematic assertion, especially in Kosinski's case, as I will discuss. This Afterword was written after the book's first edition had weathered some controversy, and after the critics had turned their attention to who the author was and what his wartime experiences had been. The Painted Bird was first published in 1965, seven years after Primo Levi published If This is a Man and five years after Elie Wiesel published Night. Holocaust literature memoir, testimony and history - was still an emerging genre and Holocaust fiction was younger still. The shock of the events was still fresh, and critics, historians, and the general readership were anxious about the ethics of writing about the Holocaust. What did it mean to fictionalise it? Would fiction turn the Holocaust into some kind of gruesome, voyeuristic form of entertainment? In this climate, survivors were figures who readers could trust: they were the victims; their suffering had earned them the right to talk about it, to write about it, 
to use fiction to speak the 'truth'. But could it only be 'truth' if they had lived through it? What if they were Jews who had escaped? What if they hadn't suffered on the same scale as Levi and Wiesel?

The Painted Bird approaches the Holocaust through allegory. Vice describes it as a '"translation" [of] the political, bureaucratic and sadistic layers of genocide into scenes of local horror' (68). It is the story of a boy — possibly Gypsy, possibly Jew — wandering through a nightmare landscape of violence and abuse, fleeing from one brutal and terrifying hiding place to the next. The opening paragraphs position the boy in an historical period: 'In the first weeks of World War II, in the fall of 1939, a six-year-old boy from a large city in Eastern Europe was sent by his parents, like thousands of other children, to the shelter of a distant village' (3).

The tone of this two-page introduction is again reminiscent of folk tales and fairy-tales; it sets the scene, establishing how the boy comes to be wandering alone, who is chasing him and why, and the fact that the villagers are also suffering under the Nazi regime. The rest of the book is a first person narrative, deep in the traumatised, dissociated psyche of the boy. The boy, like Bruno in The Boy in the Striped Pyjamas, is a naïve narrator. He seems unaware of the political and cartographic landscape he finds himself in, and the introductory pages help us to locate him historically. The events of the novel are not explicitly linked to the Holocaust by the boy himself and he repeats the prejudices and superstitions of the villagers he encounters without displaying a clear understanding of what they mean. For example, when commenting on his time with a village woman named Marta, he says: 'I was never allowed to pick up any of her lost hairs from the floor. It was well known that even a single lost hair, if spied by an evil eye, could be the cause of serious throat trouble' (10). The anti-Semitism is implicit and not subjected to analysis by the narrator, and therefore the introductory paragraphs of the novel serve to guide readers in filling in 
the text's lacunae. We know we are in the presence of genocide. There is little else in the narrative to indicate the presence of the Holocaust (the photographs thrown from the trainloads of deported Jews and the invasion by the Soviet forces are rare examples) and the novel reads like a folk tale, a tale of an 'everyplace'.

In The Painted Bird the brutal world of the villagers comes to stand for the brutal world of the camps. The boy takes shelter with increasingly abusive and vile villagers, such as the miller who suspects a plowboy of coveting his wife, and who gouges the plowboy's eyes out with a spoon; or the farmer Garbos, who hangs the boy from the ceiling and terrorises him with his dog; or Makar, who copulates with his children and his farm animals, and who has the Billy goat rape his daughter. This is a world where the inhuman has become the norm, where the rules of civilisation have been swept aside and bestial natures rule. It is a strong and horrific allegory for the dehumanisation of the Nazi system. Kosinski strips away the bureaucracy and sterile language of Nazism to reveal the horror beneath.

The Painted Bird features scenes of extreme pornographic violence, mapping an emotional experience of a Jew in hiding, rather than a literal truth. The boy has become, in Schwarz's words, an 'almost anaesthetised witness' (187): the violence has ground him down to a base level where he is operating merely to survive. This is a psychological state that is represented in many memoirs of Holocaust survivors; there tends to be a flatness of prose, which suggests dissociation resulting from severe trauma. The boy in The Painted Bird has adapted to the world in which he finds himself, becoming prey to the endless brutalisers. $\mathrm{He}$ is naïve but not innocent, able to save himself by killing others, such as when he tricks the carpenter into the rat pit and watches him being devoured by the rats:

Mad with greed, they tore from one another scraps of clothing, skin, and formless chunks of the trunk. They dived into the 
center of the man's body only to jump out through another chewed hole. The corpse sank under renewed thrusts. When next it came to the surface of the bloody writhing sludge, it was a completely bare skeleton. (64)

The violence is confronting and it illuminates the way the Holocaust overturned familiar, 'civilised' and humane behaviours. In Kosinski's novel, the time, places and events of Holocaust narratives have more in common with the brutality of early fairy-tale narratives (witches eating children, stepsisters being forced to dance themselves to death) than with later novelistic forms.

Kosinski's work has been criticised for the extremity of the violence and the graphic sexual content. There is a sense, Schwarz feels, that 'Kosinski enjoys describing sexual excess beyond the need of his text' (192). For example, there is a scene where the village women attack Stupid Ludmilla:

Stupid Ludmilla lay bleeding. Blue bruises appeared on her tormented body. She groaned loudly, arched her back, trembled, vainly trying to free herself. One of the women now approached, holding a corked bottle of brownish-black manure. To the accompaniment of raucous laughter and loud encouragements from the others, she kneeled between Ludmilla's legs and rammed the entire bottle inside her abused, assaulted slit, while she began to moan and howl like a beast.

Kosinski indulges in detailed description of such assaults. In fact, they form the structure of the novel as the boy lurches from violent episode to violent episode. Many critics feel that Kosinski's use of violence is exploitative. For example, Ezrahi contends that the novel is:

an orgy of scatology and cruelty and dwells of the grotesque details of sexual perversion and death largely in order to exploit the shocking, sensational effects which no other historical experience so easily affords. (161) 
I argue that the relentlessness of the repulsive violence and unremitting horror seeks to create an affect; to assault the reader's body, as well as their thoughts, with the horror. The experience of reading the book is gruelling; it left me feeling soiled and degraded. The Painted Bird is about the felt experience of Holocaust violence. Kosinski shocks his reader in an attempt to convey an emotional experience. According to Langer, he 'seeks to transform [Auschwitz's] legacy into primary truths more basic and universal' (Literary Imagination 167).

Leslie Epstein has criticised Kosinski for this interpretation of the Holocaust experience, objecting to the extreme violence and arguing that the Holocaust experience was largely defined by its banality. Epstein believes that The Painted Bird 'divert[s] us from what the actual atrocity - most unbearable in its monotony, its regularity, its unobtrusiveness - was like' (Vice 70). Langer disagrees, feeling that 'Kosinski has been one of the few who has not flinched before the ultimate cruelty of the age of the Holocaust - dying in a situation of literally unutterable horror' (Literary Imagination 185).

Kosinski's defence has rested on his personal history. Any reading of this text is determined by an unusually complex contract, due to Kosinski's background and the scandals that have surrounded him. If a writer with no concrete personal connection to the Holocaust were to write Holocaust fiction as brutal and pornographic as Kosinski's there would undoubtedly be an outcry over the exploitation of the material. It would be seen as an act of appropriation, the Holocaust lifted from its historical context and made to serve a novelist's personal and/or artistic and/or commercial agenda. While Kosinski was not a survivor of the camps, he was a Jew who spent the war in hiding with his family in Eastern Europe. The journalist Stefan Maechler doesn't believe Kosinksi committed an act of appropriation, mostly because of this personal connection to the Holocaust. Maechler is known for his investigation of the Benjamin Wilkormirski fraud (a case in which the 
author of a Holocaust memoir was revealed not to be a survivor, as he had claimed, but someone who had recovered 'false' memories through recovered memory therapy) and he is at pains to differentiate Kosinski from cases such as Wilkormirski's. Commenting on The Painted Bird, Maechler says that the 'plot was invented, but the pain was genuine and rooted in early childhood' (214).

Much of the criticism of Kosinski and the novel stemmed from the extra-textual claims Kosinski made about the book. For example, in an interview with historian Lawrence Langer, three years after the book was first published, he claimed, as Langer put it, that 'what happened to him during the war was even worse than what happened to the boy in The Painted Bird. As it turned out, he was lying' (Maechler 158). In claiming his work was autobiographical, Kosinski sought to define his contract with the reader. Or rather, to redefine it. Elie Wiesel claims that 'when he told me it was autobiography I tore up my review and wrote one a thousand times better' (Maechler 214). The label of autobiography grants The Painted Bird not only authenticity but heightened emotional impact. As fiction, the violence is repulsive and somewhat voyeuristic. But as autobiography it carries an emotional weight that fiction does not, and the charges of voyeurism and exploitation become empty if readers take it as literal truth: as a form of testimony. Kosinski's use of the first person voice intensifies the autobiographical effect, although it is a voice completely contained to the perspective of a six year-old, without the hindsight of an older narrator.

The problem is that The Painted Bird wasn't autobiography and it became impossible for Kosinski to maintain the pretence. In the Afterword to the second edition in 1976, Kosinski claims: 'I did not see myself as a vendor of personal guilt and private reminiscences, nor as a chronicler of the disaster that befell my people and my generation, but purely as a storyteller' (xi). This statement reveals a conflict with his earlier claims of autobiography. The fact is that Kosinski told multiple 
versions of the 'truth' - for example, 'he told contradictory versions of leaving Poland to emigrate to the United States' (Maechler 213). These multiple versions of his history rendered the 'truth' of his past unknowable (and his statements about them untrustworthy).

Kosinski's 1976 Afterword is an attempt to renegotiate a contract with his reader, presenting himself as 'storyteller' and the text as fiction rather than autobiography. The difference between fiction and autobiography, Kosinski maintained, is that fiction 'forces the reader to contribute: he does not simply compare; he actually enters a fictional role, expanding it in terms of his own experience, his own creative and imaginative powers' (xiv). This redistributes power in the reader/author dynamic. Testimony, memoir and work by survivors of the camps such as Wiesel and Levi grant the imaginative power to the author; the implicit claim is: 'I am bearing witness; this is how it was; do not imagine more in the picture than my words paint for you.' But Kosinksi's claim of 'storytelling' shifts the power: the reader is now requested to take some responsibility for the imaginative act; Kosinski's words become a guide for the imagination, rather than the ultimate creating force.

Even as fiction, however, The Painted Bird cannot escape the burden of its historicity, as it was written by a man who survived the war in hiding (even if it was a form of hiding more banal than his character's). As Maechler suggests, the work can be read as Kosinski's emotional experience, even if it wasn't his literal experience. Vice believes that the critics treated Kosinski overly harshly: 'unable to accuse Kosinski of lacking a personal connection with the Holocaust, critics instead subjected the precise details of his connection to unforgiving scrutiny' (162). This raises the question of moral authority again, but this time introducing the concept of scale. Kosinski was a Jew who lived in hiding. But he wasn't captured. He didn't see the gates of Auschwitz or Treblinka; he didn't starve and suffer in the barracks 
while the smoke of the crematoria blackened the sky over his head. Vice seems to be saying that this meant he wasn't accorded the same moral authority as writers such as Wiesel, who suffered in ways Kosinski did not. The Holocaust was always a threat to Kosinski, something he hid from, something that threatened to sweep him into the maw of history. But he escaped (at least physically). So the camps and the torture and the crematoria and the death pits remain in his imagination, rather than in his lived experience. And we are nervous about this imagined Holocaust, for all the reasons I have outlined in earlier chapters. His moral authority is questionable to critics not because he isn't Jewish, not because he didn't live through the Nazi regime, not because he wasn't persecuted, but because his Holocaust is an imagined one. This is heightened because he misled readers into thinking the book relayed his actual experience. When it comes to history, critics and readers alike seem to be leery of imagination. Beside the weight and bulk of History, Imagination can seem as flimsy and mean as a lie.

This is the crux of the unease: the question of lying. If it isn't historically rigorous, if it isn't testimony, if it hasn't been lived by the author, if the author's connection to the material isn't tangible and substantiated, then it is a construction. And in this context is 'construction' another word for a lie? Is fiction a lie? Is 'storyteller' just another word for 'liar'? The concept of lying has negative connotations, even though humans engage in the act of lying constantly in order to maintain social order. The act of lying is an act of deception; a lie is a lie because we're pretending it is the truth. Fiction may make claims to speak 'Truth' (to present a profound commentary on and understanding of humanity) but if it is marketed as fiction readers know it's not truth. We know it's a story, a construction, an act of the imagination. Readers, I suggest, accept a contract which separates fiction from the 'real' world. We read it as a fabrication, at least until we are encouraged not to. Kosinski's history complicates the contract, 
because readers are encouraged (from the author bio, or the Afterword, or author interviews, or knowledge of the scandals) to add clauses. It is fiction but he's a Jew who had to go into hiding, so he knows how it feels to be persecuted; he was there in the historical moment. Or: it was sold to me as fiction but I just read an interview where he said he suffered through worse than this, so this is true; how could anything be worse than this; now, as I read, the atrocities have gaping shadows behind them, and in the shadows are worse atrocities, unknown, unimaginable, but real because he said they happened. And, then, once aware of the scandals, readers may find ourselves in a resistive, distrustful contract: he's a liar, he lied about who he was, about what he went through; this is made up, even though he tried to say it wasn't; he can't be trusted.

The problem, Schwarz contends, is that the reader cannot help but 'read The Painted Bird with a double optics: on one hand, immersed in the world of his text, and on the other, aware that his life was often a performance, a text he created' (176). This is especially true in light of the later scandals over plagiarism and literary practice. In 1982 a Village Voice article accused Kosinski of plagiarism and of making 'extensive use of translators and collaborators' (Myers). Similarly, in her review of James Park Sloan's biography of Kosinski, Julia Bloch Frey notes that rumours had been circulating for up to ten years prior to the publication of the accusations ('Lying'). For instance, in 1975, in an unpublished doctoral thesis, Barbara Tepa argued that 'long passages of Kosinski books were more or less directly translated from Polish sources unknown to English speakers' (Frey). The plagiarism scandals, Maechler claims, 'destroyed Kosinski's credibility' (213).

Kosinski's moral authority was already being judged, but what if the novel was co-authored by translators and collaborators? How do readers understand The Painted Bird if it is co-written by people with no direct connection to the Holocaust? Do we renegotiate our reading 
practice, approaching the text in the way we approach other imaginative fiction: as an invention? Or perhaps we read with the 'double optics', aware of the shadow presences of both Kosinski (as a kind of survivor with a degree of moral authority) and the collaborators (who are unknown quantities in terms of moral authority) behind the words on the page. Would we accuse the collaborating shadows of exploitation, criticising the extremity of the sexualised violence? Or would we soften our criticism, attributing those moments to the shadow of the survivor?

Many readers, I believe, tend to want to know who the author is and what their claims are before they negotiate their relationship with the book. This is true for nonfiction and fiction, and especially so with memoir (where there are just as many fraught literary 'scandals', 'frauds', and debates).Yet perhaps it's only when authors are as slippery as Kosinski that readers become conscious of this silent and usually unconscious act of negotiation.

\section{Helen (Demidenko) Darville's The Hand that Signed the Paper}

The case of Helen Darville and her Vogel- and Miles Franklin-winning novel The Hand that Signed the Paper further illustrates the complexity of the reader/writer contract. As an Australian writing Holocaust fiction I couldn't help but be aware that I was writing in a post-Darville literary arena. Especially since in Australia there seems to be an entire sub-genre of literary criticism focused on the Demidenko scandal.

In 1993, under the name of Helen Demidenko, Darville won The Australian/Vogel Literary Award with her novel The Hand that Signed the Paper (the Vogel is an award for an unpublished manuscript by an author under the age of 35). The novel went on to be published by Allen \& Unwin and to win both the ASL Gold Medal and Australia's top literary prize, the Miles Franklin Literary Award. It is an ambitious novel that connects contemporary Australia to European history, 
speaking about our multicultural heritage, and it engages with complex issues surrounding writing from the point of view of perpetrators. It was celebrated for its spare, unflinching style and for breaking away from the 'banality' of contemporary Australian stories. The Miles Franklin Judges Report stated that Darville's novel incorporated 'into the cultural memory first hand experience of the major historical events of the century' and that 'novels about the migrant experience seem to us to be seizing the high ground in contemporary Australian fiction, in contrast to fictions about the more vapid aspects of Australian life' (Manne 64).

Yet from the moment it was published, The Hand that Signed the Paper was controversial. Initially there were charges of historical inaccuracy and anti-Semitism, followed by the largest scandal in the Australian literary world since the Ern Malley affair. Helen Demidenko wasn't the child of Ukrainians, as she claimed, but was in fact Helen Darville, of British origin.

The Hand that Signed the Paper is a novel written in a number of voices: readers are initially introduced to Fiona Kovalenko, a young Australian woman whose Uncle Vitaly has been accused of war crimes; then we have a series of first person perspectives from Vitaly, his sister Kateryna, and his first wife, Magda. As well as these first person accounts, we also have a brief vitriolic letter about the Ukrainians from a Communist doctor to her mother, and finally a third person narrative, which relates the events of the war and the roles played in the Holocaust by Vitaly, Magda, Kateryna, Kateryna's SS husband, and Fiona's father, Evheny. The variety of narrative points of view are not entirely successful, although they do give a jarring sense of cacophony, of discord. The immediacy of the first person perspectives clash with the uneven use of third person point of view; the third person narrative skips from character to character, sometimes giving insights into behaviour, sometimes remaining coldly at a distance (particularly 
during scenes of violence), leaving the author's position on events (and therefore the moral positioning of the reader, or the creation of a dominant reading) opaque. For example, in the passage where Magda sees Vitaly shooting at Jews:

Drunken guards treated the Jews very badly, deliberately frightening them by shooting into the air above the trains, or by opening the doors and firing at random into the packed flesh. She learnt to tell the difference between the sound of shot wood and the sound of shot flesh. The soft 'rrrip' of flesh. There was always blood on the railway tracks. She once saw Vitaly do this. She confronted him the next morning. (113)

The tone of this passage is numb; events are described but there is no sense of an emotional response, of horror or judgment. Even though the narrator tells us that Magda confronts her husband over the shooting, which implies some kind of disapproval, there is no indicator of emotion or affect. The vast understatement of the guards treating Jews 'very badly' is disturbing and the use of terms such as 'flesh' dehumanises the Jews - we see them through the eyes of the perpetrators - and the blood and physical violence are divorced from the victims. Even when Magda confronts Vitaly, there is a disturbing lack of judgment or sympathy: 'Look at the mess there now. See. You did that.'(113)

The flatness of the style could be read as a narrative strategy, a deliberate choice by the author to reveal the emotional and moral numbness of the perpetrators and bystanders. In fact, before the scandal about her heritage broke, many of those who admired Darville's work argued that this was the case. The journalist and critic David Marr felt that Darville was showing rather than telling (which is Lesson 1 of Creative Writing 101): 'There was no voice to tell me they were terrible; she made me feel the evil of those years' (218). Yet the flatness can also be read as authorial ineptitude or moral anesthesia, rather than 
a conscious rendering of insensitivity or denial. If the numb style is a narrative strategy, perhaps Darville has employed it with too much subtlety, not guiding her reader with regards to how to interpret its flatness.

The fact that Darville chose to write about, and from the perspective of, the perpetrators is unusual in Holocaust fiction. The perpetrators have not been the focus of much Holocaust fiction (although this may be changing, as we've seen recent books such as Jonathan Littell's The Kindly Ones) and this absence is perhaps because, as Clendinnen notes, 'Classified as non-human, as worse than the cruellest beasts, the perpetrators of the Final Solution are placed beyond human scrutiny' (96). Primo Levi believed that 'even to attempt to understand such men is to risk contamination' (Clendinnen 104). Recent writers, such as Bernard Schlink and Rachel Seiffert, have positioned their novels from the point of view of those connected with the perpetrators but have not written from the thick of the atrocities or in the direct voices of those who committed murder (although Littell did in 2009's The Kindly Ones, but Darville pre-dated him by more than a decade). Choosing to write from the perspective of the perpetrators is a difficult and daring endeavour and brings the concerns of Holocaust criticism to the fore.

If the perpetrators are regarded as 'unimaginable', if they are set aside, made 'other', we can comfort ourselves with the thought that they are 'not like us'. Choosing to write from the perspective of the perpetrators is fraught with difficulty; there is a dangerous line between representing a position and endorsing it. When it comes to the Holocaust, Alfred Kazin writes, 'literature served and serves the condemned' (Ezrahi Words Alone xi). Writers must, I suggest, be careful not to perpetrate the prejudices, or to misrepresent or explain away the events, when writing from the perspective of perpetrators rather than victims. 
Schlink, in The Reader, and Seiffert, in The Dark Room, write from the fringes of the Holocaust, analysing its moral impact of the Holocaust, considering how such choices could be made and what it means for the humanity of the perpetrators and of their descendants, however marginal their participation. Franca Signorini, in her writing on Primo Levi, shows a belief in representing other viewpoints, stating: 'When people are able to understand and be understood, they become less alien to each other' (178). However, Darville's positioning, from the thick of the concentration camps and killing squads, is controversial because her choice to write from the perpetrator's perspective can be seen to endorse misconceptions, rather than create understanding, and to justify the actions of the Ukrainian perpetrators.

I was nineteen years old when the Demidenko scandal hit. It was 1995 and I was in my third year of my first degree, studying English and History, brushing up against postcolonial and feminist theory for the first time and realising that the question of literary representation was far more political than I'd ever imagined. Helen Darville wasn't much older than me and her name was in every newspaper. She even made the current affairs shows on TV; she was a striking figure, with her bleached hair and pale eyes, and the humourless intensity with which she spoke. At nineteen I didn't absorb the complexity of the issue. I was young, and to be honest other things claimed my attention: falling in and out of love, working out what I was going to do with myself after graduation. The thing I took away from the Demidenko scandal at the time was: Wow, they're giving her a hard time; what a witch hunt. Writing about the Holocaust looks dangerous. Why would you write about if you weren't there? How dodgy. But, really, what a nutjob. Why would you pretend to be someone you're not? Why didn't she just tell the truth? What made an impression on me was the media firestorm. It taught me one lesson: people are going to go after you if you write 
about the Holocaust. I internalised it, even as I blithely went on with my undergraduate existence.

Going back to The Hand that Signed the Paper as I worked on End of the Night Girl was a surreal experience. Ghosts of myself read over my shoulder: I read it as a writer; I read it as a critic; I read it with full knowledge of the scandal; and at the same time I had the ghost of my nineteen-year-old self along for the ride. The scandal made such an imprint on me at that age; when I thought about Darville and the book, memories of my time as an undergrad swum to the surface. So re-reading it was a multi-layered experience.

But, ultimately, my author-critic selves were the dominant readers. I'd been making difficult choices as an author, feeling compromised at every turn. To be honest, I expected similar fire and judgment if my book ever saw the light of day. So I approached Darville's novel with a spirit of wary compatriotism: here was someone who had gone before me, who had made her own narrative choices with this difficult material.

But re-reading the book I was discomfited by the sense that the author herself didn't seem discomfited at all. I couldn't find a sense that she found the material difficult, or the topic fraught. This is not to say that she didn't feel that way, just that I could not find markers of it in the narrative. The flatness of tone, the lack of commentary on her characters' thoughts and actions (event the lack of a bint of commentary or of emotional nuance) failed to reveal any sense that Darville recognised the sensitivity of the material. For example, in the passage where Vitaly and Magda take their baby son down to the river Bug for a swim:

Magda seated herself comfortably on her long skirt and began breastfeeding him. Vitaly leaned against the trunk of the tree and watched in silence, smoking another cigarette. She looked 
into the distance over Vitaly's shoulder and saw the head of a scoop-shovel dip and claw at the earth, then rise with its mouth full of something. Dirt, she supposed. (140)

When Magda remarks on the stink Vitaly tells her that they are burning Jews. She responds:

'I thought so.'

'You don't mind?'

'As if I didn't know.' (141)

They go on to bathe naked, flirt, and play with their son. The contrast between their fun and the starkness of their conversation is jarring, partly because of the fact that the contrast remains undeveloped. I was horrified by the callousness, mostly because I was unsure whether the callousness belonged entirely to the characters. Was I supposed to be feeling horrified? I felt adrift as a reader, unguided. Darville positions readers to identify with Magda and Vitaly (although not too strongly, as we are denied access to their inner lives); Darville gives us no signal of authorial opinion; the opacity of the effaced narration denies the comfort of disregarding an unreliable narrator, or being guided by an authorial presence. We're left in a no-man's land. Vitaly believes the Jews deserved Treblinka; Magda is unfazed by the burning of the bodies; but what about Darville? What does she think and feel about it all? Does it matter? Should it matter?

There is no question, I argue, that The Hand that Signed the Paper seeks to explain the Ukrainian hatred of the Jews and their participation in Einsatzkommando shootings and the Treblinka death camp by blaming the events on a cycle of violence. Darville attempts to show that Ukrianians were reacting to the persecution they themselves had suffered under 'Jewish' communists. As the character Kateryna says:

Millions of us died in the famine. Carefully, they starved away our desire for national independence. The communists had 
both the money and the guns; we had neither. But, people reasoned, if someone were to come and give us either or both, then we would take revenge. We would kill every communist and Jew in the Ukraine. (9)

The explanation is horribly simplistic and, as the historian Geoffrey Jules stated, Darville and her characters 'ignored almost altogether the pre-Bolshevik history of Russian and Ukrainian antisemitism' (Manne Culture 41). Antisemitism stretches back hundreds of years in Eastern Europe and there was a long history of pogroms before the Nazis ever invaded. The impression given by The Hand that Signed the Paper is that the hatred of Jews by Ukrainians rose directly from their persecution by Jewish Bolsheviks. The novel never questions its own crude simplifications. The major danger of this contention is that the 'twinning of Bolshevism and the Jews is near the centre of the Nazi world-view' (Manne 156) and therefore Darville is perpetuating a Nazi belief, while ignoring the established history of anti-Semitism in the Ukraine.

The other dangers of Darville's simplistic theory go beyond the text itself, because in the case of Darville it is difficult to divorce the text from the author, due to her performance of Ukrainianess. She cultivated a very high public profile and spoke often about her Ukrainian heritage. For example, in her article 'Writing after Winning', Helen 'Demidenko' tells of how her Baba (grandmother) was broken-hearted because her granddaughter did not attend a Ukrainian school. And, defending herself in both The Age and The Sydney Morning Herald, she claimed most of her father's family 'were killed by Jewish Communist Party officials in Vynnytsa' (Manne 77). She contended that she had the right to voice the contentious opinions aired in the novel because they were the 'facts' as her family saw them, legitimate beliefs held by the Ukrainian community she was a member of. She is quoted in Vic Alhadeff's article in the Australian Jewish News as stating that the 
'extent of the Ukrainian collaboration depended on how many Jews were in the Communist Party in the area, how close to the frontline the people were and how severe famine had been in that particular area' (6). Essentially, Darville claimed she was merely representing the widely held beliefs of a community, without offering commentary or judgment on those beliefs. This already problematic position was made untenable when it was revealed that she was not Helen Demidenko at all, and that the novel was pure invention and did not draw on a lived experience of family/community oral histories, complete with embedded prejudice. As I've argued, with regards to Holocaust literature, there is a fear that if history is not fully understood and acknowledged it will be repeated. The Hand that Signed the Paper came under intense scrutiny because of its perceived anti-Semitism; once the author was revealed to have no connection to the Ukrainian community the novel was judged more harshly as a vehicle for propagating and reinforcing anti-Semitism.

When authors are interviewed or invited to speak about their novels, they are encouraged to give their readers guidance as to where they stand in relation to their work; this is true for most authors, not only for those who write about the Holocaust. The packaging and marketing of a book, the author photo and bio, websites and social media, all carve out a position for the author, so readers can contextualise the book in terms of who the author is and what they say about their own work. In Holocaust literature, dust jackets proclaim survivorhood, familial connection, or lack thereof, and give seemingly concrete definitions of genre: 'a novel'; 'a fable'; 'memoir'. Industry-wide, in every genre and market, authors are trotted out to perform their authorship in person at book signings, writers' festivals, and for interviews (and in the twentyfirst century in online forums such as blogs, webinars, Facebook and Twitter). Authors not only have to write the book, they also have to talk about it, seemingly endlessly, sometimes over the course of years. I don't have access to Helen Darville's motivations, but I can guess from 
her behaviour that she felt the pressure to prove her moral authority as an author.

The Australian woman Helen Darville wrote a book about Ukrainian perpetrators of the Holocaust. She used the pseudonym Demidenko and performed 'Ukrainianess' whenever she appeared, even going so far as to wear the Ukrainian national costume. She claimed that the 'cycle of violence' theory in her book, which is used to explain the Ukrainian violence against the Jews, was transmitted to her by her family. This performance positioned her as having a tangible connection to history. It transferred the cause of the novel's anti-Semitism away from her and onto the Ukrainian-Australian community. It made the text in many ways a historical-cultural document: oral histories rerepresented as fiction.

Her performance can be seen as a (misguided) response to the fierce attention focused on Holocaust fictions. It seems to imply her awarenesss of the fraught nature of the endeavour, and an expectation of an interest in her family history and heritage. Did she think the book wouldn't be taken as seriously if she didn't have a tangible connection to the Holocaust? Was she afraid of being accused of voyeurism and/or appropriation? Was she aware of how anti-Semitic her novel seemed?

A complex blurring between author and text occurred in this instance, both before her deception was revealed and afterwards. As Helen Demidenko, her public performances of her 'Ukrainianess' influenced how the book was read and how it was critically received, although not in the case of the initial decision by the Vogel judges, who read the book without meeting the author or knowing about her constructed identity. What was possibly a first-time author's inexperienced handling of authorial voice and polyphony (or lack thereof) within the text, became politically charged because of the nature of the material and because of her performance of identity. 
Point of view is a tricky beast and hard to tame. Darville attempted an ambitious project, writing the Holocaust from the perspective of perpetrators. Managing the multiple points of view, particularly the effaced third person perspectives in the depths of the horror, requires an enormous amount of skill. Writing monstrous characters and describing monstrous acts often requires the creation of an awareness that multiple voices are operating in the text, and a separation between the represented voice, and the representing voice; in other words, a separation between character, narrator and author. Darville doesn't signal this separation, leading to a blurring of the author's position and the text's position. Commenting on the novel, Brian Castro (himself a previous winner of the Vogel) noted that the jingoism evident in the novel was 'sometimes indistinguishable from the author's viewpoint' (Manne 37).

Robert Manne, one of Darville's harshest critics, always believed The Hand that Signed the Paper had a dangerous absence of 'a clearly defined and morally unambiguous voice' (52). Sue Vice argued against this, believing that it was a mistake to assume that the 'two voices represented and representing — are one and the same' (152). Vice draws on Mikhail Bakhtin's theory of polyphony to defend Darville's narrative choices, stating that within a polyphonic narrative the narrative voice 'operated on the same level as the characters and their voices', as it often does in Darville's text - although, the technique is imperfect in this instance (151). In Bakhtin's theory the narrator does not need to provide a detailed explanation of each character's traits and beliefs - these are revealed more organically through the character's thoughts, speech and actions. The problem in this case is, Vice notes, that Darville has not chosen to create an entirely polyphonic text, instead the novel has 'polyphonic patches' (152): sometimes the narrator is 'someone more sophisticated' than her characters, but other 
times she 'simply shows ignorance on the part of her characters, without commenting on it' (152).

Vice's criticisms address Darville's text as a technically flawed novel (which is forgiveable, surely, as she is a first time novelist attempting an incredibly ambitious task), rather than as a morally flawed novel. The problem, as I see it, is that in the case of Holocaust literature technical choices/flaws have been defined as moral choices/ flaws. Even Vice, who often defends Darville, believes that 'it is important to investigate whose opinions [the opinions expressed in the novel] are' (152). The book gives no final clue as to whether the antiSemitism belongs entirely to the characters, or whether it belongs to the author as well. In a report to his fellow Vogel judges when the novel won the award, Roger McDonald wrote: 'there will have to be a lot more work done on the roots of Ukrainian antisemitism otherwise this manuscript will be seen with justification as antisemitic' (Manne 32).

Darville's simplistic proposal that the Famine (and the role Jewish Bolsheviks played in the Famine) was a causal factor in Ukrainian participation in the Holocaust endorses a position commonly taken by Holocaust deniers. Her novel can be seen to perpetuate anti-Semitic myths. As Alan Dershowitz argues in the Australian Financial Review, 'all of the Jewish characters in the book are stereotypes' (71). One example is Judit, the Jewish doctor, who is seen through a strange post-colonial filter (Armitage 2). She is represented as prejudiced and oppressive, a coloniser attempting to inflict a new order on the natives, without attempting to understand them (a tale familiar to Darville's contemporary Australian readers). In a letter home to her mother, she writes of the villagers:

They breed like true Catholics: the women are either nursing or in pup, without any variation. They are terrified of the evil eye, and constantly have visions of saints and spirits. I have 
tried to tell them that women are to be liberated from slavery in the Soviet Union, and that this is what Comrade Lenin and Comrade Stalin fought so hard for. But they spit on the earth as they pass me, presumably to propitiate their fecund God in my presence. (24)

This passage positions the Ukrainians as victims, hated and persecuted by the Jewish intellectual, as if to justify the fact that by the end of the novel it is the Jews who are persecuted. The logic is that the Ukrainian participation in the Holocaust is a direct result of the Jewish oppression of Ukrainians during the Famine. The simplistic moral of the tale is that prejudice and violence beget prejudice and violence. This is another way of saying that the Jews were 'asking for it'. It is a distortion that ignores the Nazis and their other collaborators, who were not been subjected to Soviet-induced famines or persecution.

The events of the Holocaust are complex and people who lived through them (victims, perpetrators and bystanders), philosophers, psychologists, sociologists and artists are still grappling to find a meaning or an understandable cause. Darville's 'cycle of violence' theory reduces the quest for a cause to a frighteningly simplistic level, which is also deceptive; it avoids the more banal and seemingly irrational side of prejudice and 'race' hatred.

Part of the problem is Darville's patchy polyphony and 'cold' authorial style. She doesn't present multiple perspectives of the antiSemitism, or offer any overt commentary. Darville has opportunities is which to do this, not only through the construction of a more sympathetic Judit character (or the creation of a multiplicity of Jewish characters) but also with the contemporary figure of Fiona. Fiona offers an opportunity for commentary, for Darville to unpack what it means to be guilty of genocidal crimes and to provide a moral filter which differs from the perspectives of the perpetrators. Darville acknowledges 
the possibility of such a filter when Fiona describes her reaction to having read The Diary of Anne Frank at school. This is a moment in which a character has a visceral negative reaction to the horror. But Darville doesn't choose to use the character of Fiona as a moral centre for the novel. Overall, Fiona is sympathetic to Uncle Vitaly and there is a lack of moral inquiry and horror on her part. Seen through her eyes, Uncle Vitaly is a harmless old man, vaguely ridiculous, a victim of the system which is trying to punish war criminals but which in effect is arresting helpless old men. Fiona tells her sister:

When Uncle Vitaly first heard about the trials, he hid under the kitchen table. Staciya came home from the shops and found him hugging the table leg and yelling 'the Israelis are coming to get me!' It was funny at the time. (2)

Her sister's response is to laugh. There is no sense that Vitaly deserves to be punished, despite serving at Treblinka and being directly responsible for the deaths of hundreds of Jews. When Fiona describes finding mementoes and photos in her father's bedside drawer she isn't horrified so much as fascinated, when surely the fact that he keeps such mementoes (and so close to where he sleeps, where he can access them easily) would appall most people. Fiona's description shows no sign of moral judgment (characters don't need to have 'appropriate' moral judgment but in this case the lack of a moral guide in the novel strikes me as problematic):

An enamel badge showing a blue and yellow flag. A fancy, winged eagle clutching a swastika in its claws. A cloth patch with a silver skull and crossbones on it. The idea developed in my head that Daddy had been a pirate. Pirates were bad. They were also glamorous. (39)

Fiona's reaction trivialises the discovery, as well as according Nazism a kind of dark glamour, reducing the Nazis to fantasy pirates. In this way 
Fiona romanticises her father's past, without authorial commentary or disapproval to offer a counterpoint. Even more troubling, Fiona's sister begins to display signs of anti-Semitism, resenting the way Uncle Vitaly is being treated. The sisters cast him as a pitiable old man who suffers a stroke as a result of the stress brought on by the impending trial. Fiona's sister remarks bitterly: 'This is all because of the silver budgie Zionist, bloody Hawkie. Bob Hawke. Shit' (81). There is an implication that this hatred only arises because Vitaly is somehow being persecuted. When Fiona asks Vitaly if he still hates the Jews, he replies 'I stopped for a long while, but now it starts again. In here. In my soul' (83). There is an abdication of responsibility throughout the text: hatred and violence are not choices, they are forced upon the characters by outside circumstances. All hatred in Darville's novel is part of a cycle, stemming from a definable cause. There is no sense that Vitaly is remorseful for his actions, or even that he should be. The text offers excuses for him; it does not hold him to account.

Occasionally Darville flirts with ideas of guilt and remorse, such as when Magda finds the Ukrainian boy guard crying on her front step: 'I don't like what I ... what happens ... what we do — ' he tells her (114) but it is a rare moment in a novel that is, as Manne once said, 'as flat as the Nullabor' (118). There are not enough of these moments to balance, or call into question, the other characters' anti-Semitism and moral anesthesia, particularly in light of the author's invented justifications for actual historical figures. She creates a fictional version of Ivan the Terrible, an infamous Treblinka guard, renowned for his sadism, and she gives his sadism a cause that supports her 'cycle of violence' theory. Vitaly says of Ivan: 'He is mad because the Jews burnt his house down in front of him. With his parents and six brothers and sisters inside. In the famine' (115). Ivan is described as being 'very tall, with a calm, mild face and sandy hair; he was plainly of great strength' (115). Darville has taken one of the most reviled perpetrators of violence 
in the death camps and portrayed him as a simple, unfearsome man, a man who has been harmed by the 'Communist Jews'. As a creative act, this characterisation is highly questionable, particularly in light of historical testimony which reveals the real Ivan's enjoyment of violence and his extreme torture of Jews. In effect, Riemer says, her construction of Ivan is a 'rationalisation of sadistic brutality' (77). Manne is adamant that in the case of this particular novel, fiction should be held to account and it should be historically accurate:

For a novel which deals so dogmatically with two of the most catastrophic events in human history, in so recent a past that some survivors are still with us, and which purports to demonstrate nothing less than a causal link between the grievous suffering of the Ukrainian nation in the Famine, and the attempted genocide of the Jews, rigorous historical criticism is more than appropriate. It is obligatory. (141)

After the initial charges of anti-Semitism, but before the Demidenko deception was uncovered, Darville defended herself by saying that her critics were 'the people who could not distinguish fiction from history' (Manne 76). This was a disingenuous defence, because Darville had established a reader/writer contract which placed the book beyond the borders of pure fiction. From the moment she accepted the Vogel, clothed in Ukrainian peasant dress, Darville represented herself as a spokesperson for the Ukrainian-Australian community, and the book as 'faction'. Jost observes that there was 'legitimacy given to the substance of her novel by the fact that she was believed to be relating her family's oral history and tradition' (viii). This assumption meant that her readers were 'willing to forgive the author for sincerely repeating mis-history on the grounds that it sprang from an oral, Ukrainian source' (Jost ix). But the ani-Semitism in the novel can be read very differently when we discover that Helen Demidenko is actually Helen Darville, with no Ukrainian heritage at all. 
Once Darville's true identity was revealed, Marion Halligan observed that the critics and general media seemed 'to be saying that The Hand that Signed the Paper by Helen Darville is a quite different novel from the one written by Helen Demidenko' (170). Of course it is, I argue. It requires an entirely different contract between reader and author, and this new contract is complicated by mistrust: this author has lied to readers in the past. As I reader I am no longer so willing to forgive the 'mis-history' in The Hand that Signed the Paper when we discover that it is a work of pure imaginative fiction rather than a work derived from oral history and familial experience. Her material has been researched and selected, imagined and re-created as fiction. Readers, I suggest, hold it to a different standard, even though the words on the page haven't changed when she is a Darville and not a Demidenko. As with Kosinski, the way in which I read Darville is significantly determined by who I perceive her to be. Again, as with Kosinski, this is because of the enduring sensitivity about why writers choose to write about the Holocaust: intent matters, and motives are subject to examination.

We don't have access to Darville's thoughts and motivations; we don't know why she chose to write about the Holocaust. All we know is that she did write about it, and that she assumed a pseudonym and masked her motivations. Primo Levi felt that when non-survivors approached the Holocaust in art they should feel the 'need to interpret, but not falsify information and narratives about the event' (Feinstein 169). In this respect, Darville transgressed. Neil Thomas declared that 'she'd put on hobnail boots and marched over sacred ground' (Manne 44).

What does it say about the Australian literary community at the time that this hobnail-booted author was awarded so many literary prizes? Was the sheer ambition of her work, her engagement with issues and contexts beyond Australia, enough to cancel out the perceived anti- 
Semitism? Was celebrating Australia's multiculturalism (a hot button issue of the era) important enough to cancel out 'hate speech' and racial vilification?

The cases of Kosinski and Darville illustrate the complexity of the reader/ writer contract and the need for transparency in the cases of authors who write about the Holocaust. There is a deeply rooted suspicion of those who seek to fictionalise the Shoah, and a distaste for those who might be seeking to exploit the material for political or personal gain. Writing about the Holocaust is fraught with difficulty. Writers face complex issues such as ownership of sensitive stories, whether we have a responsibility to history, the nature of evil, the meaning of suffering, the role of God, and whether the act of fictionalising events can cause real world harm. Perhaps these very real difficulties prompted Kosinski and Darville to mask their histories with ones readers could more easily trust and accept (or perhaps they had different motivations altogether). Whatever their reasons, their acts of deception only made the reader/ author contract more important to me as I wrestled with writing End of the Night Girl. I had no 'right' to tell this story, and I wanted to make that clear on every page. 



\section{The Great Redraft}

In that first draft, Molly wasn't reading Holocaust literature. She wasn't writing Gienia's story. The two women's stories wove between one another, each throwing the other into sharper relief. But they never met. They never really even grazed each other. There was no obvious, tangible connection between them. The structure was insanely complex (insane for a first-time novelist anyway) and had tonal shifts that were difficult to manage - from the tragic-comic tone in Molly's sections to the stripped back dissociative prose of Gienia's section (which mimics the tone of Holocaust testimonies). I turned my attention to that organic, 'poetic' structure and tried to find the logic in it.

Molly's story unfolds more or less chronologically, over a short space of time, whereas Gienia's is told out of order, fragments from a time span covering a period of years. Gienia's fragments emerge from Molly's emotional states, rather than running alongside Molly's completely separately, or sutured with obvious thematic material. Molly's first person sections are immediate, expressionistic and colloquial; Gienia's third person sections are at a distance, and are sombre and spare. My supervisor Nick had pointed out that the two sections had different vocabularies. He noticed this when the word 'scuttled' appeared in both: 'Until here, you keep the vocabularies completely different. It 
should stay that way,' he said. It should? Why? I didn't know yet. What was the effect of it? It illustrated their separation. There must be more to it than that. It felt like they'd been written by two different people. Yes, there was something in that. Just what, I wasn't sure, but I noted it and left it to sit in my subconscious.

For the next several months I wrestled with the book, as I chased my crawling child and took on even more teaching. My friend Rachel was also doing her $\mathrm{PhD}$, also writing a novel and an exegetical essay. She was writing a book about the Stolen Generations in Australia (a novel called The Heaven I Swallowed, which has since been published by Wakefield Press) and was mired in ethical dilemmas, just as I was. We spent long hours over coffee (and wine, lots and lots of wine) circling the difficulties of our novels. At some point - I think around draft three - I realised that the answer was staring me in the face. I called Rachel: 'The answer's been there all along!' About two thirds of the way through the novel, there was a line which broke up one of Gienia's sections. It broke in when she was on the death march. Italicised, the line hung, separated, in a sea of white space: 'Miriam? Who the fuck is Miriam?' I'd had no idea where it had come from, it had just splurted onto the page when I was writing and I'd left it there because it felt significant. For some reason the sight of it had always filled me with a frisson, with a swelling sense of possibility and excitement. I'd felt the excitement brushing at the corner of my mind but I'd always pushed it aside.

'It's Molly,' I told Rachel now, in the wake of my bursting epiphany, 'Molly's saying that. Molly is breaking through the boundaries of the two narratives.' Who the fuck is Miriam? The voice was Molly's; the question was Molly's. From there I came to the realisation that Gienia's story wasn't a historical narrative, at least not in the way I had thought. Rather, she was created by Molly, written by Molly.

'This is why I've been so obsessed with Jonathan Safran Foer and 
Art Spiegelman!' I said. 'I'm a postmodernist! I just didn't know it!'

And again, I wish I could say that I sat back down, fixed the book, and lived happily ever after. But since I'm the poster girl for doing things the hard way, it wasn't that simple. I had this stupid idea about subtlety. I don't know where I got it from. Maybe it's because I loved the game of close reading in my English subjects, of doing the detective work to find different readings. Wherever it came from, this obsession with being subtle was to screw me up for another few drafts.

Thinking I was being all clever and subtle, I went into draft four with this idea of Molly authoring Gienia's story but with the twist that I didn't want the reader to be aware of that fact for most of the book. (Talk about subtle. Try wilfully obscure.) I suppose I thought it was interesting puzzle; in fact, it was just confusing. It also hamstrung me in terms of addressing many of the questions I wanted the text to ask, although I don't think I was aware of it at the time. I hadn't yet realised that the book was actually about that pesky old question: $w h y$ ?

During this time I sent the book in for The Australian/Vogel literary award and it managed to get long-listed. This heartened me. An agent looked at it; she thought it had potential but she was disturbed by the lack of balance between Molly and Gienia. I began to think there was no way to fix this thing. Let's face it, if I hadn't been doing a $\mathrm{PhD}$ I probably would have given the whole thing away at that point. I had no idea how to make the book work. But I was doing a PhD, I was nearing the end of my $\mathrm{PhD}$, and I figured the book didn't have to work so long as I explained myself in the accompanying exegesis. The exegesis was the critical component of the Creative Writing PhD; it was a 20,000 word essay which could be a hybrid work of literary criticism, theory, and authorly self-reflection.

I kept despondently tinkering with the novel and turned my attention to the exegesis, which looked critically at the ethics of fictionalising the Holocaust. I re-read the books I was hoping to use, 
as well as going off on a tangent with Sophie's Choice and theories about The Mutilated Woman in fiction. I worried about my ethical choices in the novel, spending weeks obsessing over Christian imagery, which is so embedded in Western culture. I worried about the scene where Schlomo presses the frozen bread into Gienia's mouth: did it have Christian overtones, and was that offensive? I'm not a Christian, I wasn't raised a Christian and I'm woefully ignorant of the Bible and Christian ceremonies, but I worried that I'd unconsciously adopted an image which could be read as Christian. In the end, I left it in, because Molly would probably have been subject to making the same mistakes I made. I worried over the ethics of every narrative choice, fiddling with the novel as I went, and taking notes as I read criticism about Foer, Kosinski, Darville and Spiegelman's works.

When the book was at draft five, still a rambling, organically structured mess, I got a mentorship with Judith Lukin Admundsen, who at the time was an editor for Picador. This was a different kind of reader to a supervisor or a fellow $\mathrm{PhD}$ candidate. This was someone who would be reading it like a publisher's editor. This threw up a whole new set of anxieties: did the book translate to a general readership? Was it a 'good read' as well as a meditation of the ethics of fictionalising the Holocaust? Could it be understood by someone who read it cold, without the accompanying academic explanation? I sent her the book; she emailed me her number and asked me to call her for the feedback. I felt sick. I sat down in an empty tutorial room, my notebook and pen in front of me. It was late in the day on a winter afternoon; I left the lights off and sat in the chalky grey light, my palms sweating with fear and, to be honest, with more than a little excitement. This woman was an editor - if anyone knew how to fix the book, surely it would be her. I dialled her number.

When I hung up I felt like I'd been hit by a truck. We'd spent an hour talking about Israel and Palestine, about the nature of evil, about 
the role of fiction, about the question of balance. 'Any publisher's editor worth their salt would focus on the question of balance between your characters,' she said, before launching into a pained and thoughtful discussion of the unsolvable heartbreak of Israel and Palestine. We talked about whether or not we had a right to happiness after the Holocaust, and whether or not we had a right to suffering. We didn't talk about a single specific page or scene. She told me I wrote well and that I managed to do something very few people could pull off: to write in two convincing voices in the same novel. 'But that's not your problem, is it?'

No. Voice was not my problem. Characterisation was not my problem. The big ideas were my problem. My lack of balance was my problem. 'These are questions art should ask,' she reassured me, but I thought I detected a note of hopelessness in her voice. Was it possible that she didn't think my book was fixable? 'What do I do?' I asked, more than a little desperately. 'I can't answer that,' she said. Her job was to point out the problems, not to fix them. 'You'll find a better solution than I ever could.'

Could I? I sat in the chalk-grey light, feeling drained of hope. Not in time to complete my $\mathrm{PhD}$, I couldn't. It was due in a few months. In a fit of despair, I took a semester's leave from my $\mathrm{PhD}$ and took on full-time teaching. Oh, and I found out I was pregnant. Again. 



\section{Triangulation of Memory}

My second pregnancy came with uncontrollable morning sickness. I'd had some nausea with my first, but this time it was revolting and it went on for the full first trimester. I was teaching a heavy load in two different undergraduate subjects, in two different disciplines, and my schedule left no room for morning sickness. I often had to hurriedly devise group work, so I could dash to the nearest bathroom. My life consisted of teaching, marking, caring for a demanding toddler who had a tendency to climb every piece of furniture he could find and generally put his life in danger, and stressing about my unfinished novel. My husband worked insane hours to make the mortgage payments (my casual teaching barely scraped minimum wage, despite the long hours) and I barely saw him. I was prone to lying awake in the depths of the night, worrying about money, worrying about my career, and worrying about the damn book.

Art Spiegelman was my companion on many of those sleepless nights. Artie, the mouse-masked narrator of Maus, articulated the fears I had about my research. He made me feel less alone in the long night. 


\section{Art Spiegelman's Maus}

If there was an answer to my novel's problems, I figured Spiegelman might well have it. Art Spiegelman is the child of survivors, and Maus, the first volume of which was published in 1973, is a daring postmodern attempt to address the position of second-generation survivors and the difficulties inherent in translating experiences (especially those not lived but heard from others) into words (and, in this case, pictures). Spiegelman is a reluctant representative of the second generation. In MetaMaus he says: 'I didn't want to become the Elie Wiesel of comic books and become the conscience and voice of a second generation' (80). The work reveals the weight of that responsibility, and the reluctance to shoulder that burden. Spiegelman has chosen to address the problems inherent in representing the Holocaust through self-reflexive means. He predates Jonathan Safran Foer by almost thirty years and pioneered a postmodern style that gained popularity in the following decades.

Spiegelman chose a controversial form to tell his father's story (and the story of his own struggle to tell the story): the form of comic book, or graphic novel. Schwarz notes that 'much of Holocaust narrative is quite conservative and traditional' (302), perhaps because, due to the extreme sensitivity of the material, writers are less inclined to experiment with form. In both volumes of Maus, published five years apart, Spiegelman draws the Jews as mice and the Germans as cats. On the surface it's a simplistic representation, but it's one that plays with the Nazi construction of Jews as vermin, as well as the perceived shallowness of the comic book form. At the beginning of Volume II, And Here My Troubles Began, Spiegelman uses a quote from a 1930s German newspaper:

Mickey Mouse is the most miserable ideal ever revealed ... Healthy emotions tell every independent young man and every honorable youth that the dirty and filth-covered vermin, the 
greatest bacteria carrier in the animal kingdom, cannot be the ideal type of animal ... Away with Jewish brutalization of the people! Down with Mickey Mouse! Wear the Swastika Cross! (epigraph)

This quote, referencing as it does Nazi attitudes to Jews and American 'Jewish' pop culture and invoking the figure of Mickey Mouse, the ultimate cartoon character, shows how Spiegelman signposts his narrative choices for the reader, alerting them to the complexity involved in his chosen form. He is taking the cartoon mouse and twisting it, taking a version of Mickey into the Kingdom of Night, and subverting our expectations of what the form of the comic can do. Instead of Fantasia and dancing broomsticks, Mickey faces Auschwitz and death, which can be read as a way of addressing the unbridgeable distance between the Holocaust and the struggle to comprehend for those who come after: our 'Mickey Mouse' perceptions jar with the horror of history.

Form is a major focus of Maus. Spiegelman explores the problems inherent in storytelling, 'replacing' his father's story with a written (and drawn) version, the inherent manipulation of storytelling, and the 'unknowability' of the past. According to Behlman, Maus acknowledges the 'impossibility of gaining any direct access to the past, or any way of representing it, except through a medium that announces its own contrived, provisional nature' (61). Throughout both volumes Spiegelman draws attention to his struggle to represent his father's story and shows an obvious concern with 'the ethics involved in converting oral testimony ... into a written and visual document' (Miller 55), a concern highlighted by the form itself. Deborah Geis notes that there has been much criticism of Spiegelman's choice of form, with many feeling that the 'comic book form inevitably trivialises the events and reduces the characters to stereotypes' (5). The form of the novel is traditionally accepted as being more 'serious', a high culture 
respected form for non-fiction and fictionalised history, whereas the comic book is a form associated (rightly or wrongly) with popular culture: superheroes and children's entertainment. Spiegelman's use of the comic book form immediately draws our attention to the 'constructedness' of the story and the ethical dilemma in representing the Holocaust in such a form and, by extension, I suggest Spiegelman is saying, any form. Spiegelman crusaded to have Maus classified as non-fiction and protested when it was listed on The New York Times bestseller list for fiction (Hungerford 123), which illustrates his belief that all representations of the past are distortions and that his work, with its open admissions of distortion, was as 'true' and accurate as any other work of non-fiction. Spiegelman has said: 'I still puzzle over what fiction and nonfiction really are' (MetaMaus 150).

The use of photographic material in Maus seeks to foreground a sense of historicity. For example, in Volume I there is a comic within a comic, 'Prisoner on the Hell Planet: a case History', about Artie's mother's suicide. This was originally published in an underground comic called Short Order, long before Maus was conceived. The first image in 'Prisoner on the Hell Planet' is a drawing of a hand (presumably Artie's) holding a black and white photo of a woman in a bathing suit, with a boy squatting at her feet (presumably Artie and his mother). While the hand is drawn and inked, as is the title and the stars and moon surrounding it, the photo is an actual photo, with a pencilled caption below it: 'Transom Lake, NY, 1958' (Volume I 100). The photograph defines the following story as 'true', and shows the photographic reality of the drawn characters (not mice in this comicwithin-a-comic, but human beings). It brings greater seriousness to the material, which, due to the cartoon-like nature of the drawings, might otherwise be more easily dismissed. It attempts 'to make history and comic one seamless reality within narrative' (Hungerford 117). 
Volume II is prefaced with a dedication, showing a photograph of a toddler in lederhosen; we later discover this is Artie's brother, who perished in the Holocaust, before Artie was born. This Volume, And Here My Troubles Began, is heavy with the absence of this unknown brother, and it is also heavy with the weight of history as Spiegelman enters the gates of Auschwitz. Spiegelman claims that beginning the book with the image of his brother 'forms a kind of grounding, of this real person who was lost' (MetaMaus 219). There is a scene between Artie and Vladek, as Vladek looks through old photographs, telling Artie what happened to his family, when Vladek says: 'All what is left, it's the photos' (Volume II 115). But in this scene Spiegelman doesn't use actual photographs, instead he draws them, with a 'lack of nominalistic detail in facial expressions and shapes' (Schwarz 290). For readers, at this point not even the photographs remain; all we have is the representation, one Spiegelman has shown us to be a distortion, however sincerely attempted.

The final photograph appears near the end of Volume II, during the section of narrative which shows Artie's parents finding each other after the war. It is a photograph of Vladek Spiegelman in striped Auschwitz pyjamas. Coming after the harrowing story of his survival in Auschwitz, and his survival of the death marches, the photo has enormous impact, bringing home the fact that the story is non-fiction, and that it happened not to comic book mice but to actual human beings. Even here, though, Spiegelman undercuts the authenticity of the photograph, as Vladek tells Artie: 'I passed once a photo place what had a camp uniform - a new and clean one - to make souvenir photos' (Volume II 134). With these words, which lead us to register how strong and healthy and unlike a camp survivor Vladek looks, Spiegelman shows that the photo is 'like his own cartoons, an illuminating distortion, a performance' (Schwarz 290). 
Throughout Maus, Spiegelman has chosen to illuminate the distortions inherent in representation, to foreground the ethical choices and transgressions of the writer, for example he reveals his broken promises:

Vladek: But this is what I just told you - about Lucia and so - I don't want you should write this in your book.

Artie: What? Why not?

Vladek: It has nothing to do with Hitler, with the Holocaust! Artie: But Pop - it's great material. It makes everything more real - more human. I want to tell your story, the way it really happened.

Vladek: But this isn't so proper, so respectful ... I can tell you other stories, but such private things, I don't want you should mention.

Artie: Okay, Okay - I promise. (Volume II)

In this section Spiegelman shows his father's desire to keep certain things private, highlighting his father's wishes in bold text, but we know he hasn't kept his promise to his father, as we've just read the story involving Lucia. Spiegelman has transgressed against his father but he's made the reader aware of his transgression, alerted us to his deception, to the fact that we're witnessing what was meant to be unwitnessed. As such, it could be argued that Maus is non-fiction in every sense, as it relates even the process of gathering the story and reveals the choices the writer makes whether to tell or not to tell.

This is a core component of Spiegelman's self-reflexive text: the naked portrayal of process. In Volume II we see Artie trying to decide which animal he should choose to represent his French wife. A moose? A poodle? A frog? A rabbit? He asks his wife Françoise what she should be:

Françoise: Huh? A mouse, of course!

Artie: But you're French! 
Françoise: Well ... how about the bunny rabbit?

Artie: Nah, too sweet and gentle.

Françoise: Hmmph.

Artie: I mean the French in general. Let's not forget centuries of anti-Semitism ... I mean, how about the Dreyfus affair? The Nazi collaborators! The -

Françoise: Okay! But if you're a mouse, I ought to be a mouse too. I converted didn't I? (Volume II 11)

Here Spiegelman alerts his reader to the process of representation, to the meanings that surround his choices of animal and to the complex definition of 'Jew'.

Later in Volume II he explores the pressure he feels as a result of the weight of the material, his concerns about the ethics of making art out of the Holocaust, and the discomfort he feels about the critical and commercial success of his Holocaust narrative (Volume I). The beginning of Chapter Two shows five panels of Artie, this time represented as a man with a mouse mask tied to his face, sitting at his drawing board, smoking and surrounded by flies. He is speaking aloud, in the fourth panel turned directly to face the reader, talking about Vladek's death and the success of Volume I. The fifth panel, which takes up the bottom third of the page, shows Artie slumped across the drawing board, still surrounded by flies, sitting atop a pile of naked mouse corpses. Through the window we can see the silhouette of a guard tower:

Artie: At least fifteen foreign editions are coming out. I've gotten 4 serious offers to turn my book into a T.V. special or movie. (I don't wanna.) In May 1968 my mother killed herself. (She left no note.) Lately I've been feeling depressed. [From off-page comes a disembodied speech-balloon]: Alright Mr Spiegelman ... We're ready to shoot! (Volume II 41) 
It's a dense and complex page, exploring the author's concerns over his popular success, the shadow cast over him by his personal connection to the material, the moral threat involved in representing such material (evident in the double meaning behind the word 'shoot') and the inherent aspect of 'performance'. In five panels Spiegelman manages to address some of the most difficult and challenging elements of Holocaust art and shows how 'Adorno's plea not to try to represent what happened shadows the narrative' (Wilner 117).

Spiegelman's subject matter is as much that of ethical representation as it is his father's Holocaust story. It is an example of a more transparent form of authorship, although, as the text illustrates, all authorship is essentially a manipulation and as such its transparency is suspect. Spiegelman feels that all 'narrative work including memoir, biography, and history presented in narrative form, is streamlined and, at least on that level, a fiction' (MetaMaus 150). The foregrounding of this 'fictionality' of representation is at the heart of Maus's ethics of representation. Maus is an inspiring Holocaust narrative because it embraces the difficulties inherent in representing such a sensitive topic. Spiegelman has the authority of a familial connection to the Holocaust and is also telling the story of his father, a story therefore over which he has some 'ownership', yet he still feels the need to tread carefully and sensitively. He is a writer who is wary.

By the time I'd burned through my obsession with Spiegelman, the semester was spent and another year was over. I was hugely pregnant and time was running out. 'I want the exegesis by the end of January,' Nick wrote in his final email of 2006. There was a towering stack of paper on my desk: printed articles about Maus, my own notes, drafts. And strewn on the floor were folders and folders, bursting with notes on every book and article I had read over the course of the last few 
years. It was time to bring order to the chaos. Or, as I learned from Spiegelman, time to embrace the chaos and collage it onto the page. It was time to answer the question.

Why? 



\section{Beyond the Kingdom of Night}

I wrote a first draft of the exegesis in two weeks and sent it off to Nick. It sounds easy - but the pre-writing had lasted for four agonising years. And it was only a first draft. I fully expected months of painful redrafting; I'd watched enough of my fellow $\mathrm{PhD}$ candidates sweat blood through the final weeks of their PhDs to know what was ahead of me. What I hadn't expected was how useful writing the exegesis would be. It clarified my thinking. On the page, contained in a 20,000 word essay, some problems which had seemed insurmountable suddenly looked manageable. A few solutions seemed laughably easy.

For instance, the concept of subtlety was a farce. Why would you want to be subtle? To hide the fact that you don't know what you're doing. The answer was like being punched it the gut. It was true. I was trying to fool everyone into thinking I knew what I was doing, and I didn't. This was why nothing worked, because I couldn't answer the question 'why'. Not for Molly, and not for me. And perhaps I wouldn't be able to before the $\mathrm{PhD}$ was due. I launched into a sixth and final draft of the novel, making it clearer that Molly was writing Gienia's story.

At the end of January I went to see Nick. Unbelievably, he had minimal notes on the exegesis. I needed to add a chapter here, unpack a 
few points there, and define my terms more thoroughly. 'And you need a section about you.'

'What?'

'About your journey with the book.'

'I thought I'd just do a critical essay,' I demurred. 'I wasn't going to have anything personal in there, or anything about my book.' He looked at me. I sighed. I'd known this was coming. I'd just been hoping, by some miracle, he'd let me get away without talking about my process. But as usual he didn't budge.

'When do you want it by?'

Then, to my horror, he printed out an 'Intention to Submit' form and filled it out on the spot. It committed me to submitting the PhD thesis. I had to come, the baby was due in April and I had to submit before then, but somehow knowing and knowing are two different things. I signed the form with a shaky signature.

I fixed up the exegesis and then stared at the blank screen, contemplating this new chapter about 'my journey'. You have to say why, I told myself firmly. Make it up, if you have to. Just write something and get it done. I swallowed hard and started typing: The first question anyone asked when I said I was writing a novel that engages with the Holocaust was why?

It was weird and confronting writing about myself (weirder and even more confronting now that I've been asked to turn it into a book) but it unlocked something. I wrote about my bafflement, my compulsion, my sense of transgression: I am robbing graves to write my novel, I am walking hobnailed on sacred ground, I cringe at what I am doing, and yet still I do it. The startling thing was that as I wrote this personal essay, I discovered the truth of my novel. I wasn't writing a novel about the Holocaust, I was writing a novel about writing about the Holocaust. What kind of idiot was I not to realise that before now? 
I thought I had realised it ('I'm a postmodernist!' I'd screeched down the phone at Rach). Subtlety. Ha. Terror, more like. I'd been too scared to commit.

I grabbed a pen and tore through the novel, looking for the places I'd chickened out. It's a book about questions, I thought frantically, remembering my conversation with Judith, my mentor. And, then, with a shock, I remembered a conversation I'd had with Nick the year before. I dug out my notebook. Thank God I wrote down everything he said. We'd been talking about big philosophical questions like evil, and art, and who has the right to write 'sacred' stories. I was probably looking freaked out because he'd suddenly said: 'You don't have to answer these questions. You just need to ask them.'

I just need to ask them, I thought, dumbstruck.

I slashed through the manuscript with my pen, asking questions. I needed to foreground the questioning. At pivotal points in the text, for example where Chef asks if Molly wants special treatment, or when Molly is watching Shoah, I inserted blunt commentary ('There is no equivalence, a little voice hisses' / 'What am I doing watching other people's agony?'). And as for the question of balance, I thought as my pen slashed blue across the pages, there is no balance, is there? That's the whole point. The whole subject, the vast malignant fact of the Holocaust, is unbalanced. Our banal, day-to-day existence in its shadow can never balance it. In fact it tips the balance.

And I fixed the book, and lived happily ever after.

Ha. If only.

I did one more draft, cleaned up the exegesis, and submitted my PhD. Nick told me about an Oxford tradition where they rang a bell as you walked your completed thesis in, and people lined the quad and applauded. That didn't happen. But my friends Chelsea and Rach walked me to the graduate centre, carrying the heavy boxes 
for me, and then we went to lunch on Rundle Street. It was a golden autumn afternoon and the hills were a sweet haze on the horizon. In honour of Nick's story about Oxford, Chels had bought a little bell and engraved my name, the name of the book, and my submission date on it. I teared up. I felt a bit like someone had cut my arm off. Something very important, something essential to me, had just been taken away. I couldn't believe it was over. I had no idea who I was if I wasn't writing that book.

Ten days later my daughter was born and I disappeared back into Babyland. I expected to have a quiet winter waiting for my examination reports and so I was completely unprepared when they came after only a matter of weeks. I'd passed. One of my examiners had loved it, the other one had grudgingly come to appreciate it, although she didn't get the humour. But I'd passed. I had a negligible list of errata, and then I had to submit bound copies to the university and I was eligible to graduate. It seemed like a whole era of my life was over.

I graduated in July, on an icy cold day when the river and city and campus were white with fog. My parents and husband sat in the crowd; Nick sat on the stage and smiled as I passed him; my parents-inlaw met us with the children and we drank Champagne. Something big was ending, and yet not ending. Because the book wasn't done.

'I'd like to see this book published in an Australian context,' one of my examiners had written. I had no idea what that meant exactly. She thought it should be published. Well, so did I. But no one wanted to publish it. I didn't know if it was because they were scared of the subject or if there was something fundamentally flawed about my novel. I went back to teaching when my daughter was ten weeks old. I needed the money and I liked getting out in the world.

Over the next three years I wrote three more books (none of which have been published yet, but I'll keep you posted). Each one taught me something new, but none of them were as difficult to write 
as End of the Night Girl. In between drafts and redrafts of these new books I went back and kept tinkering with End of the Night Girl. With each tinker I stripped out the subtlety. Molly picked up a pen earlier and earlier in the novel; it became more and more explicit that she was writing Gienia; I made her question her narrative choices as she wrote her Holocaust story. One of my examiners had mentioned Molly's relationship with Lizzie; I mulled that relationship over. What was Molly's arc? Well, by the end she was connecting to people. I could do more with that. I added in Molly's difficult relationship with her father, and with her stepfather. I wrote new scenes. And I embraced the fact that fiction can do anything.

There were fantastic elements in the first few drafts that remained undeveloped: namely, Gienia's appearance as an apparition in Molly's world. Until draft six (the final PhD draft submitted for examination) Gienia appeared to Molly twice as a ghost-like apparition: once in the reflection of the bar fridge and once by the scrap bin in the kitchen. These two appearances were unexplained and confusing but, like the 'Who the fuck is Miriam' line, they felt important and I hadn't discarded them. By draft six I had been beginning to realise that I didn't have to stick to 'reality'. Why couldn't Gienia appear to Molly? They could meet face to face. They could have a conversation. She could be a figment of Molly's imagination, or a manifestation of her conscience, a spirit calling her to account for her trespass, a time-traveller, or the ghost of history. Gienia's apparition could be any or all of these things and in draft six I had added in scenes such as her appearance when Molly was making popcorn.

I kept returning to this idea of haunting. The concept of haunting resonated with my idea of the book itself: history haunting Molly (and me); created stories haunting their creators (Molly and $\mathrm{me}$ ); narratives haunting one another (historical texts, testimonies and memoirs haunting Molly and me, and Gienia and Molly's narratives 
haunting one another); and narratives being haunted by the presence of their authors (Molly haunting Geinia, and me haunting Molly). I played around with it over the next three years and seven drafts, adding scenes and fiddling with dialogue and apparitions. Gienia read Molly's manuscript and dared to question her and she appeared to comfort Molly in the cold store. And then in the twelfth draft it occurred to me that hauntings could work the other way too. There were moments in Gienia's sections where gaps seemed to open up, as though waiting for Molly to step into them: in the haystack on the death march; in the shell of the little Czech as she looked up at Gienia in the barn; and in the shadowy figure waving to Gienia as she lay dying in Dachau. In that twelfth draft I let Molly step into Gienia's world, and I let them touch one another.

As I rewrote Gienia's final scene for the last time, I inserted Molly standing on the Warsaw street in the miraculous snowstorm, waving farewell to her ghost. And for the first time the book felt done. There was nothing more I could do with it.

I printed it out and submitted it for the Adelaide Festival Unpublished Manuscript Award, honestly expecting nothing. I'm not ego-less. I have as much of a competitive streak as any artist, but I can genuinely say that I had no expectations for End of the Night Girl. I'd spent seven years writing it, testing myself well beyond my limits, failing constantly; it had been rejected more times that I'd cared to count. I submitted it in the same spirit in which I'd buy a lottery ticket. And then I went home, started work on my fifth novel, and forgot I'd entered it.

And it won. I won't lie. That was a great moment. There was a lot of Champagne. I threw a party and invited everyone I knew. It was fun. I got to work with an editor who 'got' the book and we had some great conversations about the ideas in it. And for the first time I didn't 
feel like vomiting when someone asked me questions. Not because it won an award but because I had the answers to the questions (or at least was secure in my lack of answers). I was comfortable in my discomfort. Discomfort is an ethical response to the complexity of the project, and probably the most appropriate response; it had just taken me years to realise it. We did a minimal edit, which was mostly pruning for pace (this is the joy of having done a million drafts before you hit the editor - you've hopefully done the hard work already). The book came out and I threw another party and invited everyone I knew (choose the good times, remember?).

Having observed the Helen Demidenko scandal, and having researched the fraught debates surrounding Holocaust fiction for years, I braced for tough reviews. I expected to be called out for my insensitivity, for trespassing, for stomping about in my hobnail boots. But the reviews were good; some were even great. It made a couple of best books of 2011 lists. That was cool. And in 2012 it was shortlisted for the Nita B Kibble Dobbie Literary award and the Colin Roderick award. Which was also very cool.

I live happily ever after.

Ha. Still no. At the end of 2011, my teaching contract ended and, due to budget cuts, I wasn't offered another one. I was thrown back into the casual teaching pool, working enormous teaching loads to scrape less than minimum wage. By mid-2012 my marriage was over. I'd been with Ben for 17 years and now I was facing a future alone as a single mother. In 2002 I'd quit my job and started an Honours degree. Ten years later I found myself facing another reboot of my life. I have two degrees, first class Honours, a $\mathrm{PhD}$, a teaching award, literary awards, and I have lectured and tutored in more than a dozen courses across almost a decade. As I type these words, I am a single mother working casual contracts, facing a very uncertain future. The only thing 
that seems certain is my writing, and this symbiotic project, End of the Night Girl / Navigating the Kingdom of Night, which has dominated my life for many years.

A few months after the publication of End of the Night Girl I was approached to turn my exegesis into a book (this book). Part of me groaned. Could I go back there? Especially during what was proving to be one of the most intense and difficult years of my life. The Holocaust is not pleasant to live with; it casts a cold shadow over everything, and I had been looking forward to moving out of its shadow now the book was published. A couple of years ago I made a loud announcement at a conference that I would 'never write about the Holocaust again'. Famous last words. I was flattered by the offer to publish my exegesis, and thought it would be good for my career, so I accepted and dove back into the research, catching up on what had come out since I'd submitted my PhD. Jonathan Littell, Yann Martel and Elliot Perlman are among many authors who have released 'Holocaust books' in recent years, to mixed reviews. I read up on them and planned to add another chapter, but in the end I decided not to. Because they didn't inform the writing of End of the Night Girl, I have decided to leave writing about them for another day.

This incarnation of Navigating the Kingdom of Night is far more personal than my original essay. Ironic, since Nick had to force me to write anything personal for my $\mathrm{PhD}$. When I look back on my $\mathrm{PhD}$ I can see the tangle of the personal and professional, and how impossible it is to segregate the academic from the artist, and from the person. Creative writing is not a clinical act; it emerges from a human being. This particular human being has had a tumultuous time writing these books. Some of the best things in my life have happened while I wrote: marriage, babies, finding some of the best friends of my life, falling in love again, finding a secure sense of self. Some of the worst has happened too: my mother's illness, my divorce, the long years of 
insecure work, lurching from exploitative casual contract to exploitative casual contract (this, at least, is now at an end, as of mid-2013 I am a Lecturer in Creative Writing at Flinders University).

History is never over, politically or personally. The stain of the Holocaust remains on every aspect of our current geo-politics, and the psyche of Western cultures. History is not contained; rather, it's like the rock formations beneath our feet: we build on it. Why did I write about the Holocaust? Because it spoke to me. Because when I read about it, it affected me. Because I felt on a fundamental level that it mattered to me. It was messy and uncontainable and too big for me to manage. There were times I wish I'd never started the novel, but from where I sit now I am glad I did.

I am thirty-seven years old. Some days I feel the same as I felt at nineteen, as blithe as my undergrads. Other days I feel a thousand years old and I don't know how I'm going to manage the stress of my life. Some readers like to think writers have answers; that they have wisdom; that they write to teach us about the human condition; that they sit serenely as clear thought flows from them onto the page. Judging by the number of addicts and mad people among the lists of great writers in the canon, I doubt this is the case for any of them. I wonder how many of them feel as lost and confused as I feel on a daily basis. I watch writers on panels at festivals, I listen to them in interviews, I read about them, and I see how they struggle to distil the messy business of writing into understandable sound bites. The truth is: most of the time we have no idea what we're doing. And it scares us. But we keep writing, and word by word we make sentences, and sentence by sentence we make chapters, and chapter by chapter we make books. We might be lost, but we have faith that breadcrumb trail of words will lead us to the finished work.

I used to think I would finish the novel and there would be serenity. That I could end a chapter of my life. But life isn't a book. 
148 Amy T Matthews

Things do end, but their memory and effect persist. End of the Night Girl is finished; published. And these are the last words I will write for Navigating the Kingdom of Night. But it will not be over. I guarantee these books will haunt me for the rest of my life. 


\section{Acknowledgements}

Where do I even start? At the book launch for End of the Night Girl I had a speech written out; it was a thoughtful, heartfelt speech, in which I thanked the people I needed to thank. Unfortunately it remained balled up in my hot little hand. Overwhelmed as I looked out into the crush of some of my all-time-favourite people, I completely forgot to give it. I wouldn't mind giving another version of it now - and in the two years since I first wrote it, I have found even more people to add to the list.

The New Yorker columnist Malcolm Gladwell wrote an article called 'Late Bloomers', which has always stayed with me. It was about the difference between precocious artists and late bloomers: he used Picasso as an example of precocity, and Cézanne as an example of a late bloomer. The thing that really resonated with me was the idea that the story of the late bloomer was a love story. Some artists take decades to realise projects, or to learn their craft, and they labour in obscurity, without recognition or financial reward. They can only keep going because they are loved: because they have people who support them, both financially and emotionally. They have parents, partners, friends, colleagues, children. They have people who pick them up when they fall down, who encourage them in their dreams, who listen to them 
snivel, who tell them to shut up and get on with it when their snivelling gets too self-indulgent. And they have people who let them bang on for years about a project, even when it bores everyone to tears. The late bloomer can seem like a failure for most of their careers. But the people who love them refuse to see them as failures, they believe in the value of their work, and in the potential of their future work. The people in their lives are patrons, and the art can only be made because of their patronage.

I have been blessed to live a love story. Thanks to everyone who makes it so. My parents, Barry and Su, to whom I dedicated End of the Night Girl, have never wavered in their belief that I can do this writing thing. They have supported me in every way it's possible to support a person and I want you both to know how much I appreciate it and how much I love you. Also to my little bro, Gerald, who reads every draft I write and engages with them like they're actual books: thank you. I think you are an enormously talented architect and musician and I'm so proud to be your sister.

To Ben. We might not be married anymore but you've been part of my life for 18 years and you supported me tirelessly. You paid the bills while I pursued my dreams, you encouraged me when I despaired, and you gave me a damn good title for the book.

Chelsea Avard. We threw ourselves into writing at the same time; we got married at the same time; we had children at the same time; we did our PhDs at the same time; we have suffered the ignominy of casual academia at the same time. You have been my ideal reader, and someone whose opinion means the world to me. You are an immensely talented writer and a keen thinker and you deserve all good things.

Thanks to Lynn Ward. You are so disco. And all the girls at SARA. To Jill, Jim and Jeremy Marton, and to Hanna and Ryan Martyn (and Ally!): still love you. 
To the staff and students, past and present, in the Discipline of English and Creative Writing at the University of Adelaide, cheers. I love teaching; I love talking books; I have loved every Friday night sitting around the staff club. Special shout outs to Patrick Allington, Henry Ashley-Brown, Anne Bartlett, Gillian Britton, Shannon Burns, Phil Butterss, Alison Coppe, Katherine Doube, Rachel Hennessy, Sue Hosking, Nick Jose, Heather Kerr, Carol LeFevre, Helen Mitchell, Vanna Morosini, Amanda Nettelbeck, Kelli Rowe, Anna Solding, Heather Taylor-Johnson, Steph Thomson, Maggie Tonkin, Mandy Treagus, Malcolm Walker and Sean Williams, and in memory of Stephen Lawrence.

Thank you to Patrick and everyone at the University of Adelaide Press, for inviting me to write this book, and for pushing me to make it a better book.

I saved my fave three for last:

Jonny: You don't have a clue, what it is like to be next to you. I'm here to tell you that it is good, that it is true. Thank you. For the playlists, and for unlocking the door.

And my monkeys: Kirby and Isla. I'm writing this sitting at the kitchen table; they keep interrupting. With typical drama, Isla opens her eyes wide and pouts and says 'Don't you love me? Why won't you play with me?' Kirby rolls his eyes. 'She's finishing a book.'

Yes, I am. And once I press send, I will come and play. 



\section{Works Cited}

Adorno, Theodor W. 'Cultural Criticism and Society.' Prisms. Trans. Samuel Weber and Shierry Weber. 1967. Cambridge: MIT, 1990. 19-34.

Adorno, Theodor W. Negative Dialectics. Trans. E.B. Ashton. 1966.

London: Routledge \& Kegan Paul, 1973.

Alhadeff, Vic. 'Analysis of Mindless Hatred.' The Demidenko File. Ed. John Jost, Gianna Totaro, and Christine Tyshing. Ringwood: Penguin, 1996. 4-7.

Alvarez, A. Beyond All This Fiddle. London: Penguin, 1968.

Amis, Martin. 'The DM Thomas Phenomenon.' The War Against Cliché: Essays and Reviews 1971-2000. Random House: ebook.

Armitage, Catherine. 'The Horror from the Other Side.' The

Demidenko File. Ed. John Jost, Gianna Totaro, and Christine Tyshing. Ringwood: Penguin, 1996. 2-3.

Bauman, Zygmunt. Modernity and the Holocaust. New York: Cornell UP, 1989.

Behlman, Lee. 'The Escapist: Fantasy, Folklore, and the Pleasures 
of the Comic Book in Recent Jewish American Holocaust Fiction.' Shofar: An Interdisciplinary Journal of Jewish Studies 22.3 (2004) 56-71.

Berenbaum, Michael. The Vision of the Void: Theological Reflections on the Works of Elie Wiesel. Middletown: Wesleyan UP, 1979.

Berenbaum, Michael. 'Yaffa Eliach, Hasidic Tales of the

Holocaust.' 1982. <http://motlc.wiesenthal.com/site/ pp.asp?c=gvKVLcMVIuG\&b=394993> 25 April 2006.

Boyne, John. The Boy in the Striped Pyjamas. Oxford: David Fickling, 2006.

Clendinnen, Inga. Reading the Holocaust. Melbourne: The Text, 2000.

Cross, Richard K. 'The Soul is a Far Country: DM Thomas and The White Hotel.' Journal of Modern Literature. 18: 1 (Winter 1992). 19-47.

Dahlin, Robert. 'Mr Author = Mr Protagonist.' Publisher's Weekly 28 January $2002<$ http://web.ebscohost.com.proxy.library. adelaide.edu.au/ehost/detail?vid=5=hid=115 ..> 19 October 2006.

Darville, Helen. The Hand that Signed the Paper. 1994. St Leonards: Allen \& Unwin, 1995.

Demidenko, Helen. 'Writing after Winning.' $1995<$ http://www.lib. latrobe.edu.au/AHR/archive/demidenko/darville.1.htm> 6 February 2006.

Dershowitz, Alan. 'Holocaust "Abuse Excuse" Fails to Disguise Murder Most Foul'. The Demidenko File. Ed. John Jost, Gianna Totaro, and Christine Tyshing. Ringwood: Penguin, 1996. 71-73.

'Elaine Canty interviews Helen Daniel'. The Demidenko File. Ed. 
John Jost, Gianna Totaro, and Christine Tyshing. Ringwood: Penguin, 1996. 120.

Eliach, Yaffa. Hasidic Tales of the Holocaust. 1982. New York: Vintage, 1988.

Eskin, Blake. A Life In Pieces. London: Arum, 2002.

Ezrahi, Sidra. 'The Holocaust Writer and the Midrashic Tradition:

Responses to Catastrophe in Jewish Literature.' Confronting the Holocaust: The Impact of Elie Wiesel. Ed. Alvin H Rosenfeld and Irving Greenberg. Bloomington: Indiana UP, 1978. 133-149.

Ezrahi, Sidra DeKoven. By Words Alone: The Holocaust in Literature. Chicago: Chicago UP, 1980.

Feinstein, Stephen C. 'Bridging the Narrative and Visual: Primo Levi as a Source of Inspiration for Contemporary Artists.' Memory and Mastery: Primo Levi as Writer and Witness. Ed. Roberta S. Kremer. Albany: New York State UP, 2001. 133-172.

Foer, Jonathan Safran. Everything is Illuminated. London: Penguin, 2002.

Frey, Julia Bloch. 'Lying: A Life Story; BIOGRAPHY; JERZY KOSINSKI. A Biography By James Park Sloan.' 1996. <http:// www.geocities.com/hollywood/8200/kosinski.htm> 24 February 2006.

Fridman, Lea Wernick. Words and Witness: Narrative and Aesthetic Strategies in the Representation of the Holocaust. Albany: New York UP, 2000.

Furman, Andrew. 'Inheriting the Holocaust: Jewish American Fiction and the Double-Bind of the Second-Generation Survivor.' The Americanization of the Holocaust. Ed. Hilene Flanzbaum. Baltimore: Johns Hopkins UP, 1999. 83-101. 
Geis, Deborah R. Ed. Considering Maus: Approaches to Art Spiegelman's "Survivor's Tale" of the Holocaust. Tuscaloosa: Alabama UP, 2003.

Gladwell, Malcolm. What the Dog Saw and Other Adventures.

London: Allen Lane, 2009.

Gomel, Elana. Bloodscripts: Writing the Violent Subject. Columbus: Ohio State UP, 2003.

Gubar, Susan. Poetry After Auschwitz. Bloomington: Indiana UP, 2003.

Halligan, Marion. 'That Book: Some Judges of Novels Found Wanting.' The Demidenko File. Ed. John Jost, Gianna Totaro, and Christine Tyshing. Ringwood: Penguin, 1996. 170-172.

Hughes, Kathryn. 'Educating Bruno.' <http://books.gueardian.co.uk/ print/0,5378451-9943,00.html> 5 June 2006.

Hungerford, Amy. 'Surviving Rego Park: Holocaust Theory from Art Spiegelman to Berel Lang.' The Americanization of the Holocaust. Ed. Hilene Flanzbaum. Baltimore: Johns Hopkins UP, 1999. 102-124.

Jost, John, Gianna Totaro and Christine Tyshing, Eds. The Demidenko File. Ringwood: Penguin, 1996.

Kosinski, Jerzy. The Painted Bird. 1965. New York: Grove, 1976.

Kremer, Roberta S. Ed. Memory and Mastery: Primo Levi as Writer and Witness. Albany: New York State UP, 2001.

Kuznetsov, A Anatolii. Babi Yar: a document in the form of a novel. Trans. David Floyd. London: Sphere, 1972.

Langer, Lawrence L. The Holocaust and the Literary Imagination. New Haven: Yale UP, 1975. 
Langer, Lawrence L. 'The Divided Voice: Elie Wiesel and the challenge of the Holocaust.' Confronting the Holocaust: The Impact of Elie Wiesel. Ed. Alvin H Rosenfeld and Irving Greenberg. Bloomington: Indiana UP, 1978. 31-48.

Levi, Primo. If This is a Man. 1958. Trans. Stuart Woolf. 1965. London: Abacus, 1998.

Littell, Jonathan. The Kindly Ones. New York: Harper, 2009.

Maechler, Stefan. The Wilkomirski Affair: A Study in Biographical Truth. Trans. John E Woods. New York: Schocken, 2001.

Manne, Robert. The Culture of Forgetting: Helen Demidenko and the Holocaust. Ringwood: Penguin, 1996.

Marr, David. 'Dabbling with Demons.' The Demidenko File. Ed. John Jost and Gianna Totaro and Christine Tyshing. Ringwood: Penguin, 1996. 217-218.

Matthews, Amy T. End of the Night Girl. Kent Town: Wakefield Press, 2011.

Michael, Magali Cornier. 'Materiality versus Abstraction in DM Thomas's The White Hotel.' Critique. 43: 1 (Fall 2001). 63-83.

Miller, Nancy K. 'Cartoons of the Self: Portrait of the Artist as a Young Murderer: Art Spiegelman's Maus.' Considering Maus: Approaches to Art Spiegelman's "Survivor's Tale" of the Holocaust. Ed. Deborah R Geis. Tuscaloosa: Alabama UP, 2003. 44-62.

Mitchell, Margaret. Gone with the Wind. 1936. London: Pan, 1974. Myers, D.G. 'Jerzy Kosinski: A Biography.' 1996. <http://www. leaderu.com/ftissues/ft9610/myers.html> 24 February 2006.

Patruno, Nicholas. 'At an Uncertain Hour: the Other Side of Primo Levi.' Memory and Mastery: Primo Levi as Writer and Witness. 
Ed. Roberta S Kremer. Albany: New York State UP, 2001. 91102.

Reimer, Andrew. The Demidenko Debate. St Leonards: Allen \& Unwin, 1996.

Robertson, Mary F. 'Hystery, Herstory, History: "Imagining the Real" in Thomas's The White Hotel'. Contemporary Literature. 25: 4. 452-477.

Rosenfeld, A.H. 'The Problematics of Holocaust Literature'.

Confronting the Holocaust: the Impact of Elie Wiesel. Eds A.H.

Rosenfeld and I. Greenberg. Bloomington: Indiana UP, 1978. $1-30$.

Rosenfeld, Alvin H. A Double Dying: Reflections on Holocaust

Literature. Bloomington: Indiana UP, 1980.

Rothberg, Michael P. 'We Were Talking Jewish: Art Spiegelman's

Maus as "Holocaust" Production.' Considering Maus:

Approaches to Art Spiegelman's "Survivor's Tale" of the Holocaust.

Ed. Deborah R Geis. Tuscaloosa: Alabama UP, 2003. 137-158.

Schlink, Bernhard. The Reader. Trans. Carol Brown Janeway. 1997.

London: Phoenix, 1998.

Schwarz, Daniel R. Imagining the Holocaust. New York: St Martin's, 1999.

Seiffert, Rachel. The Dark Room. 2001. Sydney: Vintage, 2002.

Signorini, Franca Molino. 'The Duty and Risk of Testimony: Primo Levi as Keeper of Memory.' Memory and Mastery: Primo Levi as Writer and Witness. Ed. Roberta S Kremer. Albany: New York State UP, 2001. 173-196.

Simonds, Peggy Munoz. 'The White Hotel: A Sexual Satire.' Critique. (Fall 1985). 51-63. 
Singer, Isaac Bashevis. Short Friday and Other Stories. 1961.

Harmondsworth: Penguin, 1984.

Spiegelman, Art. Maus: A Survivor's Tale: Volume I: My Father Bleeds History. 1973. New York: Pantheon, 1986.

Spiegelman, Art. Maus: A Survivor's Tale: Volume II: And Here My

Troubles Began. 1986. New York: Pantheon, 1991.

Steiner, George. Language and Silence. 1958. London: Faber and Faber, 1967.

Thomas, D.M. The White Hotel. 1981. London: Phoenix, 2004.

'Unoriginal Sins' 2003. <http://www.smh.com.au/ articles/2003/01/17/1042520765320.html> 6 February 2006.

Vice, Sue. Holocaust Fiction. London: Routledge, 2000.

Vine, Steve. 'Sublime Anamnesis: Hysteria and Temporality in Thomas's The White Hotel.' Twentieth Century Literature. 56:2 (Summer 2010). 196-220.

Wiesel, Elie. Night. 1960. Trans. Stella Rodway. New York: Bantam, 1982.

Wiesel, Elie. 'Why I Write.' Confronting the Holocaust: The Impact of Elie Wiesel. Ed. Alvin H Rosenfeld and Irving Greenberg. Bloomington: Indiana UP, 1978. 200-206.

Wilner, Arlene Fish. 'Happy, Happy Ever After: Story and History in Art Spiegelman's Maus.' Considering Maus: Approaches to Art Spiegelman's "Survivor's Tale" of the Holocaust. Ed. Deborah R Geis. Tuscaloosa: Alabama UP, 2003. 105-121.

Wright, Ed. 'The Boy in the Striped Pyjamas.'2006. <http://theage. com.au/news/book-reviews/the-boy-in-the-striped-pyjamas $>5$ June 2006. 
160 Amy T Matthews

Young, James E. Writing and Rewriting the Holocaust: Narrative and the Consequences of Interpretation. Bloomington: Indiana UP, 1988. 
This book is available as a free fully-searchable PDF from www.adelaide.edu.au/press 


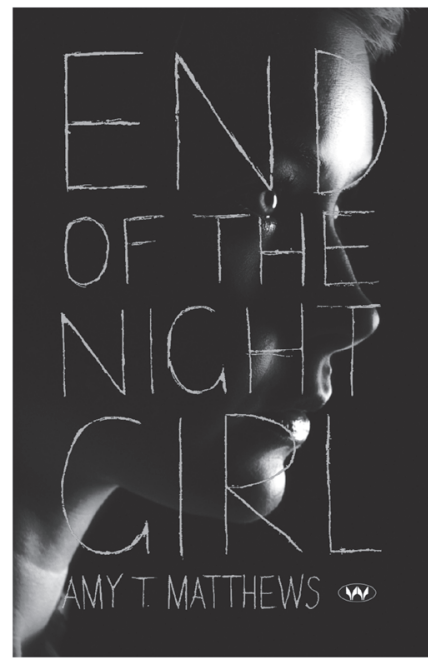

\section{End of the Night Girl}

Amy T. Matthews

ISBN: 9781862549449 (pbk)

9781862549685 (epub)

9781862549692 (pdf)

Molly, a sassy Australian waitress, is haunted by the ghost of a murdered Polish Jew. The two young women's stories, each a compelling page-turner, combine teasingly in one as End of the Night Girl explores shadows cast by the Holocaust across decades, continents and cultures.

'A brilliant testimonial to the power of the literary imagination.' - Nicholas Jose 'Clothed in prose that sparks and simmers, End of the Night Girl slowly reveals her dark and beautiful bones.' - Carol Lefevre

'This is a remarkable novel of contemporary rootlessness, haunted histories and redemptive decency.' - Brian Castro

'Can atrocity be changed somehow in art? This book cannot answer this, but it powerfully suggests that the creative act is meaningful even when atrocity is too big for us to mould it. As Molly attempts to imagine and create from an atrocity she hasn't shared, she herself is remade.' - Eva Hornung

'Bravo for this brilliant novel - the most engaging I have read for a while.' -

Debra Zott, Transnational Literature

'I recommend this book without reserve.' - Ian Lipke, M/C Reviews

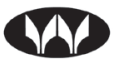

Wakefield

Press
1 The Parade West, Kent Town, South Australia 5067

www.wakefieldpress.com.au 